Georg-August-Universität Göttingen

Department für Agrarökonomie und Rurale Entwicklung

\title{
Volatile agricultural markets, how much is oil to blame?
}

\author{
Dissertation \\ to obtain the Ph. D. degree \\ in the International Ph. D. Program for Agricultural Sciences in Goettingen (IPAG) \\ at the Faculty of Agricultural Sciences, \\ Georg-August-University Göttingen, Germany
}

\author{
presented by \\ Lucio Alberto Saucedo \\ born in Santa Cruz de la Sierra, Bolivia
}

Göttingen, March 2016 
D7

1. Name of supervisor: Prof. Dr. Bernhard Brümmer

2. Name of co-supervisor: Prof. Dr. Olaf Korn

Date of dissertation: May $12^{\text {th }}, 2016$ 


\section{Contents}

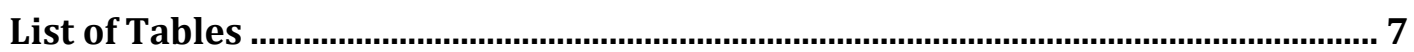

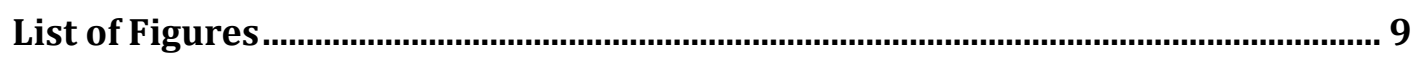

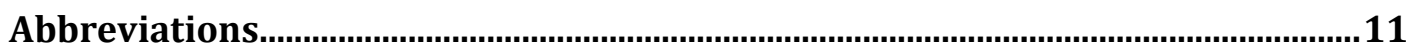

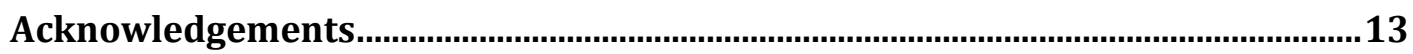

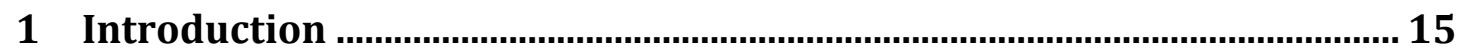

2 Volatility in the after crisis period - A literature review of recent

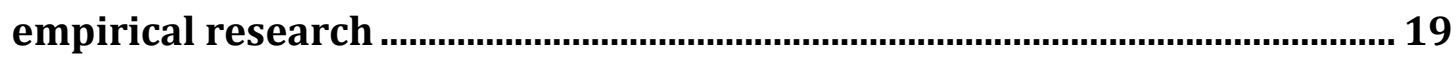

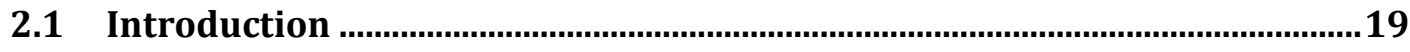

2.2 Volatility concepts and measurement ….........................................................20

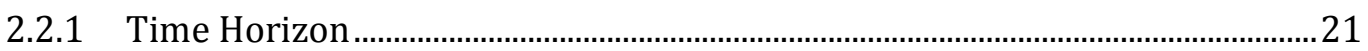

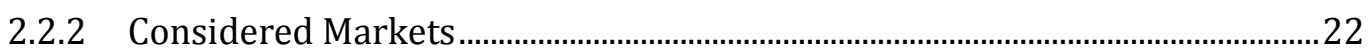

2.2.3 Ex-post measurement versus ex-ante prediction..................................................22

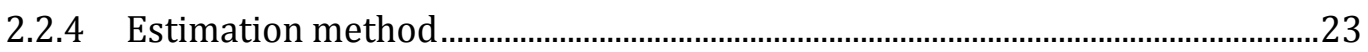

$2.3 \quad$ Literature review on food price volatility …....................................................28

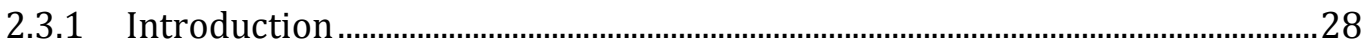

2.3.2 Studies on price volatility ......................................................................................28

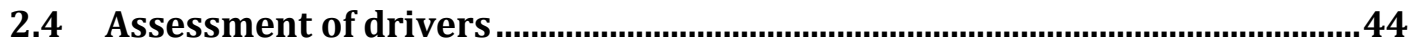

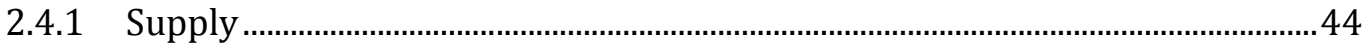

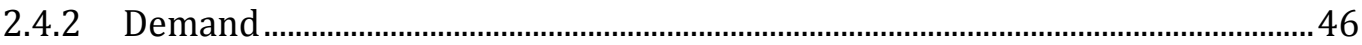

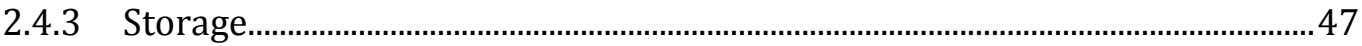

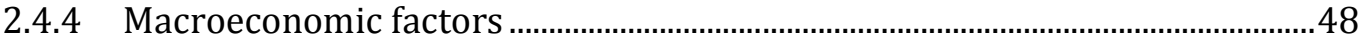

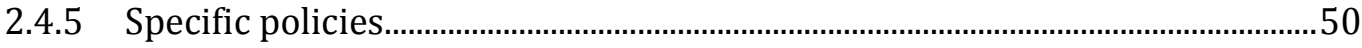

2.4.6 Financialisation ..................................................................................................52

2.4.7 Miscellaneous drivers of price volatility …………................................................55

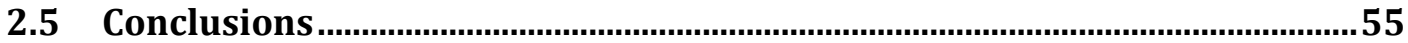

3 The dynamic pattern of volatility spillovers between oil and

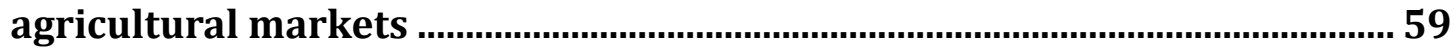

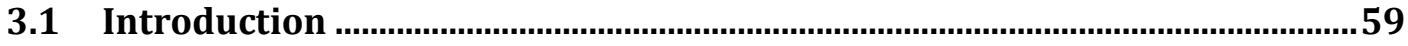

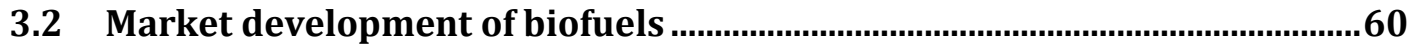

3.2.1 Price co-movements between oil and biofuel feedstocks ...................................63 


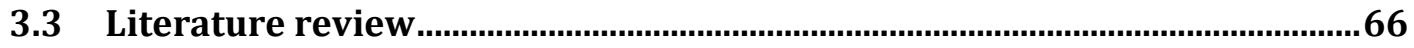

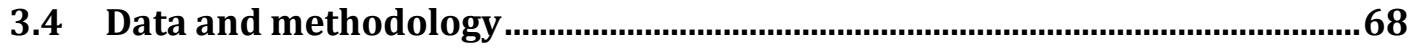

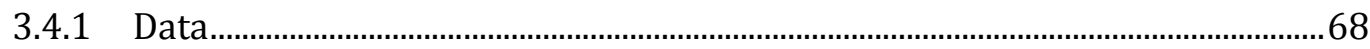

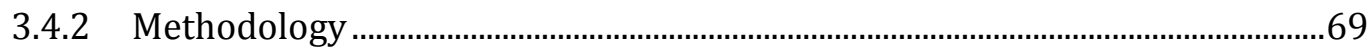

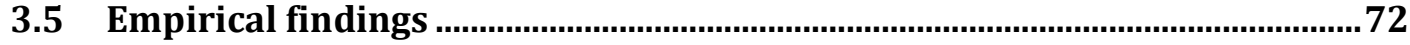

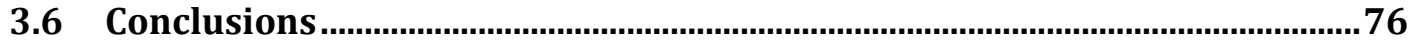

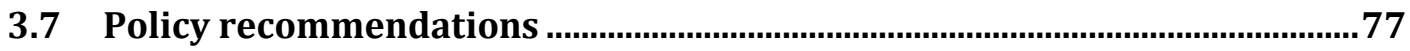

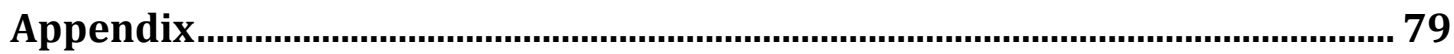

4 Volatile agricultural markets, the role of oil before and after the Great

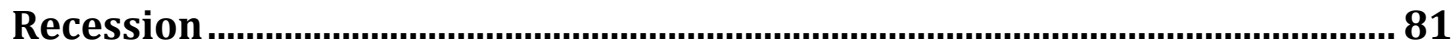

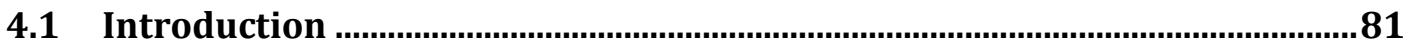

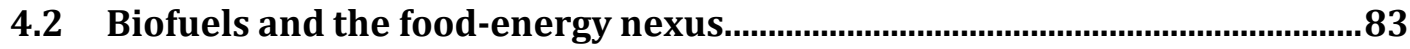

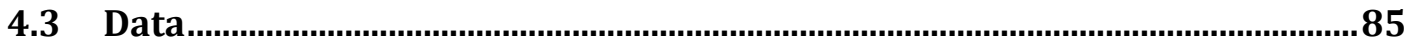

4.3.1 Log price changes of energy and food markets ......................................................86

4.3.2 Development of market uncertainties in commodity markets...........................87

4.3.3 Unconditional second order moment interactions among commodities......88

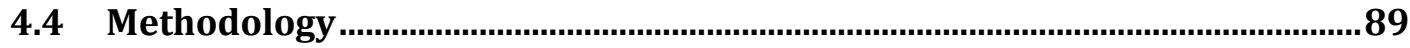

4.4.1 Volatility spillover indices..................................................................................93

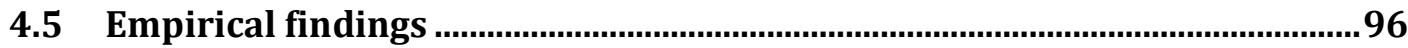

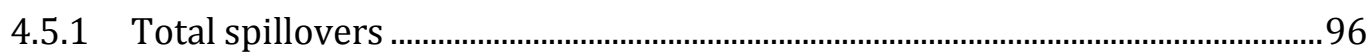

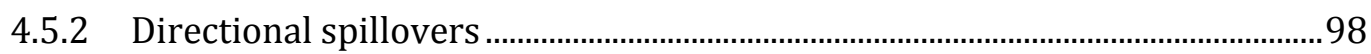

4.5.3 Composite spillover indices and the contribution of oil...................................101

4.5.4 Integration between oil and agricultural markets .............................................105

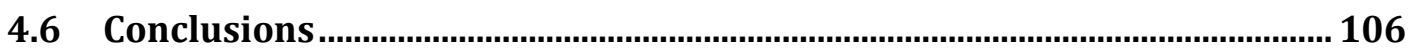

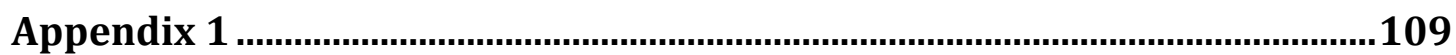

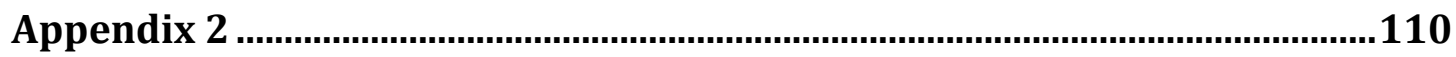

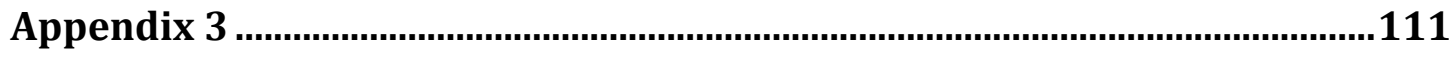

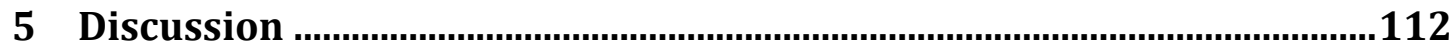

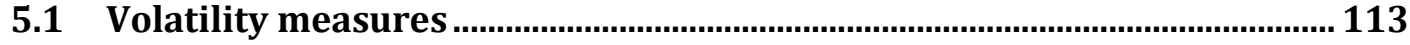

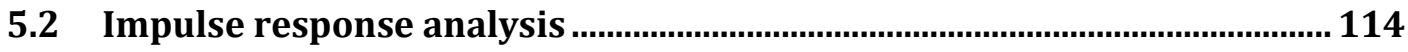

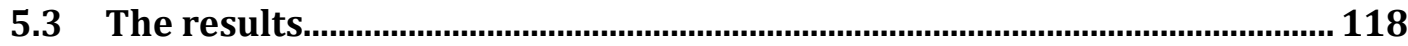

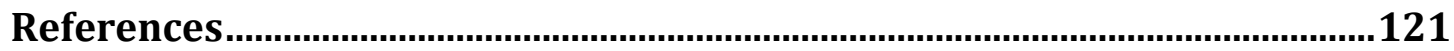




\section{List of Tables}

TABLE 1. DESCRIPTIVE STATISTICS OF THE VOLATILITY MEASURES SHOWN IN FIGURE 1 1........................................2.

TABLE 2. ESTIMATES OF TOTAL SUPPORT FOR THE BIOFUEL INDUSTRY IN DEVELOPED COUNTRIES .........................61

TABLE 3. DESCRIPTIVE STATISTICS OF THE DATA................................................................................................69

TABLE 4. VARIANCE DECOMPOSITION MATRIX, ETHANOL GROUP.........................................................................72

TABLE 5. RELATIVE AVERAGE CoNTRIBUTIONS TO THE SPILLOVER INDEX, ETHANOL GROUP ...................................74

TABLE 6. RELATIVE AVERAGE CONTRIBUTIONS TO THE SPILLOVER INDEX, BIODIESEL GROUP..................................75

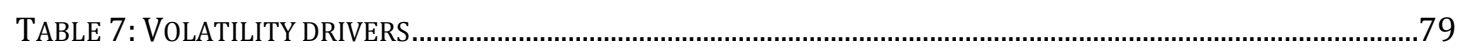

TABLE 8. DESCRIPTIVE STATISTICS OF THE DATA...........................................................................................86

TABLE 9. Co-VOLATILITIES CIJ FOR THE COMMODITY GROUPS AND PERIODS..............................................................89

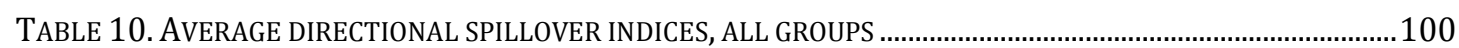

TABLE 11. AVERAGE OWN/CROSS CONTRIBUTIONS OF OIL AND AGRICULTURAL SPILLOVERS AS SHARES OF THE TSI 102

TABLE 12. AVERAGE CONTRIBUTIONS OF OIL TO VOLATILITY SPILLOVERS IN AGRICULTURAL MARKETS 104

TABLE 13. RANK CORRELATIONS BETWEEN OIL'S CONDITIONAL VOLATILITY AND ITS CONTRIBUTIONS TO TSI.106

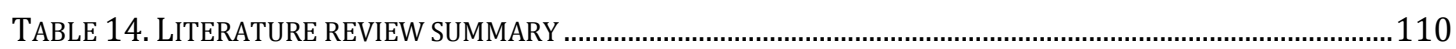

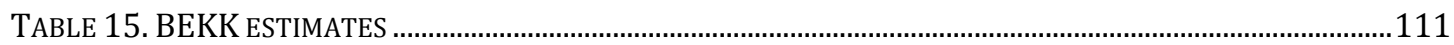




\section{List of Figures}

FIGURE 1. DIFFERENCES AMONG COMMONLY USED VOLATILITY MEASURES..........................................................26

FIGURE 2. WORLD'S LEADING BIOFUEL PRODUCING COUNTRIES, 2011 ………....................................................62

FIGURE 3. WORLD BIOFUEL PRODUCTION AND OIL EQUIVALENT CONSUMPTION, 1991-2011.................................63

FIGURE 4. EVOLUTION OF THE PRICE OF CEREALS AND SUGAR, 1996 - 2014 ………………………...................64

FIGURE 5. EVOLUTION OF THE PRICE OF VEGETABLE OILS, 1996 - 2014 ............................................................65

FIGURE 6. VOLATILITY SPILLOVER INDEX EVOLUTION FOR THE ETHANOL AND BIODIESEL GROUPS ...........................73

FigURE 7. RELATIVE CONTRIBUTION OF OIL TO THE SPILLOVER INDEX, ETHANOL GROUP..........................................74

FigURE 8. RELATIVE CONTRIBUTION OF OIL TO THE SPILLOVER INDEX, BIODIESEL GROUP ......................................76

FIGURE 9. CONDITIONAL GARCH VARIANCES OF AGRICULTURAL MARKETS...........................................................8

FIGURE 10. STRUCTURE OF $\Lambda$ T FOR THE ETHANOL GROUP ..................................................................................93

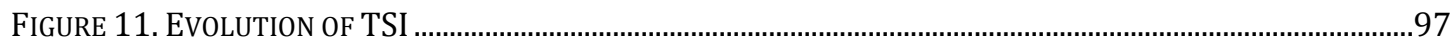

FIGURE 12. NET DIRECTIONAL SPILLOVERS...................................................................................................98

FIGURE 13. DEVELOPMENT OF OWN/CROSS CONTRIBUTIONS OF OIL AND AGRICULTURAL SPILLOVERS AS SHARES

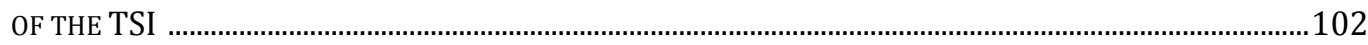

FIGURE 14. DEVELOPMENT OF THE CONTRIBUTIONS OF OIL TO VOLATILITY SPILLOVERS IN AGRICULTURAL MARKETS. .103

FIGURE 15. SYNCHRONY BETWEEN THE CONDITIONAL GARCH VARIANCE OF OIL AND ITS AVERAGE

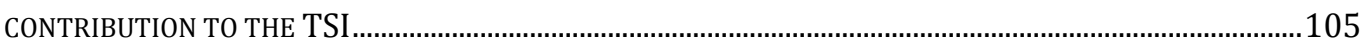

FIGURE 16. MAJOR BIOFUEL PRODUCING COUNTRIES, 2011 ..........................................................................109

FIGURE 17. VOLATILITY FEEDBACKS FROM AGRICULTURAL MARKETS TO OIL........................................................116

FIGURE 18. SPILLOVER INDEX FOR DIFFERENT ORDERINGS OF THE VARIABLES, ETHANOL GROUP ........................116

FIGURE 19. SPILLOVER INDEX FOR DIFFERENT ORDERINGS OF THE VARIABLES, BIODIESEL GROUP.......................117 


\section{Abbreviations}

CARBIO

CBOT

$\mathrm{EU}$

FAO

FAPRI

$\mathrm{Ha}$

IFPRI

IMF

ISU

Lt

Mt

NBER

NYMEX

OECD

OPEC

US

US\$

USDA

WTI

WTO
Argentinian Chamber of Biofuels

Chicago Board of Trade

European Union

United Nations Food and Agriculture Organisation

Food and Agricultural Policy Research Institute

Hectare

International Food Policy Research Institute

International Monetary Fund

Iowa State University

Litre

Metric tonne

National Bureau of Economics Research

New York Mercantile Exchange

Organisation for Economic Cooperation and Development

Organisation of the Petroleum Exporting Countries

United States

United States Dollar

United States Department of Agriculture

West Texas Intermediate

World Trade Organisation 


\section{Acknowledgements}

I would like to give thanks firstly and foremost to God our Lord and to his beloved Mother our Lady of Fatima for guiding my life, in particular during this blessed and important period. As Einstein once said: "God does not play dice with the universe", nor does He play with anyone's life. We all are part of a perfect plan, we just need to trust and listen to Him to find the right path (much easier to say than to do, I must admit). So clear was God's hand during this time that I'm receiving my PhD diploma on May, $13^{\text {th }}$, anniversary of the first apparition of our Lady of Fatima (Portugal, 1917) and $10^{\text {th }}$ anniversary of my mother's decease. From the very beginning He put the right persons in the right moments to lead me through the PhD. I'm grateful to my wife and kids for accepting with me the challenges of this new adventure and for their continuous and unconditional support. I thank God every day for my parents who were, are and always will be there for me. I'm very thankful to Prof. Dr. Brümmer who supervised my research, answered always my technical enquiries and continuously provided me support through my professional development as agricultural economist. My gratitude goes also to Prof. Dr. Olaf Korn for acting as my second supervisor. Thank him for patiently preparing the frequent reports I was asked for by my scholarship donors. I not only enjoyed the ULYSSES discussions at his office but also learned a lot from his experience on financial markets. Likewise, I appreciate the dedication and support received by Prof. Dr. Helmut Herwartz during the preparation of the last paper of this thesis. I would also like to thank Prof. Dr. Stephan v. Cramon for participating of my examination committee as a third referee and Dr. Sebastian Lakner for his constant support as responsible for the Joint-Program in Agricultural Economics I'm part of. Finally, a special acknowledgement to the Deutscher Akademischer Austauschdienst (DAAD), the institution which provided me with the funding necessary to fulfil this dream, and to all my colleagues and friends at the chair of Agricultural Market Analysis for being part of it.

\section{Thanks to all of you for being the right persons at the right moments!}




\section{Introduction}

The rise of food prices combined with periods of high volatility leads to considerable economic private and social costs. Since food expenditures represent a large portion of the income for many people in developing countries, they are particularly exposed especially those net-food-buyers living in urban areas. Unexpected price surges prevent them from acceding to food in appropriate quantity and quality. Moreover, price uncertainty delays new investments in agriculture, putting in the mid term further pressure not only on food access but also on food availability (Prakash, 2011). This situation may in turn lead to social unrest and political instability worldwide as evidenced by the so-called 'Arab Spring'.

With tranquil agricultural markets following a historical downward trend in prices over the past decades, little research had been devoted to understanding and managing food volatility. However, after the 2007/2008 food and financial crisis - which was coupled with high volatility periods- the issue of food price development was brought back to the top of the international political agenda (FAO et al., 2011). In the after crisis period many factors were identified as potential contributors to the steep upsurge of food prices and volatility. The provision of many staple foods, for instance, was affected by a declining trend of investments in agriculture, and by decreasing scales of production, which were coupled with more frequent weather disruptions. It has been also a change in consumption patterns in emerging countries towards protein rich aliments, coupled with a global demographic expansion, raising further concerns on food availability. These patterns were identified as structural or long-term determinants of price volatility in food markets. Additionally, in the shortterm, factors like the intractability of grain stocks and unexpected 'poor' harvests due to more frequent weather disruptions exacerbate further agricultural prices. Moreover, increased connectedness to intrinsic volatile markets like oil, discretionary biofuel policies and the so-called financialisation added complexity and uncertainties to agricultural and food markets. 
There are special concerns in the international community, however, around the increasing participation of investment funds in agricultural markets and the tightening relation between oil and agricultural markets due to biofuel policies. While many studies conclude that the alleged financial speculation in commodity futures does not have a significant impact on spot price levels or volatility (for a summary review see Will et al. (2012), there is increasing evidence on the role of biofuels as volatility drivers in agricultural markets. The biofuel industry emerged as a consequence of technological progresses, which allowed processing agricultural products into secondary energy carriers, namely ethanol and biodiesel, substitutes for gasoline and diesel, respectively. Though, the rapid growth of the market was driven mainly by political decisions aiming at reducing greenhouse gas emissions, promoting energy diversification and fostering rural development. The discretionality and unpredictability of these policies, however, added further complexity and uncertainties to agricultural markets (see De Gorter et al., 2015). Mitchell (2008), for instance, estimates that the production of biofuels in the US and Europe explain between $70 \%$ and $75 \%$ of the rise of food prices owing to the depletion of wheat and corn stockholdings, land use changes, increased speculative activity and export restrictions. Baffes and Haniotis (2010) find also evidence of the contribution of biofuels to the escalation of food prices, though their predictions are more conservative. Wright $(2011,2014)$ argues that the imposition of permanent and ambitious biofuel mandates, coupled with support policies, diverts substantial amounts of grains exacerbating further agricultural prices. The International Energy Agency forecasts in US\$ 1.4 trillion the aggregated costs of biofuels (including subsidies and mandates globally), between 2011 and 2035 (Gerasimchuk et al., 2012). This disproportionate support provoked that an average of $20 \%$ of sugar cane production, $9 \%$ of oilseeds and cereals, and $7 \%$ of sugar beet were diverted to biofuels between 2007 and 2009 (OECD and FAO, 2010). While stockholdings serve as price buffers for agricultural commodities, due to the permanent character of the biofuel mandates and the low responsiveness of agricultural supply, stock levels have been steadily declining. At low levels, the smoothing role of stocks renders ineffective against market shocks, resulting in longer periods of high volatility (Bobenrieth et al., 2013). 
The broad purpose of this research is therefore to provide new insights to the fuel versus food debate, including the effects of the financial and food crisis of 2007/2008. While research in price linkages between these markets is prolific, literature on volatility spillovers is recent and scant. We aim particularly at improving the understanding of the functioning and development of second order moment dynamics between agricultural markets and oil. The main body of this study comprises the following sections:

Section 2. We start this section addressing methodological issues concerning the estimation of volatility. We draw attention to important considerations like market definition, data frequency, time horizon, and modelling approach before empirically measuring price volatility. This in turn would certainly facilitate an accurate interpretation of the results. We continue with a comprehensive, though not exhaustive, review of recent literature concerning different aspects of volatility. Particularly, we focus on identifying key drivers of volatility in agricultural and food markets. We conclude this section commenting which drivers the scientific community agree on and where still remain some controversy.

Section 3. In this section we begin the volatility spillover assessment between oil and agricultural markets, implying that biofuels play a role in this relation. Based on the approach of Diebold and Yilmaz (2009) we derive spillover indices from forecast error variance decompositions using systems of realised-monthly volatilities of ethanol and biodiesel feedstocks, respectively. The spillover index measures the share of the variance-covariance matrix due to shocks spilling across markets (off diagonal elements), leaving out the effects of own markets innovations (diagonal elements). It is therefore indicative of the level of connection among a group of markets. We run the analysis dynamically applying successive rolling windows of 60 months. As suggested in the literature and to control for external effects, we add US Dollar exchange rate volatility as an exogenous variable. In order to identify contemporaneous shocks among oil and biofuel feedstocks we use a Cholesky factorisation with empirically predetermined orderings. Results demonstrate a steep increase of volatility spillovers in both systems, particularly between 2011 and 2013. In general, however, cereals and sugar markets behave more stable than vegetable oils during the considered period. 
Section 4. This section presents a refinement of the methodology proposed in the previous section which allows us to derive more informative and new volatility spillover measures as proposed by Diebold and Yilmaz (2012, 2014). While the Cholesky decomposition provides results sensible to the pre-imposed causality orders, the methodology presented in this section is not only invariant to orderings but also provides a tool to monitor volatility spillover levels on a daily basis. It is built upon a Vector Autoregressive Moving Average (VARMA) representation of a (half-vec) BEKK model which delivers daily spillovers estimates conditional on time- $t$ observations (Fengler and Herwartz, 2015). Results confirm (slightly) more spillover dynamics for vegetable oils compared to cereals and sugar. However, when considering a mix of ethanol and biodiesel feedstocks, the high-risk transmission between corn and soybean markets renders this system the most volatile in terms of spillovers. Evidence suggests also that, in general, the interdependences between oil and agricultural markets strengthened substantially after the financial and food crisis of $2007 / 2008$.

We end this study in section 5 with a discussion on the applied methodologies, their differences, advantages and weaknesses, as well as on the results and their relevance for policy advice. 


\section{Volatility in the after crisis period - A literature review of recent empirical research}

This section corresponds to the Working Paper No.1 prepared by the research team of the University of Göttingen for the EC-funded ULYSSES Project ${ }^{1}$. Prof. Dr. Olaf Korn and Kristina Schlüssler from the Faculty of Economics, Chair of Finance, were in charge of Section 2.2. Prof. Dr. Bernhard Brümmer, Dr. Tinoush Jamali and I, from the Faculty of Agricultural Sciences, Chair of Agricultural Market Analyses, were responsible for the remaining part of the paper. My main contribution to this study corresponds to Section 2.3, which I prepared jointly with my colleague and friend Dr. Jamali.

\subsection{Introduction}

Over recent years, price volatility on agricultural and food markets has become a major concern of policymakers worldwide. This increased attention was triggered by the food price crisis of 2007/2008, when prices for major agricultural products were increasing at an accelerating pace, before quickly coming down again in the last year of the crisis. Price changes over this period were often viewed as excessive, raising the question of which drivers were responsible for these patterns.

Scientists and market commentators have responded to these concerns over recent years, resulting in a rich body of literature. However, most of the literature is focused on price levels rather than price volatility. There is a need for a clear distinction between these two aspects. Most internationally traded agricultural commodities are storable; this makes high price volatility more likely when prices are high (and stocks

\footnotetext{
${ }^{1}$ Brümmer, B., Korn, O., Schlüssler, K., Jaghdani, T.J. and Saucedo, A., 2013. Volatility in the after crisis period - A literature review of recent empirical research, Working Paper 1, ULYSSES project, EU 7th Framework Programme, Project 312182 KBBE.2012.1.4-05, http://www.fp7-ulysses.eu/ , 46 pp.
} 
are low). Nevertheless, a qualified discussion of the drivers of price volatility requires careful distinction between drivers of price levels and drivers of price volatility.

Volatility relates to unexpected price changes. Hence, it is important to specify an explicit model for the expected price in order to be able to distinguish between expected price changes and unexpected price changes. In addition, there are a number of conceptual choices which have to be made in order to empirically assess price volatility, e.g., market definition, data frequency, time horizon, and methodological approach. The specific choices have repercussion on the interpretation of the generated price volatility measure. Therefore, we start section 2.2 of our review by exploring the consequences of the various possibilities with regard to these choices. Section 2.3 continues with an extensive review of the relevant literature on drivers of agricultural price volatility (broadly defined). The studies are categorised according to both methodological and topical criteria so that the most relevant strands of thought in the literature become clear. Next, Section 2.4 contains discussions concerning current perceptions on the relative importance of the potential drivers of agricultural price volatility. We elicit the consensus on major drivers from the literature where possible, and highlight the areas where the literature provides no clear guidance on whether or not a certain driver is relevant for price volatility on agricultural and food markets. Section 2.5 concludes with a focus on the research gaps in the literature.

\subsection{Volatility concepts and measurement}

This review article mainly focuses on the literature that contributes to the understanding of volatility drivers. Any attempt, however, to identify factors that govern volatility in agricultural commodity markets depends on the applied volatility concept. In particular, any empirical analysis of volatility and its drivers requires a definition of volatility that is specific enough to make the empirical volatility measurement operational. Therefore, this section sets some groundwork by dealing with the concept of volatility itself, i.e., the quantity to be explained, and not with its driving factors, i.e., the variables that explain volatility.

Almost all papers reviewed in this report base their analysis of volatility on the following definition: Volatility is the standard deviation of relative price changes 
(logarithmic-returns). ${ }^{2}$ This simple definition has several important implications. (i) Since the standard deviation is the square root of the expected squared deviation between the actual (relative) price change and the expected price change, such a volatility concept clearly distinguishes between expected price changes and unexpected price changes. In the words of Andersen et al. (2010), p. 69, volatility is stated to be “...the component of a given price increment that represents a return innovation as opposed to an expected price movement”. (ii) Since volatility expresses the magnitude of deviations from the expected price movement, any attempt to measure volatility empirically requires modelling of the price process, for instance, by modelling trends, seasonality, or cyclical components. Such trend models are often not discussed explicitly in the literature on volatility, but they are always present. For example, the popular assumptions of zero expected returns, or expected returns that are constant over time, imply the absence of any trend or a simple linear trend, respectively. These simple trend models may be perfectly appropriate for short time intervals like a minute or a day. However, for longer time intervals it is important to deal with both long-term trends and cycles as well as with seasonalities according to harvest cycles. If these were ignored, the corresponding expected price changes would be mistaken for volatility. (iii) Since volatility addresses potential price changes, it inevitably refers to a period (over which a price change can happen) and not only to a single point in time. (iv) According to the previous definition, volatility is not a directly observable quantity like a price, and has to be estimated. Although the literature largely agrees on this definition of volatility, its concrete measurement or estimation still involves many choices. Because different choices could lead to different volatility estimates, which in turn could lead to different conclusions about volatility drivers and policy implications, we briefly discuss these options.

\subsubsection{Time Horizon}

Volatility always refers to a time period. The end of this period defines the time horizon. The selection of an appropriate horizon is a major decision one has to make for the analysis of volatility; this decision clearly depends on the goal of the analysis. For example, for an understanding of the effects of volatility on producers and

\footnotetext{
${ }^{2}$ The only alternative concept that is used in some papers is the coefficient of variation, however, this measure contains the standard deviation in the numerator.
} 
consumers, a time horizon of at least one month seems appropriate, but it could also be much longer. It is important to note that the time horizon does not necessarily coincide with the frequency of the data, which is used to estimate volatility. On the contrary, some estimation methods require that data is available at a higher frequency than the time horizon under consideration. However, several studies were reviewed that do not explicitly discuss the time horizon they are focusing on. Moreover, the time horizon should not be confused with the data period that defines the total period of historical data that is available for volatility estimation.

\subsubsection{Considered Markets}

Another central issue is the choice of markets to be considered in a study. The goal of the analysis should in principle determine which commodities and which regions are investigated. In practice, however, it can be a difficult task. Even if one is interested in a single commodity and a specific region, connections between markets and spill over effects might require an analysis of several markets to obtain a clear understanding of the factors that drive the volatility of the commodity of interest. Another important aspect concerning the choice of markets is the use of spot data versus futures data. Even if one is interested in the spot price volatility, futures markets are frequently used because of data availability and quality. It is important to note, however, that volatilities obtained from futures data can be quite different from the corresponding spot price volatilities. For example, Schwartz (1997) provides a theoretical and empirical analysis of this issue. He shows that spot volatilities tend to be higher than futures volatilities, an observation that can be explained by the dependence between spot prices and convenience yields.

\subsubsection{Ex-post measurement versus ex-ante prediction}

It is important to clearly distinguish between ex-post volatility and ex-ante volatility. In general, the ex-post measurement of volatility can use all available information, including the price changes that occurred in the period of interest (see above the discussion on the time horizon), and even price changes that occurred later. In contrast, a measurement of ex-ante volatility is based entirely on information up to the beginning of the time period. This distinction has several implications: (i) The preferred approach depends on the objectives of the volatility assessment. Ex-post volatility is most useful in an analysis that aims to explain what has driven volatility 
in the past, whereas ex-ante volatility helps us to understand expectations about future volatility. Both perspectives are economically relevant. In terms of policy implications, the ex-post analysis can be used to guide longer-term reforms, whereas ex-ante measures could provide an early warning system that may indicate the need for immediate action. (ii) Ex-post volatility can be interpreted as an in-sample volatility, whereas ex-ante volatility can be seen as a forward-looking out-of-sample volatility. Ex-ante approaches hence require that the estimated volatility model continue to be valid for the time horizon outside the observation sample. (iii) Different estimation methods are available for ex-post and ex-ante volatility. In particular, implied volatilities based on the expectations of options markets participants can be used as measures of ex-ante volatility.

\subsubsection{Estimation method}

Given all the choices mentioned above, the concrete selection of the estimation method still allows us to make a great number of decisions. This could have a large impact on the resulting volatility estimate. The most common approach is the use of a parametric volatility model coupled with historical data. Models of the Generalised Autoregressive Conditional Heteroskedasticity (GARCH) class ${ }^{3}$ and stochastic volatility models ${ }^{4}$ are two important approaches. A GARCH model explains (squared) volatility by past return innovations and past (squared) volatilities (plus potentially some exogenous explanatory variables (GARCH-X)). A stochastic volatility model treats volatility as a random variable and describes it using a stochastic process. GARCH models are commonly used for the analysis of volatility in agricultural commodity markets, too. Model specification in this context involves several choices: (i) To obtain the return innovations, one has to specify a model for the expected price changes (see discussion above). In the discussion to follow, we concentrate on the volatility part of the model. (ii) Some general specification issues involve questions on whether to use a univariate GARCH model for every individual market or to treat several markets simultaneously via a multivariate (vector) GARCH model. Additional considerations are the integration property of the volatility

\footnotetext{
${ }^{3}$ The approach dates back to the seminal work by Engle (1982) and Bollerslev (1986).

${ }^{4}$ An early example of a model that treats volatility itself as stochastic is Clark (1973). A very popular stochastic volatility model is the one by Heston (1993). For a review paper that covers both GARCH models and stochastic volatility models see Andersen et al. (2010).
} 
(stationary, integrated, or fractionally integrated GARCH models) and the question of whether the volatility response to past return innovations is asymmetric (GJRGARCH) ${ }^{5}$ or depends on certain thresholds (T-GARCH). For storable agricultural commodities, the fact that demand for storage tends to become more elastic at low price levels suggests that asymmetry or threshold effects are likely present. (iii) One has to select the order of the GARCH model, i.e. the number of lagged return innovations and lagged volatilities to be included. (iv) Finally, the data frequency and the historical period are additional important aspects. One disadvantage though, is that GARCH models assume that the structure of the model remains constant over the whole sample period, including any possible forecast horizon.

An alternative to parametric volatility models is a nonparametric approach often called "realised volatility". ${ }^{6}$ The basic idea is that the volatility of a certain time period can only be estimated with data from this period, which is available on a higher frequency. For example, the volatility referring to a certain month is estimated from the daily price changes within this month. The major advantage of this approach is that it does not require the assumption of a fixed model structure over quite a long period of time (the data period used for GARCH models usually spans several years). One disadvantage of the approach is its need for price data measured at relatively high frequencies, which might not be available. Moreover, we are presented with the issue of how volatility scales over different frequencies. For example, if daily data is used to estimate the volatility for a time horizon of one month, we have to convert the daily volatility into a monthly one. Simple scaling rules for the volatility, like the square root of time rule, might not work very well because of dependencies in the daily price changes. ${ }^{7}$

Parametric and nonparametric methods based on historical price data can in principle be used both for the ex-post measurement of volatility and for ex-ante predictions. Prediction is rather straightforward with the parametric models. Given the parameter estimates, volatility forecasts for different time horizons are often easily obtained from the model, e.g., for the standard GARCH model. The nonparametric approach

\footnotetext{
${ }^{5}$ GJR stands for Glosten-Jagannathan-Runkle.

6 This approach was first introduced and applied by French et al. (1987), Schwert (1989, 1990a, 1990b), and Schwert and Seguin (1990). It was later formalised by Andersen and Bollerslev (1998).

${ }^{7}$ See Lo and MacKinlay (1988) for an analysis of the scaling of volatility in the stock market.
} 
delivers a time series of "realised volatilities" that can build the basis for out-ofsample predictions of volatilities. The specification of the concrete prediction model, however, is an additional task that again entails many choices to be made by the researcher. A completely different approach to ex-ante volatility prediction is the use of options data to reveal volatility expectations of market participants. This leads to the concept of implied volatility. This concept relies on the idea that volatility is an input variable in standard option pricing models. Given observed market prices for options, the corresponding pricing formula can be inverted to obtain a volatility estimate that is in line with observed market prices. A drawback of this approach is its reliance on a particular option-pricing model. For example, a standard approach uses the model of Black (1976) for options on futures or a corresponding discrete-time approximation. Alternatively, model-free approaches to estimate implied volatilities have been developed by Britten-Jones and Neuberger (2000) and Bakshi et al. (2003). These are computationally more complex but do not require the assumption of any specific pricing model. The major advantage of the implied approach to volatility estimation, in general, is that it does not require any historical data, which in turn may no longer be representative of the future. It relies instead only on current option prices. It can therefore exploit the most recent information available to market participants in derivatives markets, often leading to better predictions than alternative methods based on historical price data. ${ }^{8}$

\footnotetext{
${ }^{8}$ See Poon and Granger (2003, 2005) and Christoffersen et al. (2012) for survey articles that document the excellent predictive performance of implied methods for many different markets. This result still holds despite the fact that implied estimates can be biased due to risk premia.
} 
Figure 1. Differences among commonly used volatility measures

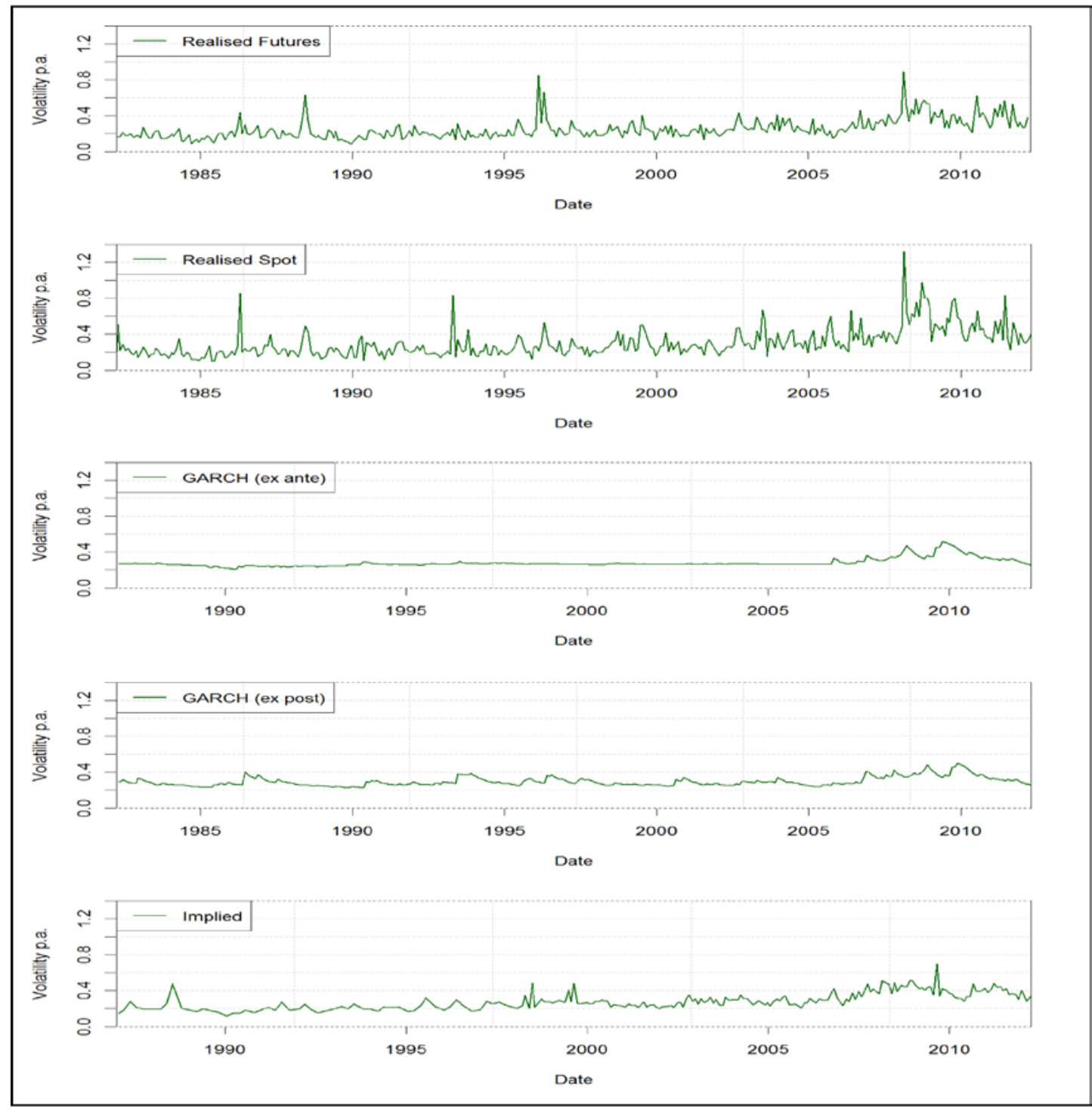

Source: Own elaboration.

Note: All graphs show the annualised standard deviations of logarithmic price changes of wheat (annualised volatility). The futures used for the estimation are the ones traded at CME (soft red winter), as well as their corresponding spot prices (WHEATSF from Data Stream). The time series of futures prices are constructed by using the futures contract with the shortest time to maturity and rolling it over to the second shortest contract, when there are less than five trading days for the shortest contract. The realised volatilities for the futures and spot markets refer to a period starting on the 20th calendar day or the next trading day (if there is no trading on the 20th) of each month using the following 20 daily (logarithmic) price changes. The full data period is March 1982 to April 2012. For the ex-post and ex-ante GARCH estimation, a GARCH $(1,1)$-model is selected and estimated with monthly spot market returns. The data period for the ex-post GARCH estimation is also March 1982 to April 2012. The first GARCH-based ex-ante prediction is made in January 1987 for the next month's volatility, using monthly returns from April 1982 to January 1987 for the estimation of model parameters. The following predictions use a successively extended estimation window up to March 2012. Implied volatilities are calculated based on a discrete version of Black's (1976) option pricing model that can handle American-style options. For the calculation, at-the-money options on wheat futures traded at CME between January 1987 and March 2012 are used, with times to maturity between 29 and 32 calendar days. 
As a brief illustration of some of the approaches presented previously, consider the examples given in Figure 1 for the wheat market. We choose a common time horizon of one month and present three different ex-post measures of wheat price volatility and two different approaches to ex-ante volatility prediction. The total sample period for the ex-post measures is March 1982 to April 2012. The ex-ante approaches deliver predictions for every month between February 1987 and April 2012. All numbers refer to annualised values.

Table 1. Descriptive statistics of the volatility measures shown in Figure 1

\begin{tabular}{lrrrrr}
\hline \multicolumn{5}{c}{ Volatility measures } \\
\hline & Realised Futures & Realised Spot & GARCH (ex post) & GARCH (ex ante) & \multicolumn{1}{c}{ Implied } \\
\hline Maximum & $89.12 \%$ & $132.11 \%$ & $50.27 \%$ & $51.45 \%$ & $70.30 \%$ \\
Minimum & $8.44 \%$ & $9.78 \%$ & $22.73 \%$ & $20.96 \%$ & $11.82 \%$ \\
Average & $24.92 \%$ & $29.75 \%$ & $29.65 \%$ & $27.90 \%$ & $29.28 \%$ \\
Standard Deviation & $11.00 \%$ & $15.49 \%$ & $5.10 \%$ & $4.91 \%$ & $9.27 \%$
\end{tabular}

Source: Own elaboration.

Note: The summary statistics of the volatility measures are calculated from 362 observations for the ex-post measures (Realised Futures, Realised Spot and GARCH (ex post)) and 303 observations for the ex-ante predictions (GARCH (ex ante) and Implied).

We make an initial distinction between futures and spot markets. As the upper two graphs of Figure 1 and the first two columns of Table 1 show, realised volatilities (using daily data) obtained from futures and spot markets are rather different. Our example confirms previous results from the literature (e.g., Schwartz, 1997), that futures returns show lower volatility than spot returns. Although we use the futures with the shortest maturity available, the difference is substantial. On average, the spot volatility (29.75\%) is about five percentage points higher than futures volatility (24.92\%). Moreover, spot volatilities are less stable over time. There is also a distinction between the non-parametric realised volatility and the volatility resulting from a parametric GARCH $(1,1)$ model (Figure 1, second and fourth graphs). Although both approaches use spot data and deliver similar average volatility levels (29.75\% and 29.65\%, respectively), they develop differently over time. The GARCH model presents a much more stable evolution of volatility. Its standard deviation (5.1\%) is much lower compared to the realised volatility (15.49\%). A third aspect to note is that ex-post and ex-ante volatilities can be rather different, even if they are based on the same model (GARCH $(1,1)$ ). In particular, the series of ex-ante volatilities shown in Figure 1 are smoother than the corresponding series of ex-post volatilities over the period 1987-2006. Finally, a comparison between GARCH and 
implied volatility predictions reveals that the option-based values fluctuate more over time.

The discussion of this section and the examples presented for the wheat market, although not exhaustive, reveal the wide range of issues a researcher has to confront. Any empirical study should therefore explicitly recognise the diversity of approaches and transparently document their outcomes. This would certainly facilitate the understanding and correct interpretation of the results.

\subsection{Literature review on food price volatility}

\subsubsection{Introduction}

In this section we present a comprehensive review on agricultural and food price volatility research conducted over the last decade. We focus not only on peerreviewed articles but also include a selected number of working papers, policy briefs, and discussion papers ('grey literature') from recognised international organisations and research institutes. We separate the studies according to their contribution to the theory underlying volatility estimation; volatility drivers; volatility spillover effects; and medium to long term changes in volatility pattern.

\subsubsection{Studies on price volatility}

Food price volatility is a major focus of research and policy advising for many international organisations or research institutes such as the FAO, IFPRI, NBER, IMF, World Bank, etc. The issue of food price development was brought back to the top of the international political agenda after the food price crisis of 2007/2008. For instance, the book edited by Prakash (2011) presents a comprehensive overview of food price volatility, its drivers, consequences, and case studies. This book partially reflects FAO's view on food price volatility. Other international organisations like IFPRI conducted empirical research on food price volatility (e.g. Pietola et al., 2010) and released policy briefings (e.g. Robles et al., 2009). There are also publications which represent the shared vision of different development organisations (e.g. FAO et al., 2011). Similar policy papers can be found by other organisations. The main focus of these types of policy briefings is to present the drivers of food price volatility or to give policy recommendations to deal with this problem. The aim of this section is to

review the established body of literature on food price volatility with a 
methodological and analytical background. The precedent discussion on volatility concepts illustrates that identifying food price volatility drivers requires a clear methodological and analytical framework. It highlights the central role of conceptual choices for the findings and implications of any empirical study on this topic.

In general, food price volatility literature can be categorised into studies looking at:

$>$ Volatility levels

$>$ Theoretical aspects of price volatility analysis

$>$ Empirical analysis of price volatility drivers

$>$ Volatility spillover effects

$>$ Interaction between spot and futures price volatility

$>$ Price formation in futures markets

In the following section we will present detailed information on empirical studies in each of the above-mentioned categories.

\subsubsection{Volatility levels}

The after crisis period has shown, in general, high price volatility for many agricultural commodities. However, when compared to the 1970s, it seems that recent volatility spikes remain below their historical levels for most commodities. Gilbert and Morgan (2010) conclude that the volatility for agricultural products was lower over the past two decades than it was in the 1970s and 1980s, with the exception of rice. Despite the fact that there has been no growing tendency for food volatility over recent years, volatility of the major grains and some oil seeds (groundnut oil, soybean and soybean oil) have increased steeply. Gilbert and Prakash in Prakash (2011) argue that periods of extreme volatility in agricultural markets are seldom. They distinguish the episode of 1973-1974 as a 'crisis' with extreme high price levels and volatility in commodity markets, whereas the recent period of 2006-2007 - despite showing relatively high price levels and volatility - is not comparable in size and effects (ca. five million malnutrition related deaths). Huchet-Bourdon (2011) finds from the analysis of ten products (1957-2010) that agricultural price volatility is on average lower for beef and sugar. She also concludes that volatility is higher over the last decade than in the 1990s, but not higher than the 1970s. Moreover, she confirms that recent volatility episodes are only higher than the 1970s for cereals. Ocran and Biekpe (2007) determine whether long-run price volatility and trends have changed over the past four decades for 18 food and non-food commodities in Sub-Saharan countries. 
Their findings reveal that the volatility does not show any significant change over the period considered for aluminium, beef, cocoa, groundnut oil, crude oil, palm oil, rubber, timber, and tobacco. For gold, sisal, shrimps, groundnuts, and sugar the volatility decreases while for copper, coffee, cotton, and tea it increases. Crude oil price exhibits the highest volatility persistence followed by sugar, aluminium, and coffee.

\subsubsection{Theoretical aspects of price volatility analysis}

There are few works comparing models and studies in the area of price volatility. For instance, Poon and Granger (2003, 2005) review different understandings of price volatility, check empirical volatility models, and run some empirical trials in the area of finance. Analogously, Gouel (2012) does a review of the major theoretical studies on price volatility, but oriented to agricultural markets instead.

The papers presented in this section use empirical statistical methods to shed some light on various theoretical aspects of volatility estimation in agricultural markets.

Lence and Hayes (2002) consider a 'Rational Expectations Storage model' to uncover the potential effects of the FAIR Act on the US corn and soybean markets. Results suggest that the price volatility was driven mainly by an unusual sequence of events during the 1995 crop year. Symeonidis et al. (2012) analyse the relation between stock levels and the shape of the forward curve. They use daily futures of grains and livestock for the US market. As predicted by the theory of storage they demonstrate that low (high) inventory is related to curves in backwardation (contango) and price volatility is a decreasing function of stock levels for most of the commodities considered.

Black and Tonks (2000) use a multi-period futures model to test whether price volatility increases or decreases as the maturity date of the futures contract approaches (also known as the Samuelson effect (Samuelson, 1965)). They find that if output uncertainty is resolved before the maturity of the contract, and if the re-trade market ${ }^{9}$ is informationally efficient, the Samuelson hypothesis does not hold. Smith (2005) develops a Partially Overlapping Time Series (POTS) framework to jointly model volatility dynamics of traded futures contracts with different delivery dates. This

\footnotetext{
${ }^{9}$ The market that appears after some new information arrives between the beginning and the maturity of the contract.
} 
model incorporates time-to-delivery, storability, seasonality, and GARCH effects. Using US corn futures, the author shows the dynamic structure of the data and reveals substantial inefficiency in the contract delivery. His results also provide evidence in favour of both the theory of storage and the relevance of the Samuelson effect. Karali et al. (2011), using weekly data on soybean, corn, and wheat in the US futures market, apply a Stochastic Volatility (SV) and Bayesian Seemingly Unrelated Regression (SUR) method. They aim to prove whether modelling volatility as a stochastic instead of a deterministic variable leads to improved inference about its relationship with seasonality, storage, and time to delivery. Results show that volatility decreases the closer it gets to the time of delivery for soybeans and wheat; however, it increases for corn. This study provides limited support for the theory of storage and for Samuelson's maturity hypothesis.

Yang et al. (2001) investigate the effects of the US FAIR act of 1996 on agricultural price volatility. They use GARCH models for corn, oat, soybeans, wheat, and cotton daily futures. Their findings show that agricultural liberalisation policy provoked an increase in price volatility for the three major commodities (corn, soybean and wheat), a little change for oats, and a decrease for cotton. Fong and See (2001) examine the relevance of considering volatility regime switches. Using daily settlement spot and futures prices, they find that the simple GARCH is not adequate to treat volatility in the presence of regime shifts since the shift dominates the GARCH effects. Jin and Kim (2012), contribute to the discussion about regime switches. They use real prices for rice, red pepper, onion, and sesame in South Korea, to test different regime switching techniques. They suggest a new type of measure using a model which incorporates multiple structural changes in the unconditional mean to overcome the problem of amplified variance. They prove that this method performs better when the regime switches are given a form of parallel mean shift. However if the series are more dominated by trends than by mean shifts, this method is not suitable.

Ramírez and Fadiga (2003) use soybean, sorghum, and wheat deflated farm gate prices, in order to evaluate an Asymmetric Error GARCH model. They find that this type of model is a viable alternative for forecasting time-series when the conditional probability distribution of the dependent variable is asymmetric. With leptokurtic but not skewed errors, they suggest using either the Threshold GARCH or the Asymmetric GARCH models. If there is positive kurtosis and positive or negative 
skewness, then the Exponential Generalised Beta 2-GARCH or the Asymmetric GARCH are appropriate choices. Complementarily, Onour and Sergi (2011) compare the performance of models to capture volatility in food commodities when considering a normal instead of a t-distribution. They use monthly prices for wheat, rice, sugar, beef, coffee, and groundnut and conclude that the t-distribution performs better. This implies that the normality assumption of the residuals may lead to unreliable volatility results.

Jin and Frechette (2004) investigate the long memory phenomenon in agricultural futures markets; they find that a Fractionally Integrated GARCH approach can be a better way to model long dependence in volatility by allowing for fractional integration in the variance equation. Elder and Jin (2007) argue that wavelet methodology can explain long memory processes in agricultural futures better than the Fractionally Integrated GARCH model. Sephton (2009), using the same dataset as Jin and Frechette (2004), tests a fractional integration model but incorporating additionally leverage effect. He finds that the Fractionally Integrated Asymmetric Power ARCH (FIAPARCH) model explains the long dependence in futures prices for some of the crops better than Fractionally Integrated GARCHs. The reason is that some agricultural futures display asymmetric leverage effects. Power and Turvey (2010) assess the presence of the long-memory in the volatility of energy and agricultural commodities. They use an improved Hurst coefficient estimator in a wavelet-based rescaled range (R/S) analysis. Using daily futures for coffee, cotton, sugar, cocoa, orange juice, wheat, live cattle, lean hogs, corn, and soybeans, they find evidence of long memory and a non-constant Hurst parameter in most of the considered commodities.

Egelkraut and García (2006) investigate the predictive accuracy of implied forward volatility for agricultural commodities with different seasonalities. They use daily futures prices for corn, soybeans, soybean meal, wheat, and hogs and their results indicate that the implied forward volatility has better predictive power for commodities whose uncertainty resolution is concentrated in space and time. Similarly, Giot (2003) evaluates the information content of the implied volatility for options on futures contracts of cacao, coffee, and sugar. He shows that lagged squared returns slightly improve the information content provided by the lagged implied volatility in a GARCH framework. Moreover, Value at Risk (VaR) models that rely 
on past-implied volatilities perform as well as those with ARCH-type modelled conditional variances. The author concludes that implied volatility has high informative content for the studied commodities.

Westerhoff and Reitz (2005) and Reitz and Westerhoff (2007) develop a simple commodity market model which explains the cyclical nature of commodity prices by considering the behaviour of two types of heterogeneous agents, the fundamentalists and the technical traders. They use monthly data for agricultural and non-agricultural commodities in a Smooth Transition Autoregressive GARCH model. Evidence shows that technical traders progressively enter the market as price deviates from its long run equilibrium. This trend-following pattern initially enforces market's mispricing. At the same time fundamentalists become more active, forcing the price back to its fundamental value and leading to cyclical motions. Voituriez (2001) uses the 'Trader Behaviour model' for the palm oil market to test the hypothesis that the overlapping of operators' expectations (short versus long term expectation horizon) is triggering volatility changes. Using monthly prices he finds that volatility might increase as long as operators with a short-term expectations horizon superimpose on the long-term expectations traders, precluding the argument that larger markets reduce volatility.

Taylor (2004) compares the performance of the Periodic GARCH with alternative Periodic Conditional Volatility (PCV) models using 5-minute data of cocoa futures. When considering high-frequency commodity futures returns, the periodicity in conditional return volatility is a key issue. He argues that neglecting periodicities in high frequency data could lead to poor volatility forecasts. Moreover, the author concludes that return volatility forecasts, obtained by the Spline Periodic GARCH model, are shown to be less accurate than those generated by PCV models, but if used in a Value at Risk framework, the Spline model produces accurate and consistent measures.

\subsubsection{Empirical analysis of price volatility drivers}

There are some empirical works which do not explicitly present quantitative estimates: They are descriptive in nature. Gilbert and Morgan (2010) are an appropriate example; they recognise that the volatility during the recent crisis period is not as high as in the 1970s, nevertheless they argue that factors like global warming, oil price volatility transmitted via biofuels, and the relative large investments in index funds might permanently increase agricultural volatility, 
especially in grain markets. Anderson and Nelgen (2012), using annual prices for rice, wheat, corn, soybean, sugar, cotton, coconut, coffee, beef, pork, and poultry, assess the trade responses of 75 countries to provide empirical evidence on how governments, both in developing and developed countries, reacted during the past price spikes. They conclude that responses of agricultural importing and exporting countries are offsetting, and therefore the domestic price-stabilising effect of their interventions was ineffective. Nissanke (2012) argues that the financialisation of commodity markets served as a transmission channel for the financial crisis from developed to developing countries. He proposes more regulation and transparency in futures markets, minimal stockholding of essential commodities, and innovative market oriented stabilisation mechanisms like virtual reserve holdings or multi-tier transaction taxes. Jennifer Clapp (2009) considers agricultural commodities on different periods. She argues that the falling value of the US dollar, increasing speculation activities in commodity futures markets, and trade measures have an important influence on food price volatility. Wright (2011) identifies the low grain stocks due to biofuel mandates as a major cause of food volatility. He concludes that accumulated shocks such as the long drought in Australia and oil price spikes would have caused panic leading to a cascade of export bans and taxes. Chandrasekhar (2012) finds that for the case of India the 2008/2010 food crises were driven mainly by food inflation and to a lesser extent by an increase in volatility.

A smaller set of studies uses mathematical models to explain food price volatility. For instance, Babcock (2012) uses a stochastic partial equilibrium model to analyse the price volatility in US soybean, corn, and wheat markets in order to assess the impact of domestic biofuel policies on agricultural price levels and volatility. He finds that US ethanol policy barely increased corn prices from 2006-2009, but under tighter market conditions like those in 2010-2011 the impacts on prices were larger. Moreover, US biofuel policy increases price volatility especially on the upside when demand for feedstocks is high or supply is tight. Miao et al. (2011) model the 'Herd Behaviour Theory' to test the risk and regulations on price volatility for non-staple agricultural commodities in China. They find that speculation and price manipulation, originating from asymmetries of information, bring about a herd-like behaviour. This phenomenon has pervasive and difficult to manage consequences that especially affect farmers and consumers. 
The last group of literature uses different statistical methods to examine food price volatility drivers. Zheng et al. (2008) apply an Exponential GARCH model to examine whether unexpected news affects food price volatility. They use monthly prices for 45 food products in the US. Their results confirm that the amplifying effect of the news is present only in one third of the products. The authors argue that the increasing concentration of food distribution and retailing in large firms act to absorb the price volatility. Hayo et al. (2012) measure the impact of the US monetary policy on the price volatility of different commodities (agricultural, livestock, energy and metals) with a GARCH model. They arrive at the conclusion that changes in expected (target) interest rates and communications do decrease volatility, whereas unexpected interest rate movements and innovative measures increase it. Roache (2010) runs a Spline-GARCH model with US corn, palm oil, rice, soybeans, sugar, and wheat monthly spot prices. He aims at explaining what drives low frequency volatility. The author shows that the slow-moving component of spot price volatility is positively correlated across the different commodities, proving the presence of common factors affecting the low frequency volatility. He argues that the variables with the largest effect on this type of volatility - since the mid 1990s - are volatilities in the US dollar exchange rate and inflation. Du et al. (2011) use a Stochastic Volatility model with Merton Jumps in returns (SVMJ) to investigate the role of speculation in crude oil price variability and to what extent oil volatility transmits to agricultural markets. Using weekly futures of oil, corn, and wheat they conclude that scalping ${ }^{10}$, speculation, and petroleum inventories explain crude oil volatility. Oil price shocks appear to trigger sharp price changes in agricultural commodities, especially in the corn and wheat markets, arguably because of the tightening relation between oil and agricultural markets. In a study by IFPRI, Pietola et al. (2010) assess the empirical relationship among US weekly wheat prices, inventories, and volatility. They use a Co-integrated Vector Autoregressive model, and add price volatility in the form of the estimated variance to the basic model. Volatility and inventories have a significant negative relation in the very short run, but this relation levels off over time. Thus, in the short run, increasing wheat prices coincide with decreasing inventories. Decreasing prices imply either inventory build-ups or postponement of inventory

\footnotetext{
${ }^{10}$ Scalping refers to a trading strategy that opens and closes contract positions within a very short period of time to realise small gains.
} 
withdrawals. Ghosh et al. (2010) employ different models (GARCH, GARCH dummy, Exponential GARCH in mean, and Ordinary Least Squares) to examine price volatility and supply responses of rice, jowar, bajra, corn, groundnut, and cotton. Using annual prices, they check whether trade liberalisation exacerbates volatility of agricultural products in India. The results reveal that prices of major agricultural products became unstable in India after the signing of the WTO agreement. Swaray (2007) applies Exponential and Threshold GARCH models to assess the impact of the suspension of trade agreements on the asymmetry and persistency of volatility. They use monthly prices of cocoa, coffee, rubber, sugar, and tin. Their results demonstrate a rise in the asymmetry but a decrease in the persistence of the shocks.

\subsubsection{Volatility spillover effects}

A large body of the literature concerning food price volatility investigates volatility transmission, or spillovers, across markets. With this purpose in mind, many researchers use bivariate or multivariate GARCH models. Others also apply (Granger) causality-in-variance tests. The spillover articles have different focuses; some authors investigate spillover effects between different types of commodities, for instance between oil and agricultural products. Others analyse the impact of macroeconomic variables on agricultural markets or the spillover effects along the food supply chains.

\section{Macroeconomic factors}

The interaction between food commodities and macroeconomic variables is an important area of research of the volatility literature. Udoh and Egwaikhide (2012) employ GARCH, Vector Autoregressive and Ordinary Least Squares methods to test for Dutch Disease effects in agricultural markets in Nigeria. They use domestic prices between 1970 and 2008, and conclude that oil price volatility has a complementary relation with food inflation in Nigeria. Oleg (2011) focuses on the conditional correlations between commodity futures and traditional asset classes in periods of high equity and bond volatility. He applies a bivariate GARCH model to a variety of products (Shanghai Stock Index (SSI), China’s 10-year Government Bond Index, and different agricultural and non-agricultural commodities) for the period 2006-2010. The author shows that conditional correlation between commodity futures and the SSI rises in periods of recession and high market risks. Moreover, the negative correlation between bonds and commodity futures rises with the bond volatility, suggesting that a bond-commodity portfolio should not be tilted towards commodity futures in periods 
of high bond volatility. Busse et al. (2011) analyse the behaviour of price volatility in EU biofuel markets, during and after the 2007/2008 financial crisis. They use a Dynamic Conditional Correlation (DCC) model to investigate the correlation between oil volatility and the volatilities of rapeseed, rapeseed oil and soybean oil. The authors find significant correlations between oil and both rapeseed oil and soybean. However, they clarify that the model neither allows for conclusions about causal mechanisms of volatility spillovers nor is it able to capture the magnitude of the influence of one market on the other. Apergis and Rezitis (2003b) employ a multivariate GARCH model to assess volatility spillovers between food markets and macroeconomic fundamentals in Greece. They recognise positive spillovers from macroeconomic fundamentals to food markets.

\section{Volatility spillovers along the supply chain}

This subcategory of research deals with volatility transmission between the different marketing levels of food chains.

Khaligh et al. (2012) is one of the recent studies on this topic. They apply a multivariate GARCH model to examine the degree by which price uncertainty spills over across the agricultural input, output, and retail markets in Iran. They use indices of the poultry market between 1997 and 2010. The authors show that information generated at the agricultural input and retail levels could lead to changes in the volatility of output prices. Serra (2011a) assesses the price volatility spillovers resulting from the Spanish Bovine Spongiform Encephalopathy (BSE) crisis- at different stages of the Spanish beef marketing chain. She applies a Smooth Transition Conditional Correlation GARCH model to farm-gate and consumer prices for the period 1996-2005. The author concludes that during turbulent times price volatilities can be negatively correlated. Moreover, one cannot expect that intervening with one market will stabilise other related markets. An early paper on this issue is Apergis and Rezitis (2003a). They use also a multivariate GARCH framework to investigate volatility spillovers along food chains in Greece. They consider three indices, for input, output and retail prices $(1990=100)$ for the period 1985-1999. The authors conclude that volatilities of input and retail prices positively impact on the output price volatility. Moreover, output prices are more volatile than agricultural input and retail food prices. Another pioneer work in this area is Buguk et al. (2003). In this article the researchers examine the extent to which volatility in US soybean and corn 
markets spills over to feed and catfish markets. They apply an Exponential GARCH model and find significant unidirectional volatility spillovers from corn, soybean, and menhaden to catfish prices. Additionally, the authors prove that farmers exert some market power in the chain, and consequently transmit volatility in an asymmetric manner. Kostov and Mcerlean (2004) criticised Apergis and Rezitis (2003b) by arguing that as in other financial markets, the theoretical framework of Mixture of Distribution Hypothesis (MDH) can better explain the spillover effect. Furthermore, the authors believe that a proper model for explaining agricultural price volatility should include (own) volume information.

\section{Volatility spillovers in commodity markets}

The last set of studies on volatility spillovers addresses interdependencies between commodities markets both, within and between countries. Sehgal et al. (2013) investigate whether the Indian futures market effectively serve price discovery and the introduction of futures trading resulted in volatility transmission to spot markets. They run a bivariate Exponential GARCH model for different agricultural (chana, guar seed, soybean, kapas, potato and agra), metal (gold, silver, zinc, lead and copper) and energy commodities (natural gas, crude oil) for the period 2003-2011. They find bidirectional volatility spillovers for soybean, zinc and natural gas. Moreover, spot volatility transmission to futures markets is larger. For the rest of commodities there are no significant volatility spillovers. Rezitis and Stavropoulos (2011) examine the implications of the rational expectations assumption in primary commodity markets. They use a multivariate GARCH model for major meat markets in Greece (beef, lamb, pork, and broiler) from 1993-2006. The authors conclude that uncertainty caused by price volatility is a restrictive factor for the growth of the Greek meat industry. Some other articles focus on spot markets of multiple commodities. Motivated by the issues raised by the biofuel industry, Serra et al. (2011) analyse volatility transmissions among sugar, ethanol, and oil markets in Brazil (2000-2008). Using a multivariate GARCH model, they confirm oil volatility spillovers to sugar and ethanol. Additionally, they observe spillovers between ethanol and sugar in both directions, and significant but small volatility spillovers from the sugar and ethanol markets to oil.

A group of research also concentrates on volatility spillover effects among countries and commodities. Alom et al. (2011a) use a multivariate Threshold GARCH 
(MTGARCH) to analyse the relationship of inter-country food price volatilities. They consider food indices for Australia, New Zealand, the US, Korea, Singapore, Hong Kong, Taiwan, India, and Thailand for the period 1995-2010. The countries were selected according to the following criteria: net food importing/exporting countries; geographic spread; economies in transition and participation in free trade agreements. The authors find no strong spillover effects at the returns level, except for some evidence of cross-country spillover effects between geographically close countries. Regarding volatility though, there are substantial cross-country spillovers. Kaltalioglu and Soytas (2011) examine the volatility spillovers between oil, food, and agricultural products. They examine IMF aggregated price indices between 1980 and 2008. To test for spillover effects the authors use the correlation test procedure by Cheung and Ng (1996). Results show no volatility spillovers from oil to food markets, instead there is only a contemporaneous link between oil and agricultural commodities.

\subsubsection{Price volatility between spot and futures markets}

Other articles analyse the relation between futures and spot markets. Will et al. (2012), for instance, conducts a review of 35 empirical works and conclude that the alleged financial speculation in commodity futures markets does not have any significant impact on spot price levels or volatility. They find that fundamental factors (e.g. increasing demand for agricultural and non-agricultural products, underinvestment in agriculture, increased frequency of weather shocks, etc.) are responsible instead. Algieri (2012) looks for relationships between (excessive ${ }^{11}$ ) speculation and price volatility, using as proxies for speculation the share of total open interest positions held by non-commercial traders and the speculative pressure. She applies Granger causality tests to find reciprocal effects between futures and volatility in spot markets for wheat, corn, soybean, palm kernel, palm oil, barley and rice. Her findings prove no significant relation between rice and soybeans. In the case of wheat, volatility leads speculation, whereas for corn there is a more complex bidirectional relation. Bohl and Stephan (2012) use expected and unexpected speculative open interest as explanatory variables, controlling for aggregate trading volume and aggregate open interest. They apply a GARCH model using weekly spot and futures prices for corn, soybeans, soft red wheat and sugar. Their results reveal

\footnotetext{
${ }^{11}$ Excessive is defined as the level of speculation that surpasses the need for hedging transactions and market liquidity.
} 
that even though futures prices tend to lead spot prices in agricultural markets, the speculation seems not to hinder the price discovery process. Von Braun and Tadesse (2012) apply a Seemingly Unrelated Regression to test the impact of supply (production) and oil price shocks, and futures market speculation, on spot returns and volatility. They consider monthly spot prices for corn, wheat, rice and soybeans. The volatility is calculated as the standard deviation from the long run average price. The authors consider trading volume of commercial and non-commercial positions in futures markets as proxies for speculation. Findings show that the speculation has a larger impact than oil and supply shocks on spot price spikes, and oil shocks have a larger impact than speculation and supply shocks on spot price volatility. Dwyer et al. (2011) examine the fundamental and financial factors, especially Index Fund investments, as drivers of the level and volatility of commodity prices. Using graphical representations of daily and monthly spot and futures indices, they conclude that despite the fact that speculators might play some role in spot price volatility, their contribution seems to be short termed and relatively small if compared with the effect of fundamentals. Dwyer et al. (2012) assess interactions between spot and futures prices for a group of agricultural and non-agricultural commodities. They use spot prices and futures from the Chicago Board of Trade (CBOT) price data for agricultural commodities (corn, soybeans and wheat) and London Metal Exchange (LME) prices for non-agricultural commodities (US natural gas, gold, silver, aluminium, copper, nickel and zinc) for the period 1997-2011. They apply a GARCH model together with a principal component analysis and find evidence of influence of futures on spot prices. Moreover, the authors claim that since 2003, individual commodity prices are primarily driven by macroeconomic fundamentals. Finally, they conclude that the theoretical relationship between commodity futures and spot prices does not imply that changes in futures necessarily lead to changes in spot markets. McPhail et al. (2012) evaluate the relative importance of different drivers on corn price volatility. They use a structural vector autoregressive model to obtain forecast error variance decompositions. The data used in this study consists of US corn futures prices, ethanol production, crude oil spot prices, the Working Speculative Index and the Baltic Dry Index as a proxy for corn demand. They find that within a month about $73 \%$ of variation in real corn prices is accounted for by corn market shocks, which include any shocks affecting corn prices not captured by shocks in global demand, crude oil prices, ethanol demand, or speculative demand. Additionally, speculation 
demand shocks (14\%), crude oil price (9.5\%), ethanol demand (3\%) and global demand (1\%) explain corn price variation within a month. The authors demonstrate that after own corn market shocks, speculation is the main factor driving corn price variations in the short run. However, in the long run, energy and global demand are the relevant determinants. Shanmugam et al. (2012) test the efficiency of futures market for agricultural commodities. They look for causal relations and volatility issues between spot and futures prices during periods of turmoil. They use US data (1995-2011) for corn, soybeans, wheat, soybean oil, cotton, coffee, sugar, cocoa, live cattle, lean hogs and feeder cattle. Co-integration tests show a long run relation between spot and futures prices for all commodities. Moreover, the Granger causality test shows that futures prices cause spot prices for wheat, soybean and lean hogs. A GARCH $(1,1)$ provided evidence of volatility clustering and persistency throughout the period for all series. However, the authors find no evidence of volatility increase after 2006. They conclude that US futures markets are highly efficient for agricultural commodities. Dahl and Iglesias (2009) analyse the implications of the theory of Muth (1961) within a new and general empirical modelling framework. According to the rational expectations theory of Muth (1961), current spot prices are functionals of futures prices (and vice versa). Therefore, they suggested to model spot prices jointly with futures prices of traded commodities. The authors find evidence to support Muth's theory i.e. spot price risk associated with storable commodities has predictive content. Furthermore, inventory carryover, which is reduced by a larger price variance, creates autoregressive conditional heteroskedasticity in (storable) commodity spot prices. Yang et al. (2005) empirically assess the lead-lag relationship between the level of trading activity and cash price volatility in futures markets. They use US corn, soybean, wheat, cotton, hogs, and live cattle futures and the international sugar price between 1992 and 2001. By means of a forecast error variance decomposition analysis the authors conclude that an unexpected increase in futures trading volume causes an increase in cash price volatility for most commodities, while there is weak causal feedback between open interest and cash price volatility.

\subsubsection{Price formation in futures markets}

This section presents a compilation of studies, which concentrates on the impact of speculation in index funds and on the level and volatility of futures prices. Aulerich et al. (2012), for instance, assess the impact of financial index investments on 
agricultural futures prices and (implied) volatility, using disaggregated data from the Large Trading Reporting System (LTRS) of the US Commodity Futures Trading Commission (CFTC). The advantage of this new dataset is that commodity index trading positions are available on a daily frequency, contracts are separated by maturity, and there is information available before 2006. They use futures for corn, soybeans, soybean oil, wheat, feeder cattle, lean hogs, live cattle, cocoa, cotton, coffee, and sugar. The authors apply Bivariate Granger causality tests. They consider as explanatory variables the changes in aggregate new net inflows and the rolling of existing index positions from one contract to another. Results confirm no bidirectional causality between aggregate positions and returns/volatility. Moreover, rolling positions do not cause futures price returns or volatility. Brunetti et al. (2011) apply Granger causality tests using Generalised Methods of Moments with Newey-West robust standard errors. Their findings demonstrate that speculators do not lead price changes; rather they reduce market volatility and add liquidity to the system. Irwin and Sanders (2012) test the 'Masters Hypothesis' 12 applying the Fama-MacBeth cross-sectional regression test. They argue that a cross-section as opposed to a time series analysis of index funds is more informative. The researchers use quarterly futures data of corn, soybeans, soybean oil, wheat, cotton, live cattle, feeder cattle, lean hogs, coffee, sugar, and cocoa. As proxy for index fund activity they use the Index Investment Data from the US Commodity Futures Trading Commission. Their results fail to demonstrate the 'Masters Hypothesis'. They find no significant evidence of index funds affecting futures' returns or volatility, implying that the markets are sufficiently liquid and traders do not confuse position changes of index funds with changes in market fundamentals. Bastianin et al. (2012) investigate whether speculation drives futures' levels and volatility, and which macroeconomic or financial factors are relevant to model returns. They apply GARCH and multivariate GARCH models using weekly data for agricultural (corn, oats, soybean oil, soybeans, and wheat) and energy (gasoline, heating oil, crude oil, and natural gas) commodities. Their findings show that excess speculation does not affect commodities' returns, whereas macroeconomic and financial factors are more relevant, especially equity returns and exchange rates. They also observe that spillover effects are statistically

\footnotetext{
12 The Masters' hypothesis was called after the hedge fund manager Michael Masters, who argues that the large buy-side positions from index funds created a bubble in commodities, moving prices far away from their fundamental values.
} 
significant within and between both commodity groups. Bohl et al. (2012) use a Stochastic Volatility model to reveal whether index fund activity induces volatility in futures' markets. This type of model can be used to control for simultaneity problems between conditional volatility and trading activity, which are jointly influenced by new information. They use weekly data for cocoa, coffee, corn, cotton, feeder cattle, lean hogs, live cattle, soybean oil, soybeans, sugar, and soft/hard red wheat. Results present no robust evidence that expected and unexpected index trading activity causes higher volatility in futures markets. Sanders and Irwin (2011) assess the impact of index fund investment in the US commodity futures market. They use weekly nearby futures contracts for wheat, soybean, and corn, alongside commodity index trader data. The researchers apply Granger causality tests and long-horizon regression. Their results don't provide evidence of linkages between commodity index positions and grain futures. Gilbert (2012) focuses on the influence of speculative trading on grain volatilities. He uses the cash prices of futures' contracts for soft wheat, corn, soybeans, and soybean oil, together with position data from the CBOT Commitments of Traders report (2006-2011). His results prove no significant effects of financialisation on cash and futures returns. Manera et al. (2012) conduct a detailed study about speculation issues between 1986 and 2010. They use Ordinary Least Squares to prove whether macroeconomic factors and speculation exert significant effects on futures prices for different energy and non-energy commodities. In a second stage, they use a Dynamic Conditional Correlation (DCC) model to recognise volatility spillovers across markets. Their findings prove that financial speculation does not significantly affect futures returns. Moreover, they find volatility spillovers among commodities and high, time-varying conditional correlations. Frenk and Turbeville (2011) consider the effects of the rolling period ${ }^{13}$, contango ${ }^{14}$, and backwardation. ${ }^{15}$ The authors test whether the behaviour of Commodity Index Traders (CIT) impacts futures prices independently from (fundamental) supply and demand forces. They examine futures prices of wheat, oil, heating oil, corn, feeder

\footnotetext{
${ }^{13}$ A set period from the 5th to 9th business day of each month, during which funds tracking the most popular commodity index, the Standard and Poor's Goldman Sachs Commodity Index (GSCI), must roll forward their expiring futures contracts.

${ }^{14}$ A situation where the futures price of a commodity is above the expected future spot price. Contango refers to a situation where the future spot price is below the current price, and people are willing to pay more for a commodity at some point in the future than the actual expected price of the commodity.

${ }^{15}$ Inverse to the Contango is Backwardation. Backwardation is the market condition where the price of a forward or futures contract is trading below the expected spot price at contract maturity.
} 
cattle, and natural gas (1983-2011) before, during, and after the monthly CIT "Roll” period. Their findings show that futures distributions display a consistent bias towards an increasing Contango curve during the Roll period. They find that the persistent bias did not exist before 2004, prior to the sharp growth in commodity index trading.

\subsection{Assessment of drivers}

In this section, we focus on the main results from the literature regarding the extent to which certain factors drive agricultural price volatility. The preceding sections have highlighted the influence of the researchers' choices on the results. The variability in terms of methods employed, of commodities included, of differences in frequency, and nature of the price data and sample period suggest that some caution is warranted in extracting the main results. In the following subsections, we distinguish between those drivers where the scientific literature seems to be largely unanimous, and the more conflicting areas. We focus on the results for the more recent episodes in food price volatility (short-run perspective) but augment these, where feasible, with the expected development and impact of the identified drivers in the years to come (longrun perspective).

\subsubsection{Supply}

There seems to be a high level of agreement in the existing literature with regard to the rule which states that short run supply shocks cause increases in volatility. For crops, short-term changes to expected harvests contribute to price volatility. This is particularly visible on futures markets, where prices immediately before the harvesting dates in key producing and exporting regions are highly responsive to new information about weather changes or about sudden occurrences of pests. Similarly, the few studies on livestock prices usually find that the disease outbreaks, which in addition to the direct reduction in supply might also negatively affect internationally traded volumes through trade restrictions because of quarantine requirements, lead to a thinning of the market on the supply side and thus to increased price volatility. Some studies emphasise the role of shocks on input markets, although the imminent effect on output price volatility is somewhat mitigated through the specific temporal nature of typical agricultural production processes, where the supply response usually takes place with a substantial delay after most inputs are applied. 
The role of long-run supply shifters is discussed more controversially in the literature. There is still some degree of accordance with regard to the role, which involves the diversion of agricultural land to non-agricultural uses and plays as a long-run shifter of the supply curve for agricultural products. However, a minority of studies judge global land supplies as sufficiently high and expect the global supply of agricultural goods to be able to keep pace with the expected demand increases. However, even these studies concede that pressure on local land markets might lead to locally thinner markets; the impact on local price volatility then depends in turn on the extent of market integration between local and international prices. Substantial underinvestment in agricultural technologies at the global level is often mentioned as an additional long-term factor. In light of the high returns promised by investment in publicly available agricultural innovations, the underinvestment observed over the past two decades or so is undoubtedly a challenge for the years to come. However, whether the looming danger of insufficient productivity growth in the future will have any impact on price volatility is much less clear than the (already hotly debated) expected increasing impact on agricultural price levels.

Climate change is often mentioned as another long-term driver of price volatility. Many scenarios for climate in the future predict an increased frequency of extreme weather events with possibly negative impacts on agricultural supplies in virtually all agricultural products. An increase in the frequency of crop failures, or an increase in the number of disease outbreaks in combination with spreading of tropical and subtropical animal disease to more temperate climate zones, would then suggest that prices of the corresponding commodities will fluctuate more strongly than in recent decades. However, the literature indicates that global agricultural commodity prices react more strongly to supply shocks in key producing regions than they do to globally occurring changes that affect all regions. This suggests that the impact of climate change on price volatility might be more complex than this simple line of reasoning suggests. In particular, its impact will be specific for commodities and regions.

A final factor in the list of long-run supply shifters is structural change in farming. The argument relies on the presumed higher resilience of small-scale, locally adapted agricultural structures in comparison to more commercially oriented large-scale farming. This argument is not frequently mentioned, which is perfectly 
understandable since the question of resilience is again very context-specific. The consensus in the existing literature does not attribute structural change in agricultural systems as being one of the key-driving factors towards increased price volatility.

\subsubsection{Demand}

On the demand side, the most frequently listed short-run driver is the increasing role of bioenergy, in particularly grain- or oilseed-based biofuels. Virtually all studies which look into demand-side drivers discuss the role of bioenergy markets and policies for agricultural price volatility. A general consensus exists that biofuel policies exert a substantial influence on price volatility; in most countries the relevant policies are implemented in a way that makes the resulting additional demand for agricultural raw materials rather price inelastic. A given quantity shock requires, ceteris paribus, a stronger price change in order to balance supply and demand. This concern about the lack of flexibility in biofuel mandates is particularly strong for corn-based bioethanol in the US, and vegetable oil-based biodiesel in the EU. While the general mechanism is broadly supported in the literature, there is much less agreement as to its relative importance. The most recent price developments for corn in 2012 illustrate that even the US bioethanol blending requirements are actually more flexible than initially expected, mainly because of the possibility to roll over parts of the blending mandates between years.

In the 2007/2008 episodes, additional demand was observed by hoarding behaviour of some major importing countries. In most cases, such hoarding was observed in particular in those countries where the import of agricultural commodities is substantially controlled by state trading enterprises. The resulting positive demand shock at a time where prices were already following an upward trend exacerbated the price momentum but also had an impact on price volatility since the market tended to react very sensitively to new information, even new rumours, about the actions of state trading enterprises. Timmer (2010) also highlights the particular relevance of such hoarding behaviour at the individual level of consumers and producers.

In the long run, demand for agricultural products with potential repercussions on price volatility is affected by three factors. First, income and population growth in developing countries is expected to exert an influence on the tightness of the global balance sheets for major food crops. The tighter the markets, the more susceptible to 
shocks they will generally be. Second, the role of the "westernisation" of diets might additionally exacerbate these shifts in the constellation of supply and demand. The increasing move toward higher meat shares in hitherto more vegetarian diets in Asia and Africa will lead to an increasing competition in major agricultural products between food and feed. Again, this will make market balances tighter unless rapid productivity growth (see above) overcompensates this effect. Third, the longer term perspectives for bioenergy, in particular biofuels, could inflate price volatility levels if the policy instruments employed are retained with similar inflexibility as in the past. The majority of literature is in agreement on these longer run factors.

\subsubsection{Storage}

Most of the staple foods traded on international markets are storable. Carry-over stocks from year to year (i.e., the quantities in stock in excess of working stocks) play a crucial role for dampening price volatility over time. The nature of demand for and supply from storage, in combination with the impossibility of negative stocks, suggests that the impact of stocks on price volatility is asymmetric: At relatively low stock levels, the dampening effect is close to nil, while with sufficiently filled stocks, storage demand and supply is able to neutralise shocks to a substantial extent. Since stocking outs are likely to occur at high prices, while low prices increase ceteris paribus the demand for storage, phases of increased volatility for storable commodities are likely to coincide with high prices (Wright, 2011).

The usual approach in the literature is based on an analysis of stocks-to-use ratios, and gives rather robust results. For cereals, low levels of carry-over stocks are indeed a major factor for volatility increases. For wheat, the early literature already reports a perceived threshold of about $20 \%$ although there is substantial residual uncertainty about the exact figure where to locate the critical threshold.

Speculative stockholding is a phenomenon which also can exert a substantial impact on price volatility. The literature here is often related to the emergence of bubbles in commodity markets (which seemed to play a role in futures price developments for major agricultural products over recent decades, e.g., Gutierrez, 2012). However, for the specific case of the 2007/2008 crisis, speculative stockholding has been regularly rejected in the literature as one of the causes of the crisis because the official figures on stocks did not see any increase in stocks over the relevant time period. 
There is a third aspect related to storage, which will probably also exert a substantial impact on price volatility in the longer term. Official figures on stocks are usually published regularly, and aim at giving information on both private and public stocks, e.g., for major crops at a monthly frequency by the USDA in their World Agricultural Supply and Demand Estimates (WASDE). The published information on public stocks typically relies on national statistics, with varying degrees of precision. Reasons include the reluctance of some countries to provide sufficient and transparent figures on their public stocks (usually for political reasons), but also general problems with the statistical information systems in other countries. However, with the exception of a few countries, the situation is drastically worse as far as private holdings of stocks are concerned. A few countries (notably the US for major crops) have established reporting systems at both the farm and the downstream sector level. The vast majority of countries rely on 'guesstimates' for private stocks. It is thus expected that figures on global stocks would be severely affected by statistical errors.

The impact on price volatility is impressively illustrated by the development of wheat prices over the 2007/2008 crisis. Prices started to increase at an accelerating pace after the publication of the USDA WASDE report in May 2007. This report included the first forecast for the ending stocks of the wheat marketing year 2007/2008, and contained an alarmingly low figure for expected global wheat stocks at the end of this marketing year in June 2008. In the WASDE reports for the subsequent 9 months, the forecasts were even further reduced. The turning point was reached with the report of March 2008 when the forecast at 110 million Mt of wheat was again roughly equal to the forecast of May 2007; subsequently, the numbers where substantially increased to a final estimate of 126 million Mt. The turning point in March 2008 not only marked the end of the rapid price increases but also the end of a period of inflated price volatility. This episode emphasises the importance of reliable information on stocks (and it also serves as a strong argument in favour of the efforts started by governments and international organisations in the AMIS initiative).

\subsubsection{Macroeconomic factors}

Under the admittedly broadly defined category of macro-economic factors, two subcategories can be identified. First, spillover effects from other markets outside agriculture are found to play an important role for the development of price volatility 
over the past five years; looking forward, they are expected to continue to be significant for years to come. Second, general economic policies and developments affect agricultural markets since the latter have become increasingly integrated with the rest of the economy. Macro policies have a substantial impact on the stability of a whole economy, which in turn affects price volatility for agricultural products.

Spillover effects from markets outside agriculture are frequently listed among the major explanatory factors for the food price crisis of 2007/2008. Most studies emphasise the importance of energy markets (usually exemplified through the crude oil markets), and conclude that these have been an important factor in driving price developments prior to 2007/08. The causal linkages, however, are much less clear. There are a number of potential linkages discussed in the literature. The intensification of agriculture in many production systems worldwide has made production processes in crop production more dependent on fossil fuels over time since fossil fuels are of substantial importance directly through diesel use in agriculture, and indirectly via increased use of fertilisers and pesticides, which both depend on fossil fuels in their production. For example, a substantial part of nitrogen fertiliser production is highly dependent on natural gas. Thus, the relevance of the fossil fuel market as an input to agricultural production has increased over time. Over the past decade, the interdependence between agricultural and energy markets was further increased through the emergence of bioenergy related policies, mostly in emerging and industrialised economies. Biodiesel policies in the EU (Busse et al., 2012) and bioethanol policies in the US and Brazil have made the price formation processes between energy and agricultural markets interrelated in a complex and often regime-dependent manner. The interdependence is not confined to price levels but also leads to price volatility spillover effects. Relative market sizes strongly suggest that the net effect of both input and output linkages leads to an inflated vulnerability of the relatively small international markets for agricultural products to price volatility shocks from the notoriously volatile global markets for crude oil.

Other commodity markets are occasionally mentioned as drivers of agricultural price volatility in the literature, too. Over the course of the food price crisis of 2007/2008, virtually all the major commodities were experiencing substantial price level changes. However, it is difficult to think of direct causal linkages between agricultural and most of the non-agricultural commodities. Therefore, most of the studies mentioning 
non-agricultural commodity market development focus on two indirect channels: macro-economic policies (to be discussed in the next paragraph) and linkages through increasing financialisation (which deserves a separate section, see below).

Among macro-economic policies, exchange rates are viewed as important drivers of price levels. This holds particularly true for the US-Dollar rates, since most of the global trade in agricultural products is still denominated in US dollars. Volatility in exchange rates might hence be transmitted to domestic markets even in cases where international prices are not particularly volatile. During the food price crisis of 2007/2008, exchange rates have generally been acknowledged as a driver for price levels but have not been singled out as particularly important for volatility transmission. For the longer run, exchange rate fluctuations might become more important, depending on the overall stability of the world economy.

This leads to the second major factor among macro-economic policies, the changing nature of monetary policies in many - if not virtually all - countries. Money authorities have gradually loosened monetary policy regimes in response to the economic and financial crisis and have injected liquidity for a long period of time, in combination with interest rate policies, which frequently lead to negative real interest rates. The quantitative easing policies of the US are an important case at hand, as is the recent move of the Japanese central bank to loosen its monetary policy and to weaken the Yen exchange rate. The loose monetary policies will likely put an upward pressure on general price levels in the longer run, although current sluggish economic growth suggests that there is no immediate danger of substantial inflation. The impact on price volatility, however, is already felt in the shorter run. With substantial and virtually open-ended liquidity injections, price boom and bust cycles for individual commodities including agricultural and food commodities become more likely. This mechanism is most likely an import driver for future price volatility.

\subsubsection{Specific policies}

The literature on the causes of the 2007/2008 food price crisis reaches a broad consensus: Policy measures in the field of trade policies by both exporters and importers have substantially contributed to the price development for major agricultural products, in particular for crops. Timmer (2010) explores this in detail for the case of rice. Many exporters introduced some type of export restriction in order to 
shield domestic consumers from international price increases. The measures included export taxes, quotas, or complete bans. Importing countries often responded with import alleviations, e.g., tariff reductions, import levy reductions, or new preferential market access opportunities. The overall impact of these measures on global price levels and volatilities should not be underestimated. Even if it seemed to make perfectly sense from the perspective of an individual country to introduce some policy which allows for a wedge between international and domestic prices, the combined use of such policies in many countries at the same time added to the upward trend in international prices while reducing global trade volumes. The new world trade equilibrium was then characterised by higher prices in thinner markets. Such a constellation inevitably increases the susceptibility of agricultural markets to shocks, in particular if there is a substantial lag in re-adjusting trade policy measures.

It is difficult to predict how such agricultural policies are going to affect price volatility in the longer run. It will be crucial in deciding the extent to which countries pursue 'beggar-thy-neighbour’ policies in the future. The experience of the 2007/2008 crisis has clearly shown that the outcome of the WTO Uruguay round with its (relatively) strict disciplines on bound tariffs and on the use of export subsidies is not effective against 'beggar-thy-neighbour' policies which aim at lowering domestic agri-food prices below the international level. The Uruguay round agreement is a child of the experience of the 80s and 90s, where the major concern was about pushing domestic agri-food prices above international levels. In the aftermath of the crisis, many countries verbally committed themselves to aim at export policy related disciplines in the ongoing WTO negotiations. However, given the lack of progress in the ongoing WTO talks, it seems unlikely that effective rules on such policies will become mandatory in the near future. The observable move toward regional and preferential trade agreements in the past cannot be expected to substitute for the lack of progress in multilateral trade negotiations. It is more likely that the additional degrees of freedom which trading blocs have in negotiating such agreements might lead to a complex network of trade relationships which in total might be harmful to global market integration. In consequence, discretionary policies in the agricultural sector can be expected as an additional driver for higher price volatility in the future.

Another longer-term factor, albeit observable at a much lower frequency, is related to agricultural policy cycles. In many countries of the world, in particular in OECD 
countries, agricultural policies are subject to major revisions in relatively constant phases (e.g., US farm bill legislation, EU Common Agricultural Policy). Major policy shifts cause uncertainty, which might lead to a higher degree of caution in investments in production capacities. After the uncertainty is resolved, previously delayed decisions will be taken relatively quickly, which might induce synchronisation in investments, and hence contribute to cyclical supply patterns which in turn might lead to low-frequency price volatility.

Specific policies in other economic sectors might also contribute to agricultural price volatility in the longer run. This holds particularly true for policy measures with an impact on land use. Bioenergy related policies have already been discussed above, but broader environmental policies might also divert agricultural land to other purposes so that intensification of the remaining agricultural areas might become necessary. This would not necessarily lead to higher price volatility, however, since the relationship between intensification and output variability is complex.

\subsubsection{Financialisation}

Financialisation in the context of the overall economy usually refers to the increasing importance of financial organisations and institutions in comparison to real economic activities. In the context of price formation for agricultural and food products, the term is less clearly defined but usually refers to the increasing role of non-commercial investors (perceived important actors include index funds, hedge funds, and OTC swap dealers) in agricultural markets (usually in futures or options). Concerns are voiced that financialisation might hamper the price discovery function of futures markets so that agricultural prices both on spot and futures markets are driven by money rather than by fundamentals. In order to shed light on the impact of financialisation on agricultural price volatility, it is helpful to clearly distinguish three aspects of financialisation, which might have an impact.

Firstly, financialisation might open the window for market manipulation if individual economic agents are sufficiently large to exert influence on price formation. This danger is particularly obvious in futures markets, which are not sufficiently liquid. A recent episode in London cacao futures, dating from 2010, involved the funds 'Armajaro' taking delivery at maturity of the July contract of cocoa volumes equivalent to about $7 \%$ of annual world production. Since the open position held by 
'Armajaro' was anticipated before maturity of the July contract, prices experienced a substantial increase in July. However, this episode also serves as an example of how difficult such mid-term market manipulation attempts are. Over the second half of 2010, prices for cocoa dropped by about a quarter so that the actual profit over this period for 'Armajaro' was likely negative. Nevertheless, market manipulation fears, be they justified or not, will lead to increased price volatility because of the uncertainty they introduce to the market. Transparency requirements involving, for example, regular reporting on open positions, seem to be an appropriate and effective instrument for reducing market manipulation attempts.

Secondly, financialisation is often associated with speculative bubbles. Speculative bubbles are characterised by prices which grow over a longer period of time up to a point where market participants seem to (suddenly) realise that prices are way above the fundamental values. Bubbles are a common feature in market economies. They have also been observed for agricultural products as early as the $17^{\text {th }}$ century, when the famous Dutch tulip bubble led first to skyrocketing tulip prices, which crumbled down quickly again after the bubble burst.

Agricultural commodity price bubbles exert an increasing influence on price volatility through their typical boom and bust sequence. They have recently been identified in agricultural commodity prices on futures markets, too (e.g. for the 2007/2008 food price crisis see Gutierrez, 2012). However, as is clearly stated in the published literature, finding statistical evidence for the presence of a bubble does not allow us to tie down the culprits. Self-enforcing price trends -at least over a certain period- can be driven by any group active on the relevant market; e.g., for spot markets, the hoarding behaviour of producers and consumers has been suggested as a major factor for the emergence of a price bubble. Experiences outside agriculture also suggest that bubbles (which are relatively easy to identify once the bubble has burst but difficult to recognise while a strong trend is present) are usually driven by a combination of factors, e.g., the house price bubble in the US before the economic and financial crisis was affected by credit approval practices, and by loose overall monetary policies, to name only two of the factors involved. In summary, bubbles seem to be a common feature in capitalist systems, and it is difficult to identify a clear mechanism to prevent their occurrence on agricultural commodity markets. 
Thirdly, price volatility might be affected by the composition of traders in a given market. In the context of agricultural and food prices, the literature often singles out the behaviour of index funds on futures (and related financial derivatives) markets. Index funds are a relatively new phenomenon which became more important over the course of the increasing interest in exchange traded funds (ETF). Their typical strategy is based on mimicking the price of an underlying index so that no active management of the fund composition is necessary. In the case of agricultural markets, commodity index funds are of direct interest. Concerns about the impact which these funds have on price volatility are related to the trading strategy of such a broad index fund; this is usually composed of a number of different commodities with fixed weights in terms of values. In order to follow the price movements of the underlying broad commodity index, the fund has to sell and buy futures or options in response to any relative change in the prices of the single commodities. For example, consider a hypothetical fund mimicking an index with 50\% wheat and 50\% copper. A price shock on the futures market might drive up the price of the copper's future. Thus, the value share of copper in the commodity basket becomes too high, which requires either reducing the investment in copper futures or increasing the value share of wheat. If the fund manager chooses the last option, volatility from the copper futures market might spill over to the wheat futures market (provided that the positions held by the index fund are substantial on the wheat futures market). However, if the first option is chosen (i.e., changing the position in the market where the price changes originated, in this example copper), the index fund would contribute to lower price volatility in this market. It seems natural to assume that most index fund managers follow this approach, simply because in a complex composite index it is much easier (and less costly) to adjust only those positions which actually changed. This hypothesis is not rejected by the current literature. Will et al. (2012), and Gilbert and Pfuderer (2013) survey the relevant publications and conclude that the vast majority of all studies attribute a stabilising function to the position changes associated with index funds trading.

The increasing number of positions held by index funds has one additional (albeit relatively minor) impact on price volatility on commodity futures markets. Since the funds are forced to roll over (i.e., switch from the contract close to maturity to the following one) in regular and foreseeable intervals, other market participants might 
anticipate the settlement of a huge number of long positions shortly before maturity, and might try to react to this. However, this would require the latter group to have market power. Empirically, this very short run effect has not been analysed until now.

\subsubsection{Miscellaneous drivers of price volatility}

Parts of the empirical literature emphasise the role of information shocks for price formation. For food and agricultural markets, food scares and scandals are one important shock affecting not only price levels but also volatility. The increasing media attention to negative news about food suggests that such news about food scares will lead to huge price drops, with a relatively slow and volatile recovery.

\subsection{Conclusions}

Price volatility on agricultural and food markets has attracted considerable attention in the literature, both in mainstream agricultural economics but also in related fields. This attention is reflected in a growing number of studies published in peer-review journals, which is augmented by some high-profile reports from relevant organisations. In addition, the scientific community has responded to policymakers' concerns by publishing many working papers and technical reports (so-called grey literature), a substantial part of which will be published in journals over the course of the next years.

This already rich (but still emerging) body of literature allows for the development of a relatively clear picture about the driving factors of price volatility patterns in recent years. The literature seems to be in broad agreement regarding the fundamental factors that explain most of the observed price volatility increases in recent times. Supply and demand side factors, which in the short run lead to thinner markets and thus make the price finding mechanism more susceptible to the arrival of new information, can be identified as major drivers. Many of these drivers will continue to play out in the medium and long run. On the supply side, climate change might increase the frequency of rare detrimental weather events, which will generally lead to higher price volatility. The stagnation in terms of productivity growth in agriculture in particular in OECD countries, exacerbated by land diversion for non-agricultural purposes, will certainly not help in mitigating the susceptibility of agricultural and food markets for episodes of high price volatility. On the demand side, population and 
income growth are often mentioned as long-run driving factors. These long-term trends will be difficult to change, in contrast to another major driver, biofuel policies. The specific instruments employed in this policy field often lead to additional demand, which is very price-inelastic. Given that current biofuel policies are not responsive in their requirements to short- and medium-run price changes in the main input markets, price volatility will be elevated.

However, information on stocks is an important factor, too. Much of the decentralised stockholding is not regularly monitored; even if public or private entities have the necessary information, this is often still treated by public bodies as state secretes or as potentially very rewarding private information (private bodies). With increasingly integrated agricultural markets worldwide, national level information on carryover stocks - in particular in key exporting or importing countries - spills over to global markets. Country-specific statistical information systems have an important role to play in the future, as does the global coordination of information on available stocks, which is now pushed forward within the AMIS initiative.

Nowadays agriculture is integrated into the overall economy (even though most countries interfere in agricultural markets much more intensively than in other sectors of the economy). The interdependencies with non-agricultural markets exist both on the input and on the output side. Increasing integration also implies that price volatility from input markets will have repercussions on agricultural and food markets. This mechanism has been established in the literature for fossil fuel price volatility (and is exacerbated through biofuel policies). However, as a part of the overall economy, agricultural price formation will also be subject to the impacts of overall economic policy, in particular monetary policy. Inflationary risks will affect price volatility directly and indirectly (many because investors view agricultural assets as relatively safe from inflation).

The role of speculation and financialisation when it comes to price volatility on agricultural and food markets is, however, less clearly defined in the literature. This is not surprising since speculation itself is a very broad phenomenon, which is difficult to capture quantitatively. Financialisation, on the other hand, is a relatively new phenomenon but again is not always consistently defined across different studies. However, the literature seems to have reached broad agreement on one specific aspect of financialisation, namely, the role of index funds for price volatility on futures 
markets. There is no recent sound scientific evidence in favour of a volatility increasing impact of index funds trading activities on agricultural futures. On the contrary, there is a tendency to find price volatility reducing impacts of index fund trading for major cereals. Reforms to the regulatory framework for futures markets should hence be applied rather carefully in order not to hamper the price discovery and hedging functions of those markets, although additional transparency requirements should be imposed as swiftly as possible.

A much less debated driver of volatility is the wide field of trade policies. The experience from the food price crisis of 2007/2008 showed that policy responses from both importing and exporting countries have the potential to increase price volatility in international markets. Initially triggered by concerns about domestic food price inflation, both the reduction of import barriers and the implementation of export restrictions are essentially attempts to export domestic problems to the international market. Unfortunately, the current WTO regime is not adequate to tackle these issues. A renewed impetus for the multilateral trade negotiations looks like a promising pathway toward better functioning of the international markets during a food price crisis. From our point of view, the multilateral framework is better suited for imposing self-discipline in such trade policies than the approach via negotiations on bilateral and regional trade preferences (which seems to currently be the first choice by many important trading blocs).

Notwithstanding the quite substantial body of literature reviewed in this study, there still remain some important research needs. A first set of issues is related to the methodological dimension. Price volatility is inherently unobservable and thus has to be estimated. Such estimation requires many conceptual choices; the estimates for and the interpretation of - price volatility depend crucially on these choices. Even if conceptual clarity has been reached, there are many estimation methods available. In order to apply these, additional assumptions are necessary, which often turn out to be rather restrictive. The impact on the generated volatility estimates is not always clear, and there is a danger that some of the estimated price volatility patterns might be driven by inappropriate estimation methods.

In terms of product coverage, there is a strong focus in the existing literature on cereal markets. On the one hand, this is perfectly understandable since cereal prices are still the key prices for agricultural and food markets. On the other hand, the lack of 
attention toward livestock and non-cereal staple crops is unsatisfactory since livestock products and staple crops are nowadays often more important for farmers and consumers than cereal prices. Farmers in the EU generate a substantial share of their revenues from livestock production; rural households in developing countries crucially depend on price development for local staple crops. Lack of appropriate data and heterogeneous product quality are two standard excuses for the focus on the relatively liquid international cereal markets, but researchers view this as a challenge, not as a barrier.

Finally, the identification of policy impacts with the goal to establish causal links between policy intervention and price volatility developments is also not yet settled in the existing literature. Instead of focusing too strongly on causality, the concept of predictability might prove to be more fruitful in applied research. In particular, if certain factors are useful in predicting future price volatility, then these are also natural candidates for inclusion in medium- and long-term models, with the aim of capturing observable price volatility patterns in these models. 


\section{The dynamic pattern of volatility spillovers between oil and agricultural markets}

This section corresponds to an improved version of the Scientific Paper No.8 prepared for the EC-funded ULYSSES Project. ${ }^{16}$ This paper was elaborated under the supervision of Prof. Dr. Bernhard Brümmer and with the collaboration of Dr. Tinoush Jamali. It was presented in the ULYSSES meeting held at FAO's headquarters in Rome in February 2015. An early version of this study was also presented at the Conference "Food in the Bio-based Economy” organised by the University of Wageningen in May 2015. ${ }^{17}$

\subsection{Introduction}

In the after crisis period many factors were identified as potential contributors to the steep upsurge in food prices and volatility. ${ }^{18}$ There is a special interest in the rapid financialisation of agricultural markets, the tightening relation between oil and agricultural markets, the declining and uncertainty on grain stocks levels, the exchange rate variability of US dollar-denominated agricultural international trade, and the biofuel promotion policies enforced by developed countries. Nevertheless, given the complexity of the economic system, no author has been able to clearly identify a causal order among these factors, nor quantify their impacts separately. From the set of drivers, however, the increasing participation of investment funds in agricultural markets and the biofuel boost are the most controversial. Will et al. (2012) review a sample of empirical studies. They conclude that the alleged financial

\footnotetext{
${ }^{16}$ Saucedo, A., Brümmer B., Jaghdani, T.J., 2015. The dynamic pattern of volatility spillovers between oil and agricultural markets, Scientific Paper 8, ULYSSES project, EU 7th Framework Programme, Project 312182 KBBE.2012.1.4-05, http://www.fp7-ulysses.eu/, 31 pp.

17 Saucedo, A., Brümmer B., Jaghdani, T.J. (2015). The dynamic pattern of volatility spillovers between oil and agricultural markets. International Conference - Food in the Bio-based Economy; Sustainable Provision and Access, Wageningen University, May 27 - 29, 2015, Wageningen, Netherlands.

${ }^{18}$ For a summary of the volatility drivers see Table 7 of the Appendix.
} 
speculation in commodity futures markets does not have a significant impact on the level of volatility of spot prices. Mitchell (2008) estimates that the production of biofuels in the US and Europe explain between $70 \%$ and $75 \%$ of the rise of food prices due to a reduction of the international grain stocks, changes in land use, increased speculative activity and export restrictions. Baffes and Haniotis (2010), on the other hand conclude that the impact of biofuels on rising food prices is not as high as previously thought, but that the use of commodities as a strategy of investment diversification by large institutional investors may be partly responsible for the rise. According to Nazlioglu et al. (2013), the relation between energy and food markets is driven by three factors: oil as an input for farming, transporting and processing crops; energy crops used for producing biofuels (e.g. cereals, oil seeds, and sugar crops), close substitutes, and complements for diesel and gasoline; and the co-movements of both energy commodities and agricultural commodities, due to investment funds' activity. While evidence shows that the role of speculative positions on futures markets held by investment funds has no significant impact on grain price volatility, oil-derived input costs and biofuels are some plausible channels linking energy and food markets. The aim of this paper is consequently to contribute to the 'food versus fuel' debate by shedding some light on the development of the energy-food nexus.

We show the evolution of the volatility spillover dynamics between oil and commonly used biofuel feedstocks, namely corn, wheat, and sugar for ethanol, and soybean oil, rapeseed oil, and palm oil for biodiesel. The paper is organised as follows: In section 3.2 we present the development of biofuel markets. Section 3.3 reviews the recent literature concerned with the volatility spillovers effects between energy and food markets. Section 3.4 presents the data and introduces the methodology. Section 3.5 shows our empirical findings. We conclude in Section 3.6 and provide some policy recommendations in section 3.7.

\subsection{Market development of biofuels}

The biofuel market emerges as the result of technological advancements that made it possible to obtain ethanol and biodiesel, substitutes for gasoline and diesel, respectively, from starch, sugar and oil crops, as well as the development of flex-cars that are able to run with different biofuel blends. However, the rapid growth of the market is driven mainly by political decisions aiming at reducing greenhouse gas 
emissions, promoting domestic energy diversification and fostering rural development.

With this purpose, developed countries assign large budgets to the promotion of the ethanol and biodiesel industries. In May 2003, for instance, the EU passed a first Directive 2003/30/EC to promote the use of renewable fuels, stipulating a 5.75\% replacement of transport fuels with biofuels by the end of 2010. In April 2009 the EU released a new Directive (2009/28/EC), which mandates that $20 \%$ of total energy consumption must come from renewable sources by 2020 and 10\% of transport fuels from biofuels.

Table 2. Estimates of total support for the biofuel industry in developed countries

\begin{tabular}{|c|c|c|c|c|c|c|c|c|}
\hline \multirow{2}{*}{ Countries/Region } & \multicolumn{4}{|c|}{ Ethanol } & \multicolumn{4}{|c|}{ Biodiesel } \\
\hline & 2007 & 2008 & 2009 & 2011 & 2007 & 2008 & 2009 & 2011 \\
\hline United States & $6940-8390$ & $9200-11070$ & 7700 & - & $1200-1540$ & $1540-1890$ & 400 & \\
\hline European Union & 1096 & 1237 & 2100 & $1261-1843$ & 3422 & 3192 & 5800 & $6415-7 / 55$ \\
\hline Canada & $224-251$ & $286-343$ & - & - & $43-67$ & $68-94$ & - & - \\
\hline Australia & 46 & - & - & - & 33 & - & - & - \\
\hline Switzerland & 3 & - & - & - & 11 & - & - & - \\
\hline
\end{tabular}

Note: Empty spaces mean no information is available.

Table 2 shows estimates of the Global Subsidies Initiative (GSI) concerning biofuel support budgets assigned in different developed countries. The GSI estimates that total support for ethanol in the EU was in 2011 between 1.3 and 1.8 Billion US\$ and for biodiesel between 6.4 and 7.8 Billion US\$. Similarly, the US approved the US Energy Policy Act in 2005, which mandated the consumption of 28 Billion Lt of biofuels (mainly ethanol) by 2012. In December 2007, however, a new boost for biofuels was enforced through the Energy Independence and Security Act. It requires a consumption of 136 Billion Lt by 2022, a far more ambitious target. In comparison the EU, the US promotes the (corn-based) ethanol industry more. In 2009, GSI estimates US ethanol and biodiesel budgets in 7.7 Billion US\$ and 0.4 Billion US\$, respectively. The substantial support given to the biofuel industry has diverted in turn approximately $20 \%$ of sugar cane production, $9 \%$ of oilseeds and cereals, and $7 \%$ of sugar beet between 2007 and 2009 (OECD and FAO, 2010).

Figure 2 presents the major biofuel producing countries. In 2011, the largest ethanol producer was the US with 54 Billion Lt, a 63\% share of world's production. Brazil was the second ethanol producer with 21 Billion Lt (24\%) followed by the EU with 2.7 Billion Lt (3\%), and China with 2 Billion Lt (2\%). The US was also the largest 
Figure 2. World's leading biofuel producing countries, 2011
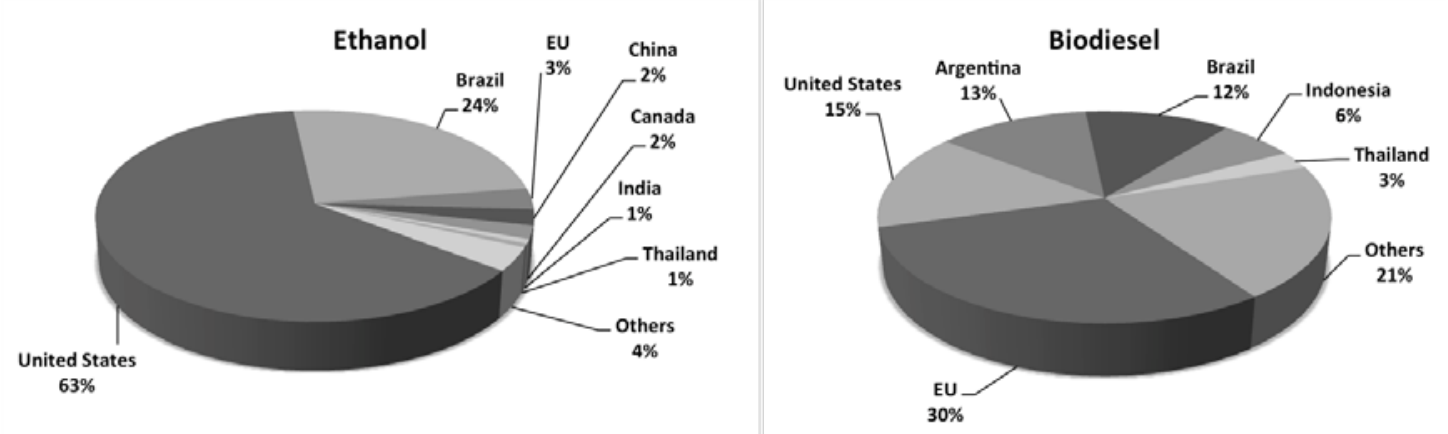

Source: Own elaboration based on estimates of the Earth Policy Institute with data from F.O. Licht.

ethanol exporter in 2011 (2.5 Billion Lt), followed by Brazil (1 Billion Lt) and China. However, China's exports are negligible in comparison (200 thousand Lt). ${ }^{19}$ From this group, Brazil is the most productive. It processes ethanol from sugar cane with average yields of 5 thousand Lt/Ha while the US corn-based ethanol only attains ca. 4 thousand Lt/Ha, a 25\% less. The EU produces ethanol mainly from wheat, but its yield is even lower than that of corn (ca. 3 thousand Lt/Ha). Besides wheat and other minor cereals, the EU also produces ethanol from sugar beets, which performs much better in terms of yields (ca. 6 thousand Lt/Ha). When it comes to biodiesel, EU is the leading region, accounting for 30\% of world's production in 2011. Within the EU, Germany has the highest processing capacity with 3 Billion Lt followed by France (1.6 Billion Lt), Spain (0.7 Billion Lt), Italy (0.6 Billion Lt) and the Netherlands (0.4 Billion Lt). The next largest biodiesel producers are the US (3.2 Billion Lt), Argentina (2.8 Billion Lt) and Brazil (2.6 Billion Lt). The EU is also a major biodiesel consumer. It imported 2.5 Billion Lt in 2011, almost $100 \%$ of net global imports. Argentina is the main exporting country with 1.6 Billion Lt, followed by Indonesia (0.3 Billion Lt) and the US (0.2 Billion Lt). In a similar fashion to ethanol, biodiesel yields are also very heterogeneous. The most efficient biodiesel producers are Malaysia and Indonesia with an average of 4 thousand Lt/Ha, derived from palm oil. The main feedstock in the EU is rapeseed oil, however, biodiesel yields from this crop are comparatively much lower (ca. 1.5 thousand Lt/Ha). Argentina, the US and Brazil obtain their biodiesel from soybean oil, which is the less productive feedstock (ca. 0.5 thousand $\mathrm{Lt} / \mathrm{Ha}$ ).

${ }^{19}$ FAPRI and ISU (2012). 
Figure 3. World biofuel production and oil equivalent consumption, 1991-2011

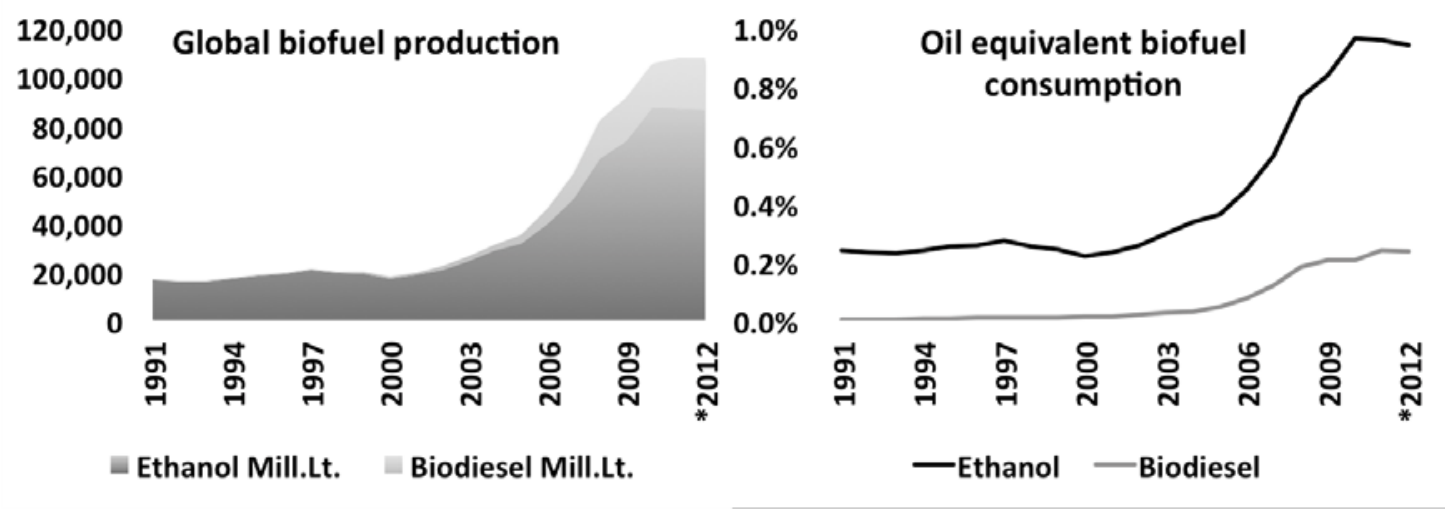

Source: Own elaboration based on Earth Policy Institute with data from F.O. Licht and the US International Energy Agency.

Note: $\left({ }^{*}\right)$ The production for 2012 has been estimated.

Over the last twenty years, the global production of ethanol and biodiesel has grown at an average annual rate of $9 \%$ and $67 \%$, respectively, reaching 86 Billion Lt of ethanol and 21 Billion Lt of biodiesel in 2011(Figure 3). One can observe a steeper increase of biofuels' production between 2005 and 2007, a time which coincides with the enforcement of the United States' energy acts. Despite the accelerate growth of biofuels, ethanol and biodiesel represented in 2011 only 1\% and $0.2 \%$ of global oil consumption, respectively. The reason is the low energy density of agricultural products if compared to fossil fuels.

\subsubsection{Price co-movements between oil and biofuel feedstocks}

The price evolution of different biofuel feedstocks with respect to oil is now shown in order to shed some light on whether this relationship has strengthened over time. We develop some understanding on the degree of interconnection among food and energy markets and the consequences for the volatility dynamics shown later. We provide additional information regarding the internationalisation of the different commodities. The larger the integration of a product to international markets, the larger its exposure to shocks from other widely traded (more volatile) commodities like oil.

\subsubsection{Ethanol feedstocks}

Corn is the main feedstock used for ethanol in terms of volume. The US is the largest user of corn for ethanol; nevertheless, it is only price competitive with the Brazilian sugar cane-based ethanol through subsidies. The second most important feedstock is sugar cane, widely used in Brazil, India, and Thailand, but since it is a non-tradable 
commodity we use the international sugar price instead. The final ethanol feedstock we consider in this study is wheat. It is mainly used in the EU and Canada. Nevertheless, its global relevance as biofuel feedstock is negligible if compared to corn and sugar cane. For the period we consider, an average of around $12 \%$ of corn production and $19 \%$ of wheat were commercialised internationally. The international trade for these cereals is relatively tight; most of their production is consumed domestically or exported as processed products like corn cakes and ethanol, or wheat flour. The international sugar market is larger. Sugar exports accounted for nearly $30 \%$ of total production. ${ }^{20}$

Figure 4. Evolution of the price of cereals and sugar, 1996 - 2014

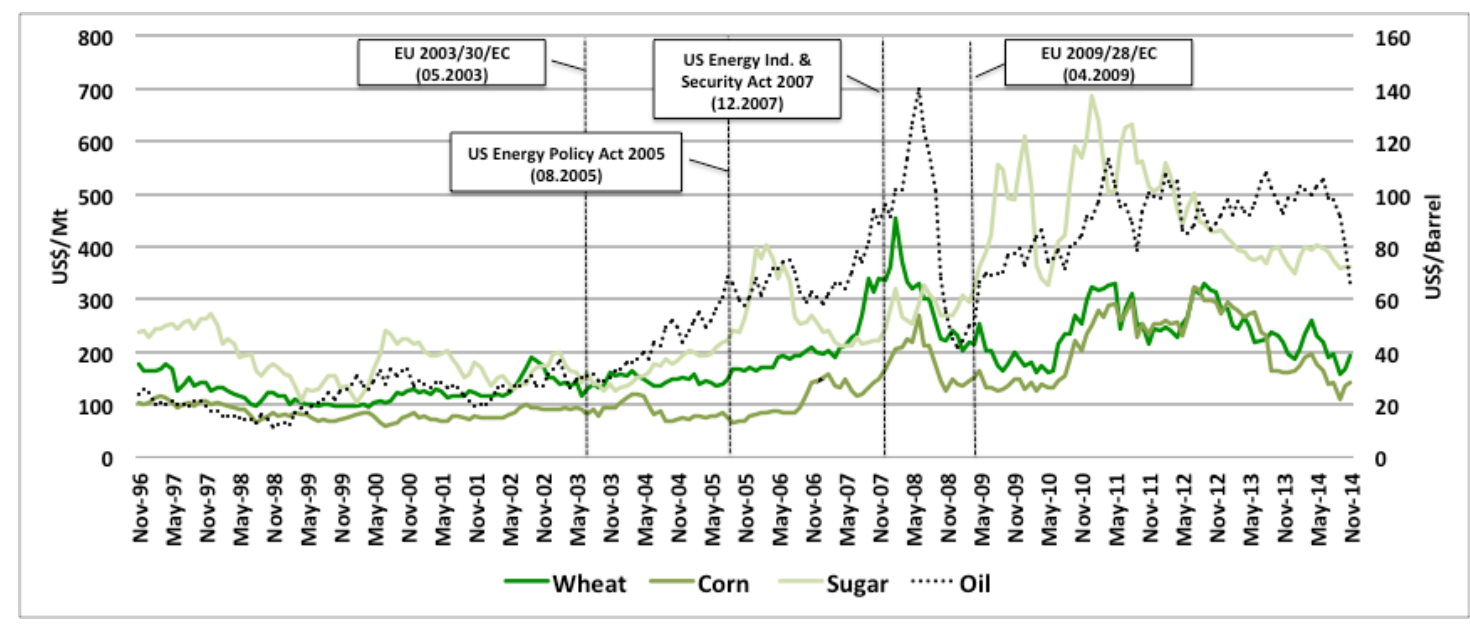

Source: Own elaboration.

Figure 4 depicts the monthly evolution of the international prices for the commodities mentioned above. It also shows the successive policies implemented by the US and the EU to support biofuel production. During the period considered, the corn and wheat series co-move while the sugar follows its own more cyclical pattern. While the sugar series tends to follow the development of oil prices more closely, wheat and corn prices start following it later, around mid 2005, coinciding with the enforcement of the US Energy Policy Act. From November 1996 the prices of wheat and corn start converging, attaining a minimal difference in April 2000. Since then, both prices start diverging and reach a maximum gap price of 250 US\$/Mt in February 2008. Nevertheless, between the end of 2006 and the beginning of 2007, the growth rate of corn prices accelerated and the gap substantially fell by February 2007. In December 20 Own estimates based on information from USDA Foreign $\quad$ Agricultural Service
http://apps.fas.usda.gov/psdonline/psdQuery.aspx , acceded on March 5 $5^{\text {th }}, 2016$. 
2007 the US increased its mandate levels further, boosting cereal prices to new highs. However, since the beginning of 2011 both series were practically tied, commoving around very similar price levels and following a decreasing trend from the second half of 2012.

\subsubsection{Biodiesel feedstocks}

Soybean oil and rapeseed oil are used for biodiesel especially in temperate zones due to their low viscosity. The US, Brazil, and Argentina mainly process biodiesel form soybean oil, whereas the EU uses rapeseed oil. Palm oil is the main feedstock in tropical countries like Indonesia, Malaysia, and Thailand in Southeast Asia, or Colombia and Ecuador in Latin America. Rapeseed oil, similar to wheat, has a relatively small international market. Only $12 \%$ of this oil is commercialised internationally. The international trade for soybean oil is more important and represents $26 \%$ of its production. However, over recent years it has been increasingly exported as biodiesel, too. For instance, Argentina, the third largest soybean producer, developed a very efficient biodiesel cluster during the last decade. Its exports reached a record of 1.9 Billion Lt in 2011 (CARBIO, 2015). While rapeseed and soybean oils are mainly consumed domestically or exported as biodiesel, the international market for palm oil accounts for roughly $70 \%$ of global production. This product is the most widely traded vegetable oil of the group. ${ }^{21}$

Figure 5. Evolution of the price of vegetable oils, 1996- 2014

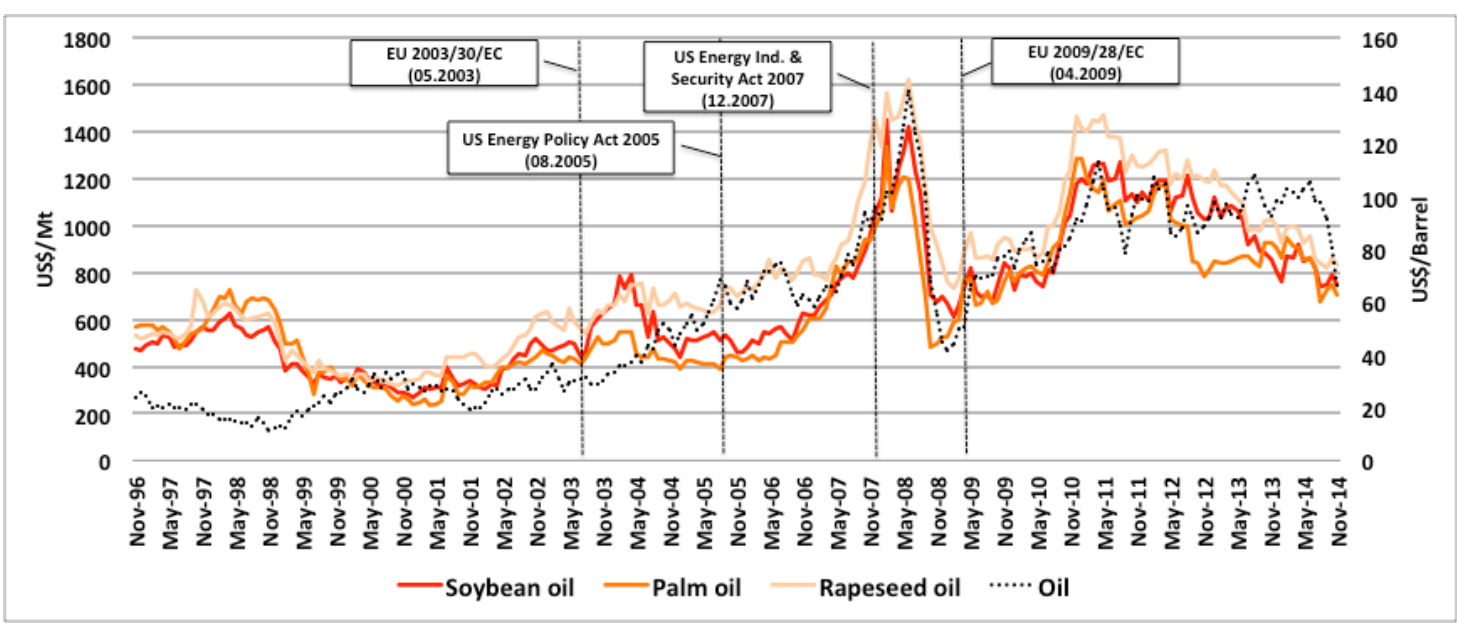

Source: Own elaboration.

21 Own estimates based on information from USDA Foreign Agricultural Service http://apps.fas.usda.gov/psdonline/psdQuery.aspx , acceded on March 5 th $^{\text {th }} 2016$. 
Figure 5 shows a narrow comovement among vegetable oils throughout the entire period. Since the beginning of 2000 they start also following oil's price development closely. Starting 2001, the three vegetable oils commence an upward trend, which ends shortly before the beginning of the financial crisis in September 2008. Oil prices start a similar trend around one year later in 2002. From the beginning of 2007, however, both oil and vegetable oil prices start commoving tightly. Soybean oil and palm oil maintain similar price levels along the considered period, except between 2003 and 2006, and 2012 and 2013, when soybean oil becomes more expensive. Short before the crisis outbreak all prices start declining. In October 2008 palm oil price plummet, followed by oil in January 2009 and soybean oil and rapeseed oil in February of the same year. In April 2009, though, the EU enacted a new biofuel directive requiring member States to replace $10 \%$ of transport fuels with biofuels by 2020. This measure seems to have exerted (at least) some pressure on vegetable oil prices as observed in Figure 5 since the beginning of 2009.

\subsection{Literature review}

In this section we review the recent findings and the methods applied to reveal foodenergy linkages and related volatility spillovers. Most of the research concentrates on finding correlations of second order moments between agricultural and oil markets. For this purpose, a commonly used method is the multivariate Generalised Autoregressive Conditional Heteroskedastic (GARCH) model with BEKK specification (Engle and Kroner, 1995). This method provides positive-definite conditional variances, while simultaneously accounting for cross effects. Regarding the conditional mean, which filters out secular and cyclical price developments, different methods are used e.g. Autoregressive Moving Averages (ARMA), Vector Autoregressive (VAR), or Vector Error Correction Models (VECM) (Engle and Granger, 1987). Another standard method is the Dynamic Conditional Correlation (DCC) model of Engle (2002). This model, however, does not consider cross dynamics among variables, which in turn allows managing larger systems. This body of literature is reflected well in Algieri (2014). He concludes that good news (e.g. the prospect of good harvests) generates less volatility than bad news (e.g. droughts, floods) for corn, while the opposite happens for wheat and sugar. Moreover, lagged oil and ethanol returns have a significant influence on corn, wheat, sugar, and soybean volatilities, implying that energy drives volatility in agricultural markets. Serra and 
Gil (2012) verify that the so-called stock-to-disappearance forecasts lower corn volatility while interest rate uncertainty increases it, and ethanol volatility spills to corn volatility. Trujillo-Barrera et al. (2012) find volatility transmission from oil to corn and ethanol markets as well as from corn to ethanol. However, they obtain no evidence of volatility spillovers from ethanol to corn. Wu et al. (2011) notice significant volatility spillovers from oil to corn spot and futures. Moreover, spillovers become larger after the introduction of the Energy Policy Act of 2005. They conclude that substantial volatility spillovers occur in periods of high ethanol-gasoline consumption rates. Chang and Su (2010) find no significant volatility spillovers from oil to corn and soybean during the low oil price period (2000-2004), but they do for the high oil episode (2004-2008). However, volatility spillovers between corn and soybean remain insignificant in both periods Zhang et al. (2009) observe bidirectional volatility spillovers between corn and soybean, and from soybean to ethanol only during the Ethanol Boom period (2000-2007). In the same period they also notice (unexpected) spillovers from corn to oil. Mensi et al. (2014) analyse volatility transmission between energy and cereal markets in both the US and EU, and the effect of OPEC decisions to cut, maintain, or reduce oil production levels. They show that oil volatility spills over to corn, whereas gasoline impacts on corn, sorghum, and barley volatilities. Moreover, cut decisions by OPEC have a much stronger effect both on energy and agricultural markets. Busse et al. (2011) find significant correlations between oil and both rapeseed oil and soybean. They conclude that causality may extend from oil to the agricultural markets. Teresa (2011b) shows that shocks in oil and sugar markets increase ethanol volatility, but ethanol does not affect either sugar or oil volatilities. Additionally, sugar volatility also spills over to ethanol volatility. Serra et al. (2011) confirm that oil volatility transmits to sugar and ethanol volatilities. Furthermore, they observe bidirectional spillovers between ethanol and sugar, and significant but small reverse spillovers from sugar and ethanol to oil. $\mathrm{Wu}$ and $\mathrm{Li}$ (2013) analyse spillover effects across oil, corn, and ethanol for the Chinese market. They find unidirectional spillovers from oil to corn and ethanol markets, but bidirectional spillovers between corn and ethanol. In particular they notice higher correlations among oil, corn, and ethanol after September 2008. Alom et al. (2011b) confirm significant mean and volatility spillovers from oil to food, though their magnitudes differ among countries and timeframes. They notice that larger spillovers appear particularly after 2001. 
A second important group of studies assess Granger causalities between oil and agricultural commodities. Harri and Hudson (2009), for example, verify volatility spillovers from oil to corn after the food crisis, whereas Kaltalioglu and Soytas (2011) don't find any volatility spillovers from oil to food and agricultural raw materials. Zilberman et al. (2012) argue that the main reason why some studies only find a weak oil-food connection is because the impact of biofuels is only reflected when the source of the change in food prices is taken into account. Nazlioglu et al. (2013) observe volatility spillovers from wheat to oil in the pre-crisis period (01.198612.2005) and bidirectional causalities between oil and soybean, and oil and wheat in the post-crisis period (01.2006-03.2011).

Finally, several studies also apply cross correlation, stochastic volatility, random parameter, and non-linear least squares models. Du et al. (2011), find spillovers from oil to both corn and wheat, as well as increased correlations between oil and corn, and oil and wheat during the period 2006-2009. Liu (2014) confirms highly significant and persistent cross correlations between the volatilities of oil and each of the considered cereals, especially during the crisis period. Balcombe (2011) verifies positive spillovers from oil to the considered agricultural products and Alghalith (2010) argues that an increase in oil price and volatility yields higher food prices, while an increase in oil supply reduces them.

\subsection{Data and methodology}

The aim of this study is to assess the evolution of the volatility spillovers between oil and the major agricultural feedstocks used for biofuels. With this purpose we use daily international prices for cereals, sugar, vegetable oils and oil from November 1996 to November 2014, obtained from Thomson Reuter's Data Stream. All prices are spot, except for the rapeseed oil series, which corresponds to a futures contract.

\subsubsection{Data}

Table 3 shows the descriptive statistics for price levels and their logarithmic price changes for every series. The Jarque-Bera test rejects normality for both price levels and their returns. Returns show a relatively high degree of kurtosis if compared to price levels. Rapeseed oil's returns present an excessive level of kurtosis followed by wheat, palm oil and crude oil. Although sugar, corn and soybean oil also exhibit some 
Table 3. Descriptive statistics of the data

\begin{tabular}{|c|c|c|c|c|c|c|c|}
\hline Price levels & Max & Min & Mean & Sd & Skewness & $\begin{array}{c}\text { Excess } \\
\text { Kurtosis }\end{array}$ & JB p-value \\
\hline Oil, crude WTI cushing US\$/BBL & 145.31 & 10.82 & 56.64 & 31.93 & 0.30 & -1.20 & 0.00 \\
\hline Wheat, No.2 hard (Kansas) US\$ Cts/Bu & 1407.00 & 238.75 & 504.86 & 191.08 & 1.00 & 0.67 & 0.00 \\
\hline Corn, No.2 yellow US\$ Cts/Bu & 849.00 & 145.00 & 339.91 & 174.08 & 1.12 & 0.06 & 0.00 \\
\hline Sugar, raw (ISA) daily Price US\$ Cts/lb & 32.57 & 4.70 & 12.95 & 6.14 & 0.86 & -0.19 & 0.00 \\
\hline Soybean oil, crude Decatur US\$ Cts/lb & 67.69 & 11.84 & 30.87 & 12.94 & 0.63 & -0.67 & 0.00 \\
\hline Palm oil, crude MAL CIF Rdam US\$/MT & 1395.00 & 215.00 & 640.43 & 267.79 & 0.55 & -0.68 & 0.00 \\
\hline Rapeseed oil, Dutch FOB NWE $1 \mathrm{~m}$ fwd EUR/MT & 1125.00 & 345.00 & 635.98 & 189.51 & 0.61 & -0.62 & 0.00 \\
\hline \multicolumn{8}{|l|}{ Ln price returns } \\
\hline Oil, crude WTI cushing US\$/BBL & 0.16 & -0.17 & $2.23 \mathrm{E}-04$ & $2.40 \mathrm{E}-02$ & -0.19 & 5.33 & 0.00 \\
\hline Wheat, No.2 hard (Kansas) US\$ Cts/Bu & 0.23 & -0.20 & $2.72 \mathrm{E}-05$ & $2.09 \mathrm{E}-02$ & 0.07 & 10.39 & 0.00 \\
\hline Corn, No.2 yellow US\$ Cts/Bu & 0.11 & -0.12 & 7.09E-05 & $1.88 \mathrm{E}-02$ & -0.13 & 3.18 & 0.00 \\
\hline Sugar, raw (ISA) daily Price US\$ Cts/lb & 0.14 & -0.19 & 9.37E-05 & $2.16 \mathrm{E}-02$ & -0.31 & 4.21 & 0.00 \\
\hline Soybean oil, crude Decatur US\$ Cts/lb & 0.08 & -0.08 & $9.84 \mathrm{E}-05$ & $1.56 \mathrm{E}-02$ & 0.11 & 2.20 & 0.00 \\
\hline Palm oil, crude MAL CIF Rdam US\$/MT & 0.16 & -0.13 & $5.65 \mathrm{E}-05$ & $1.85 \mathrm{E}-02$ & 0.13 & 7.07 & 0.00 \\
\hline Rapeseed oil, Dutch FOB NWE $1 \mathrm{~m}$ fwd EUR/MT & 0.22 & -0.19 & $1.04 \mathrm{E}-04$ & 1.73E-02 & 0.29 & 28.21 & 0.00 \\
\hline
\end{tabular}

Source: Own elaboration.

excess kurtosis, their values are closer to normality. In contrast to returns, price levels show low or even negative kurtoses, reflecting more stable values around their means. In terms of symmetry, both returns and price levels are skewed. Price levels are predominantly positive skewed, while returns show both positive and negative skewness.

\subsubsection{Methodology}

Some of the studies concerned with the relationship between agricultural and energy markets identify structural breaks around the financial crisis of 2007/2008 and base their analysis on two sample periods, before and after the crisis. Others apply econometric techniques to explicitly account for structural breaks (e.g. threshold models). In contrast to the previous methods, we use a rolling windows approach. An argument in favour of using rolling windows is that fixed-parameter models are unable to capture secular and cyclical patterns of the data (Diebold and Yilmaz, 2009). In a first step we estimate volatilities separately for different biofuel feedstocks and in a second stage we use them in Vector Autoregressive (VAR) models. We run the analysis through 158 subsamples or windows of 60 months, which covers episodes before, during, and after the financial crisis. Doing so, we provide more information about the development of the volatility spillovers through time.

\subsubsection{Realised Volatility}

To estimate the volatility we use the ex-post monthly-realised volatility (RV) estimator based on daily observations 


$$
R V=\sum_{j=1}^{m} r_{j \Delta, m}^{2}
$$

where $r_{j \Delta}^{2}$ is the square of the daily logarithmic returns summed over $m$ week-days observations in every month (between 20 and 23 days per month). The RV is further corrected for intra-month noise using a Moving Average process of order 1 (MA (1)) to account for the autocorrelation effect. The adjusted estimator is then

$$
\hat{\sigma}^{2}=m \hat{\gamma}^{2}(1+\hat{\eta})^{2}
$$

where $\hat{\gamma}^{2}$ and $\hat{\eta}$ are the variance and the moving average coefficient, respectively, from the Maximum Likelihood (ML) estimate of the MA (1). Finally, we annualised the squared root by multiplying it by the square root of twelve. While most of the literature relies on GARCH-type models to estimate the volatility, we chose the nonparametric RV estimator since this imposes less structure on the volatility process, an important advantage in highly volatile markets.

\subsubsection{Estimation of volatility spillovers}

Most of the reviewed literature on spillovers between energy and food markets relies on the BEKK specification of multivariate GARCH models. However, for systems with more than three variables, these models suffer from over-parameterisation issues. A further limitation to apply this method in a dynamic multi-period framework like rolling windows is the lag order selection, which must be done for every subsample. Another frequently used method is the Dynamic Conditional Correlation (DCC) model proposed by Engle (2002). While this method allows managing larger systems without the 'over-parameterisation' problem, it doesn't account for contemporaneous effects among variables.

Instead, we apply a two-step approach. First, we estimate realised volatilities for every commodity and use them later in VAR models. The advantage of the VAR framework is that it captures linear interdependencies among variables without requiring prior knowledge about their drivers. Instead, one needs a hypothetical relation among them. With this purpose in mind, we divide the studied agricultural products into two groups: one for ethanol and one for biodiesel feedstocks. The Ethanol Group comprises oil, corn, wheat, and sugar while the Biodiesel Group 
gathers oil, soybean oil, rapeseed oil, and palm oil. We use a Cholesky ordering to identify the contemporaneous effects in the VAR systems. Considering the relative extent and depth of the oil market, we assume its precedence against agricultural markets. In the case of agricultural commodities -and pondering again their market size and relevance as biofuel feedstocks- we assume the following ordering for the ethanol feedstocks: sugar, corn, and wheat. For the biodiesel feedstocks the order is as follows: soybean oil, rapeseed oil, and palm oil.

Based on the forecast error variance decompositions (FEVD) of the VAR models, we derive the 'Spillover Index' suggested in Diebold and Yilmaz (2009). The error variance of the H-step ahead forecast of a VAR model can be decomposed into own and cross variance shares. The former corresponds to the portion of the error variance due to shocks in the same market, while the latter represents the portion of the error variance due to shocks in different markets, or 'spillovers'. First we consider that the one step ahead forecast of a bivariate VAR system, given by

$$
e_{t+1, t}=x_{t+1}-x_{t+1, t}=A_{0} u_{t+1}=\left[\begin{array}{ll}
a_{0,11} & a_{0,12} \\
a_{0,21} & a_{0,22}
\end{array}\right]\left[\begin{array}{l}
u_{1, t+1} \\
u_{2, t+1}
\end{array}\right]
$$

has a covariance matrix

$$
E\left(e_{t+1} e_{t+1, t}^{\prime}\right)=A_{0} A_{0}^{\prime}
$$

and the one step ahead error in forecasting $x_{1 t}$ is $a_{0,11}^{2}+a_{0,12}^{2}$ and in forecasting $x_{2 t}$ is $a_{0,21}^{2}+a_{0,22}^{2}$. Then, we define the own variances as $a_{0,11}^{2}+a_{0,22}^{2}$ and the cross variances or 'spillovers' as $a_{0,12}^{2}+a_{0,21}^{2}$. The spillover index is then defined as the cross-variance share of the total forecast error variation

$$
S=\frac{a_{0,12}^{2}+a_{0,21}^{2}}{\operatorname{trace}\left(A_{0} A_{0}^{\prime}\right)} \times 100,
$$

and its generalisation, for different H-step-ahead forecast horizons and diverse VAR orders and dimensions, is

$$
S=\frac{\sum_{h=0}^{H-1} \sum_{i, j=1 \forall i \neq j}^{N} a_{h, i j}^{2}}{\sum_{h=0}^{H-1} \operatorname{trace}\left(A_{h} A_{h}^{\prime}\right)} \times 100 .
$$




\subsection{Empirical findings}

We start this section by illustrating how the spillover index proposed in (6) is built. As mentioned before, we estimate spillover indices for 158 consecutive sub-periods of 60 months. We use ten-month ahead $(\mathrm{H}=10)$ forecast errors to decompose the variances in own and cross impacts. Since most of the international trade of agricultural commodities is done in US dollars, its variations (appreciation/depreciation) not only affect the amount but also the direction of the trade flows. To control for the effects of exchange rate, which could potentially preclude spillover dynamics, we consider the (US) Dollar Index volatility as an exogenous component in the VAR systems.

Table 4. Variance decomposition matrix, Ethanol Group

\begin{tabular}{|c|c|c|c|c|c|c|}
\hline \multirow[b]{2}{*}{ To } & \multicolumn{6}{|c|}{ From } \\
\hline & Oil & Sugar & Corn & Wheat & Receptions & $\begin{array}{c}\text { Receptions without } \\
\text { own effects }\end{array}$ \\
\hline Oil & 9.41 & 0.13 & 0.35 & 0.10 & 10.00 & 0.59 \\
\hline Sugar & 0.32 & 9.53 & 0.05 & 0.10 & 10.00 & 0.47 \\
\hline Corn & 0.39 & 0.29 & 9.15 & 0.17 & 10.00 & 0.85 \\
\hline Wheat & 0.27 & 0.61 & 0.88 & 8.25 & 10.00 & 1.75 \\
\hline Transmissions & 10.39 & 10.56 & 10.43 & 8.62 & 40.00 & - \\
\hline Transmissions without own effects & 0.97 & 1.03 & 1.28 & 0.38 & - & 3.7 \\
\hline
\end{tabular}

Source: Own elaboration.

Table 4 presents the variance decompositions for the Ethanol Group considering average values of the 158 windows. Columns show the contribution of individual commodities to the forecast error variances of the remaining ones. For instance, the first column describes how innovations in oil impact on sugar (0.32), corn (0.39) and wheat (0.27). Since our interest is in cross 'spillover' effects we don't consider the diagonal elements of the matrix. In total, the contribution of oil volatility to ethanol feedstocks is 0.97. Rows, on the other hand, provide information on how much volatility a particular commodity receives from other markets. In the case of oil, sugar contributes with 0.13 , corn with 0.35 , and wheat with 0.10 . The spillover index then corresponds to the total transmissions or receptions (without own effects) divided by the full matrix (3.7/40). In the case of the Ethanol Group, its average spillover index is, on average, $9.2 \%$, whereas for the Biodiesel Group the index is $11.4 \%$.

Figure 6 depicts the development of the volatility spillovers among oil and the corresponding ethanol and biodiesel feedstocks. The thinner lines represent index estimates without considering the dollar exchange rate volatility. One can observe for 
Figure 6. Volatility spillover index evolution for the ethanol and biodiesel groups

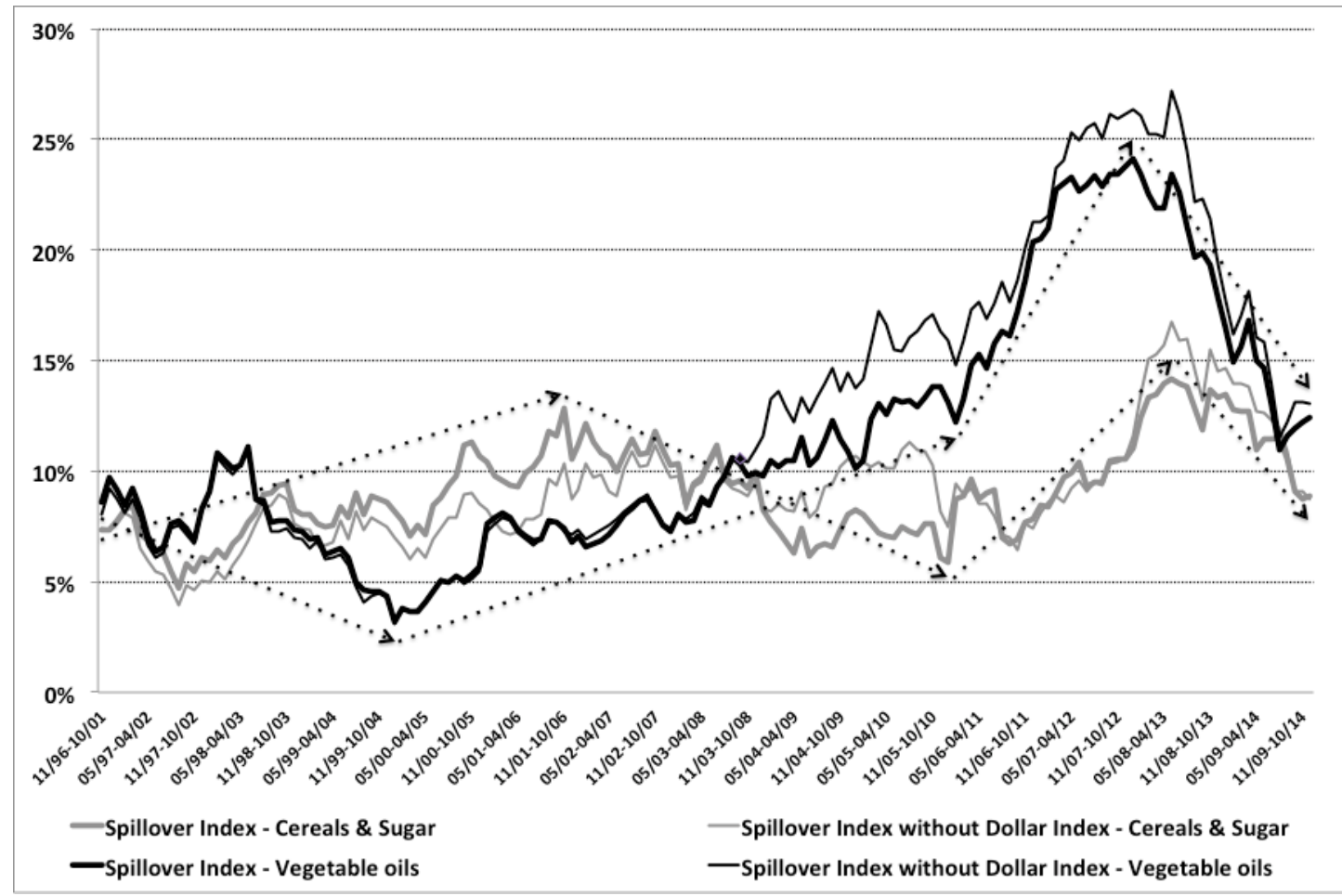

Source: Own elaboration.

Note: Dotted arrows describe the trending behaviour of the index series.

instance, that for vegetable oils the spillover index was unaffected by exchange rate volatility until September 2008, when the financial crisis started. After this point, exchange rate effects might have induced more volatility spillovers among vegetable oils and between vegetable oils and oil. In the case of ethanol feedstocks, the exchange rate effects are present before and after the crisis outbreak. In the pre-crisis episode volatility spillovers were underestimated, while after the crisis, exchange rate volatility of US dollar-denominated trade might have provoked more volatility transmission among sugar, cereals and oil. In general, the indices (controlling for US exchange rate volatility) remain between $5 \%$ and $10 \%$ for the pre-crisis period. The biodiesel index started an upward trend at the beginning of 2005, which accelerates between 2011 and 2012. At the end of 2012 it reached a maximum spillover level of $24 \%$. Since then, it falls back to pre-crisis levels close to $10 \%$. The spillover index for ethanol feedstocks is in general lower, reflecting more stable cereal and sugar markets. It grew moderately during the first decade (1996-2006). However, between 2003 and 2008 the ethanol index became temporarily larger by around 3\% (on 
average). Until 2010 this index followed a downward trend, which reverted between 2011 and the first semester of 2013.

Table 5. Relative average contributions to the spillover index, Ethanol Group

\begin{tabular}{|c|c|c|c|c|c|}
\hline \multirow[b]{2}{*}{ To } & \multicolumn{5}{|c|}{ From } \\
\hline & Oil & Sugar & Corn & Wheat & $\begin{array}{l}\text { Receptions without } \\
\text { own effects }\end{array}$ \\
\hline$\overline{\text { Oil }}$ & & $3.93 \%$ & $8.88 \%$ & $2.81 \%$ & $15.62 \%$ \\
\hline Sugar & $8.60 \%$ & & $1.34 \%$ & $2.89 \%$ & $12.83 \%$ \\
\hline Corn & $10.33 \%$ & $8.73 \%$ & & $4.76 \%$ & $23.82 \%$ \\
\hline Wheat & $7.44 \%$ & $18.59 \%$ & $21.70 \%$ & & $47.73 \%$ \\
\hline Transmissions without own effects & $26.37 \%$ & $31.25 \%$ & $31.92 \%$ & $10.47 \%$ & $100.00 \%$ \\
\hline
\end{tabular}

Source: Own elaboration.

Note: Numbers in this table represent shares of the spillover index.

To reveal the contributions of the different commodities to the spillover index, as well as to other markets, Table 5 presents the variance-covariance matrix for the Ethanol Group. Its values are expressed as shares of the total spillover index. For instance, oil's volatility transmission to other markets represents $26 \%$ of total group spillovers. We can also observe that oil is a net volatility transmitter. Its contributions to agricultural markets (26\%) are larger than its volatility receipts from them (16\%). Similar to oil, sugar and corn markets are net volatility transmitters. Wheat, on the other hand, remains the only volatility receptor of the group. One can also observe that ca. $58 \%$ of the spillovers originate in agricultural markets.

\section{Figure 7. Relative contribution of oil to the spillover index, Ethanol Group}

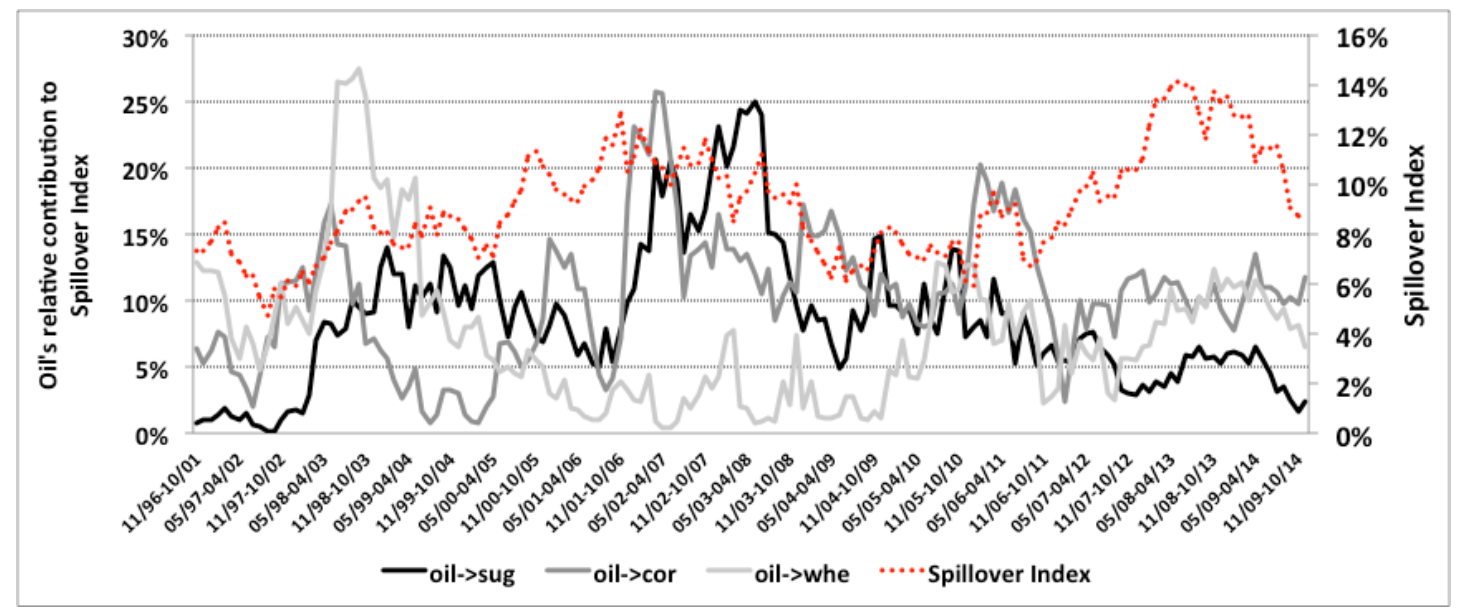

Source: Own elaboration.

To illustrate the development of oil's contribution to the spillover index, Figure 7 shows a comparison of the volatility spillovers from oil to the three ethanol feedstocks 
considered. One can observe in this graph that oil spillovers to corn, wheat and sugar markets reach similar important peak values in different periods. During the third quarter of 2003, for instance, spillovers to wheat represent $27 \%$ of the spillover index. Between 2007 and 2008 oil's volatility spillovers to corn and sugar attain similar levels. After 2011, however, oil spillovers to agricultural markets decline, while the spillover index rise. This suggests more volatility dynamics across agricultural markets than between these markets and oil.

Table 6. Relative average contributions to the spillover index, Biodiesel Group

\begin{tabular}{|c|c|c|c|c|c|}
\hline \multirow[b]{2}{*}{ To } & \multicolumn{5}{|c|}{ From } \\
\hline & Oil & Soybean oil & Rapeseed oil & Palm oil & $\begin{array}{c}\text { Receptions without } \\
\text { own effects }\end{array}$ \\
\hline Oil & & $2.13 \%$ & $1.23 \%$ & $2.40 \%$ & $5.76 \%$ \\
\hline Soybean oil & $7.18 \%$ & & $1.76 \%$ & $2.53 \%$ & $11.47 \%$ \\
\hline Rapeseed oil & $7.86 \%$ & $13.03 \%$ & & $7.12 \%$ & $28.02 \%$ \\
\hline Palm oil & $5.69 \%$ & $38.03 \%$ & $11.03 \%$ & & $54.75 \%$ \\
\hline Transmissions without own effects & $20.73 \%$ & $53.20 \%$ & $14.02 \%$ & $12.05 \%$ & $100.00 \%$ \\
\hline
\end{tabular}

Source: Own elaboration.

Note: Numbers in this table represent shares of the spillover index.

Table 6 displays the individual volatility contributions among the commodities which make up the Biodiesel Group. In this case, oil's volatility transmissions to agricultural markets are smaller (21\%). Accordingly, much of the volatility spillovers derive from vegetable oil markets (74\%). Although oil remains a net volatility transmitter, the volatility spillovers received from agricultural markets (6\%) are almost three times smaller than for the case of cereals and sugar (16\%). This is partially explained by the low integration of rapeseed oil to international markets. Besides oil, soybean oil, and rapeseed oil are also net volatility transmitters. Palm oil, on the other hand, is the only net volatility receiving market. Based on empirics, we established the following causality order for this group: oil, soybean oil, rapeseed oil and palm oil. Consequently, it is not surprising that palm oil is the major volatility receptor as is the case of wheat in the ethanol group.

Figure 8 depicts the evolution of the spillovers from oil to vegetable oils. Oil's spillover contributions to vegetable oils range, on average, between $6 \%$ and $8 \%$. In August 2002, however, there was a large volatility spillover episode to the soybean oil market representing 36\% of the spillover index alone. Between 2007 and 2008 the remaining vegetable oils were particularly volatile, reaching values between $20 \%$ and $35 \%$. However, their influence in the spillover index declined rapidly and remained 
Figure 8. Relative contribution of oil to the spillover index, Biodiesel Group

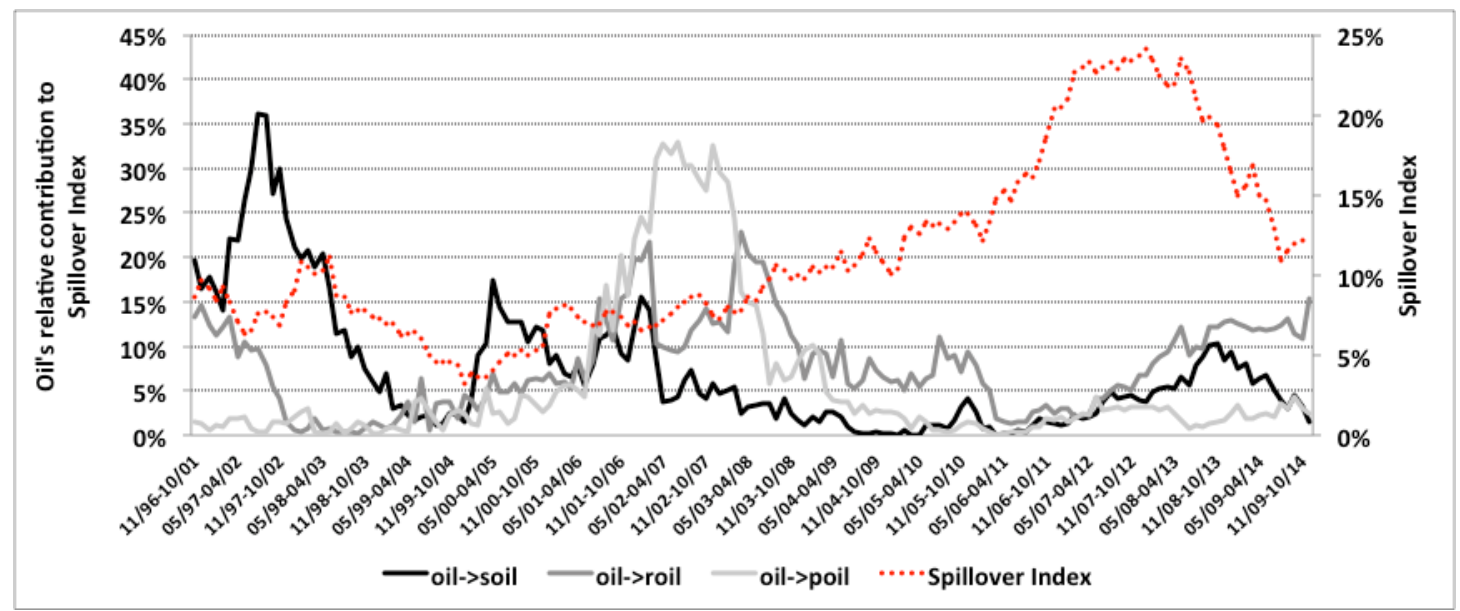

Source: Own elaboration.

mostly close to or below $10 \%$ after 2008. Since the beginning of 2009 volatilities originating and spilling over to agricultural markets are responsible for the largest share of the spillover index, suggesting a minor role of oil during this period.

\subsection{Conclusions}

Biofuel production is mainly driven by political decisions in developed (and to an increasing extent, in developing) countries, which assign large budgets to promote the ethanol and biodiesel industries as a way to reduce greenhouse gases and manage their grain surpluses.

While ethanol production is concentrated around two countries (the US and Brazil) and two major feedstocks (corn and sugar cane), biodiesel is more evenly distributed (Germany, France, US, Argentina and Brazil). Although biodiesel feedstocks are more diverse, they have low productivities, with the exception of palm oil. Comparatively, ethanol feedstocks are more productive. Owing to the generous support given to biofuels, between 1991 and 2011 ethanol and biodiesel production grew at an average annual rate of $9 \%$ and $67 \%$, respectively. However, due to the low energy density of agricultural commodities as compared to fossil fuels, the degree of substitution of oil-based liquid fuels by biofuels has been negligible and at the expense of large amounts of foodstuffs. This in turn has destabilised agricultural markets.

Until September 2008, the levels of volatility spillovers in the Biodiesel Group remained unaffected when controlling for the effect of the US dollar exchange rate 
volatility. Conversely, during this period, volatility spillovers in the Ethanol Group appeared to be overestimated. During the post-crisis period, however, exchange rate volatility might have induced more volatility in both groups amplifying the connection among markets.

The Ethanol Group shows a cyclical pattern with alternating periods of high and low volatility transmission among markets before, during and after the financial crisis. The Biodiesel Group displayed a more persistent development. It started an upward trending behaviour at the beginning of 2005, which accelerated between 2011 and 2012, and declined abruptly subsequently. Although the average spillover index for the Ethanol Group is lower (9.2\%) if compared to the Biodiesel Group (11.4\%), oil's contribution to ethanol feedstocks is comparatively larger (26\%) than for biodiesel feedstocks (21\%). This situation denotes a closer relation between oil and cereals/sugar. However, since 2009 oil's contribution to both indices decline, suggesting larger risk transmissions among agricultural markets and a secondary role of oil.

\subsection{Policy recommendations}

The analysis of volatility spillovers in the two groups has clearly indicated that these spillovers between the products rarely follow a simple pattern. We find episodes when the notoriously high oil price fluctuations induce additional volatility in key agricultural markets. These episodes are generally characterised by some common features. First, the spillovers seem to be particularly strong when the prices of the agricultural products are comparatively high. This suggests that volatility spillovers are more likely to occur in periods when stocks are low. Second, the magnitude of spillovers in these episodes has increased over time. Finally, the prevalence of spillover periods is product specific, and seems to be driven by substitutability of the products in food, feed, or biofuel use. These three characteristics suggest that the biofuel policies do indeed contribute to higher volatility spillovers from the oil market to key agricultural products. Hence, the biofuel policies should be carefully reconsidered, taking this finding into account. The fact that spillovers are relatively small for most of the pre-crisis period cannot be used as an argument that price volatility spillovers would not matter. The key episodes, even if they are limited in number, are the ones that are politically important. At those times, the impact of oil 
price volatility on agricultural markets, which are already suffering from higher price levels and inflated uncertainty, exacerbates the situation, harming poor and vulnerable consumers, and reducing the incentives to agriculture at a time when the price level would particularly favour an expansion of production.

However, biofuel policies are unlikely to be radically reformed, at least in the short run. Our analysis of volatility spillovers suggests that mitigating measures, which have the potential to limit the transmission of price volatility from oil to agriculture, might constitute a politically feasible yet helpful approach. These measures could include a more flexible handling of blending requirements for biodiesel and ethanol, an approach which is already partially in use in Brazil and the US. Developing countries contemplating increasing their support of biofuels should keep this in mind when designing their policies. Publicly managed buffer stocks held by a single country, on the other hand, seem to be considered as an alternative tool by policy makers, too. However, their potential for curbing price volatility seems rather limited, especially in those periods when oil markets drive agricultural price volatilities, given the drastic difference in the relative size of the markets. 


\section{Appendix}

Table 7: Volatility drivers

\begin{tabular}{|c|c|c|}
\hline & Supply & Demand \\
\hline \multirow{9}{*}{$\begin{array}{l}\text { Long term } \\
\text { (Structural) }\end{array}$} & Underinvestment in agriculture & Income and population growth in developing countries \\
\hline & Declining yields in main cereals & Change in dietary preferences \\
\hline & Change from large scale to small size farming & \\
\hline & Policies affecting land markets & \\
\hline & Increasing frequency in weather related shocks & \\
\hline & Diminishing international grain stocks & \\
\hline & Outcome of the & teral trade negotiations \\
\hline & Lack of reliable & ation on stock holdings \\
\hline & Developmen & croeconomic policies \\
\hline \multirow{5}{*}{$\begin{array}{l}\text { Short term } \\
\text { (Shocks) }\end{array}$} & News on expected harvests & Biofuel mandates \\
\hline & News on stock holding levels & Financialisation of agricultural markets \\
\hline & \multicolumn{2}{|c|}{ Monetary policy shocks } \\
\hline & \multicolumn{2}{|c|}{ Exchange rate volatility } \\
\hline & \multicolumn{2}{|c|}{ Trade distorting policies } \\
\hline
\end{tabular}

Source: Own elaboration. 


\section{Volatile agricultural markets, the role of oil before and after the Great Recession}

This article, which corresponds to section 4 of the thesis document, is a joint effort with Prof. Dr. Helmut Herwartz from the Faculty of Economics, Chair for Econometrics. Its introductory part is built on the paper presented in the previous section. However, it proposes a new, refined and more flexible method to estimate directional spillover indices.

\subsection{Introduction}

Although the existing literature attributes the increasing volatility of agricultural prices to different factors and their interactions, there is special interest in the effects of oil price changes in agricultural markets. ${ }^{22}$ The rise of food prices combined with periods of high price uncertainty leads to considerable economic private and social costs. Price uncertainty may impact countries differently depending on whether they are net food importers or exporters, their degree of integration to international markets and the effectiveness of their domestic policies. Developing countries are especially exposed to food price volatility, since food expenditures represent a high budget share for most of their population. Those living in urban areas, which are net food buyers, are particularly affected. Price surges may prevent them from acceding to food in appropriate quantity and quality. Additionally, price instability hinders investments in agriculture putting further pressure on production and food prices in the mid-term. This situation, in turn, may lead to social unrest and political instability worldwide (FAO et al., 2011; Prakash, 2011). Assuring stable agricultural markets is

\footnotetext{
${ }^{22}$ For a review of the different drivers of price volatility in agricultural markets see Brümmer et al. (2013).
} 
consequently a pre-requisite to address food security in developing countries (FAO, 2013).

Oil production is centred in politically unstable developing countries, most of them cartelised in the Organisation of the Petroleum Exporting Countries (OPEC). Since OPEC holds $80 \%$ of world's proven oil reserves (OPEC, 2015), uncertainties originating in these countries send shock waves throughout the world's economy, including sensible sectors like agriculture. The linkage between oil and agricultural commodities was traditionally driven by the use of oil derivatives as inputs for crop production (e.g. fuel, fertilisers, pesticides, etc.), processing and transporting. With the introduction of biofuels, however, agricultural commodities became energy carriers themselves, adding complexity to the oil-food relation. As close substitutes for fossil fuels, biofuels derived from cereals, oil seeds and sugar crops now compete directly for staple foods. The literature concerned with volatility spillovers between energy and food markets is recent. While most articles focus on finding significant correlations or causalities in the Granger sense (Granger, 1969) (e.g. Mensi et al., 2014; Busse et al., 2011; Nazlioglu et al., 2013; Harri and Hudson, 2009), only few studies attempt to quantify the role of oil in shaping volatility spillovers in agricultural markets (e.g. Trujillo-Barrera et. al, 2012). The objective of this article is consequently twofold: to provide a novel and flexible dynamic measure of the share of volatility spillovers in agricultural markets explained by price variations of oil; and to offer an improved understanding of the complex and evolving relation between agricultural and energy markets. We assess the development, magnitude and direction of volatility spillovers between oil and commonly used biofuel feedstocks. Our analysis builds on the notion of spillover indices obtained from forecast error variance decompositions (Diebold and Yilmaz, 2009, 2012, 2014). Instead of adopting this approach directly, however, we follow a more recent method introduced by Fengler and Herwartz (2015). Their spillover indices are derived from linearized versions of multivariate GARCH (MGARCH) models. Implemented at the daily frequency this framework signals spillover dynamics in a timely manner. As a further distinction from indices originating from Diebold and Yilmaz (2009), the vectorisation of MGARCH models is informative for spillover patterns, characterising both price variations and covariations. 
In section 4.2 we provide an overview of the evolution of the biofuel industry and its role on shaping the new food-energy nexus, as a context for the interpretation and discussion of results on second order price transmissions, together with a condensed review of the related work and its main findings. Section 4.3 describes the data, especially concerning its second order moment dynamics. In section 4.4 we propose a new methodology to quantify the impact of (co)variation of oil prices on volatility spillovers in agricultural markets. Empirical findings are provided in section 4.5. We conclude in section 4.6.

\subsection{Biofuels and the food-energy nexus}

Ethanol is derived mainly from sugar and starch crops like sugar cane, sugar beats, wheat and corn, whereas biodiesel is produced mainly from vegetable oils, e.g., soybean oil, palm oil and rapeseed oil. Up to a certain proportion, between $5 \%$ and $10 \%$, biodiesel can be blended with gasoline and diesel, respectively, in unmodified motor vehicles. The rapid growth of the biofuel industry was mainly driven by political decisions aiming to reduce greenhouse gas emissions, diversifying domestic energy sources, and fostering rural development. Between 1991 and 2011, the global production of ethanol and biodiesel grew at an average annual rate of $9 \%$ and $67 \%$, respectively. It reached 86 Billion Lt of ethanol and 21 Billion Lt of biodiesel in 2011. ${ }^{23}$ However, the disruptive and discretional character of biofuel policies has exacerbated agricultural markets in unforeseeable ways, adding complexity to their functioning. ${ }^{24}$ Typically, the biofuel industry has been supported by a combination of consumption mandates and production subsidies, particularly in developed countries. In August 2005 the US Government passed the Energy Policy Act, which required the consumption of 28 Billion Lt of biofuels (mainly ethanol) by 2012. In December 2007 the Energy Independence and Security Act pushed biofuel production further, requiring a consumption of 136 Billion Lt by 2022. In May 2003 the EU passed a Directive (2003/30/EC) to promote the use of renewable fuels, stipulating a 5.75\% replacement of transport fuels with biofuels by the end of 2010. In April 2009 the EU released a new Directive (2009/28/EC), which mandated that $20 \%$ of total energy consumption should come from renewable sources by 2020 and 10\% of transport

\footnotetext{
${ }^{23}$ Own estimates based on F.O. Licht.

${ }^{24}$ For a comprehensive analysis of the effects of the different biofuel policies and how they interact see De Gorter et al. (2015).
} 
fuels from biofuels. The International Energy Agency has estimated the global aggregated subsidy costs of biofuels (including consumption mandates) to be US\$ 1.4 trillion for the period between 2011 and 2035 (Gerasimchuk et al., 2012). The large mandates and the substantial production subsidies transformed the US to the major ethanol producing and exporting country surpassing Brazil, and the EU to the main biodiesel producing and consuming region. ${ }^{25}$

After the high price volatility episodes of the food crisis of 2007/2008, there has been a renewed interest of the international community in understanding and managing the sources of instabilities in agricultural markets. Based on different methodologies and assumptions, experts agree that volatility in agricultural markets has been higher since 2007/2008 when compared to the decades of the 1990s and 2000s (Huchet-Bourdon, 2011; Gilbert and Morgan, 2010). Consequently, over the last decade some research has concentrated on understanding the causes of the new volatility episodes, including the role of biofuels.

Recent studies examine mainly the correlation levels and statistical significance between second order moments of agricultural feedstocks and oil. With this aim different MGARCH models with BEKK specification (Engle and Kroner, 1995) have been used. This method guarantees that model implied (co)variances are positivedefinite under mild conditions, and simultaneously accounts for cross equation causality among the considered variables. For the parameterisation of the conditional mean other methods are used, e.g. Autoregressive Moving Averages (ARMA), Vector Autoregressive (VAR), or Vector Error Correction Models (VECM) (Engle and Granger, 1987), when there is evidence of long run relationships among the price series. Most of these studies find significant correlations, indicating some degree of spillovers from oil to agricultural markets. Few authors also use exogenous covariates. For instance, Chang and Su (2010) treat oil exogenously in the conditional mean, whereas Serra and Gil (2012) use forecasts of the corn stock-to-use ratios and interest rate volatility as weakly exogenous explanatory variables in the conditional variance. Another frequently employed method is the Dynamic Conditional Correlation (DCC) model of Engle (2002). It shows how correlations, in this case, between price changes of oil and agricultural commodities evolve over time. Unlike

\footnotetext{
${ }^{25}$ More information on lead biofuel producing countries is given in Appendix 1.
} 
MGARCH models, this model framework does not account simultaneously for cross effects among variables to estimate the conditional variance. Authors using this method find increased correlations between oil and agricultural products especially after the financial crisis of $2007 / 2008$. As an alternative to correlation estimates, other studies apply Granger-causality tests in variance. Some of them find oil volatilities Granger-causing volatilities in grain markets, whereas others do not, especially for sample periods before the financial crisis. ${ }^{26}$

Although our review is not exhaustive, it is striking to note that despite of conceptual differences, correlations and Granger-causalities are described interchangeably as "volatility spillovers" throughout the literature. Most of the reviewed articles provide, at different levels of significance, estimates of the marginal effects of oil volatility on different agricultural products. As a notable exception Trujillo-Barrera, Mallory, and Garcia (2012) propose a measure of the total contribution of oil volatility to two agricultural products, namely corn and ethanol. ${ }^{27} \mathrm{~A}$ contribution of this article is consequently to offer a more flexible method, which -besides providing timely estimates- delivers information on alternative transmission channels, without imposing unidirectional spillovers from the oil market.

\subsection{Data}

Covering the period between October 3, 1995 and February 27, 2015 we use daily data for international spot prices of wheat, corn, sugar, soybean, soybean oil, palm oil and oil, and one futures series ${ }^{28}$, namely rapeseed oil. All prices were obtained from Thomson Reuters' Data Stream. ${ }^{29}$ Hereafter in this section, and to account for the effects of the 2007/2008 financial crisis and the subsequent Great Recession, we split the series into two periods: from October 1995 to December 2005 and from January 2006 to February 2015 (Nazlioglu, Erdem and Soytas, 2013).

\footnotetext{
${ }^{26}$ See Table 14 of Appendix 2 for a summary review of the recent literature on price volatility transmission between energy and agricultural markets.

27 Trujillo-Barrera et al. (2012) build “Volatility Spillover Ratios”, which show that oil's volatility explains, on average, $14 \%$ and $16 \%$ of corn and ethanol volatilities, respectively.

${ }^{28}$ We use a futures price for rapeseed oil because of the lack of spot prices for this commodity.

${ }^{29}$ Data Stream codes: OILWTIN, WHEATHD, CORNUS2, WSUGDLY, SOYADSC, SOYAOIL, PALOLCD, RPOLDNE.
} 
To uncover the development of second order moment dynamics, this section describes some basic statistics of the logarithmic price changes for the considered commodities. Secondly, we estimate conditional volatilities and depict their evolution to identify periods of high uncertainty, which could potentially govern volatility spillovers among markets. Finally, a measure of the linear relation is provided as a means to expose the degree of second order interdependence between the considered markets.

\subsubsection{Log price changes of energy and food markets}

We provide in this section a summary of the statistical characteristics of the log price changes that are used later to assess the transmission of (co)variations of oil prices to agricultural commodities commonly used as biofuel feedstocks.

Table 8. Descriptive statistics of the data

\begin{tabular}{|c|c|c|c|c|c|c|c|c|c|c|c|c|}
\hline \multirow{2}{*}{ Log price changes } & \multicolumn{3}{|c|}{ Mean } & \multicolumn{3}{|c|}{ Sd } & \multicolumn{3}{|c|}{ Skewness } & \multicolumn{3}{|c|}{ Excess Kurtosis } \\
\hline & $\mathrm{I}$ & II & $\Delta \%$ & $\mathrm{~T}$ & II & $\Delta \%$ & $\mathrm{~T}$ & II & $\Delta \%$ & $T$ & II & $\Delta \%$ \\
\hline Oil, crude WTI cushing US\$/BBL & $4.64 \mathrm{E}-04$ & $-8.50 \mathrm{E}-05$ & $-118 \%$ & $2.47 \mathrm{E}-02$ & $2.33 \mathrm{E}-02$ & $-6 \%$ & -0.33 & 0.02 & $-105 \%$ & 4.33 & 5.97 & $38 \%$ \\
\hline Wheat, No.2 hard (Kansas) US\$ Cts/Bu & $-3.51 E-05$ & 4.34E-05 & $-224 \%$ & $1.53 \mathrm{E}-02$ & $2.51 \mathrm{E}-02$ & $64 \%$ & -0.09 & 0.10 & $-205 \%$ & 4.32 & 8.64 & $100 \%$ \\
\hline Corn, No.2 yellow US\$ Cts/Bu & $-1.46 \mathrm{E}-04$ & 2.55E-04 & $-274 \%$ & $1.60 \mathrm{E}-02$ & $2.14 \mathrm{E}-02$ & $34 \%$ & -0.17 & -0.16 & $-4 \%$ & 2.90 & 2.66 & $-8 \%$ \\
\hline Sugar, raw (ISA) daily Price US\$ Cts/lb & $6.85 \mathrm{E}-05$ & $8.81 \mathrm{E}-06$ & $-87 \%$ & $2.18 \mathrm{E}-02$ & $2.04 \mathrm{E}-02$ & $-6 \%$ & -0.29 & -0.31 & $4 \%$ & 4.70 & 3.75 & $-20 \%$ \\
\hline Soybean, No.1 yellow Cts/Bushel & $-1.74 \mathrm{E}-05$ & $2.31 \mathrm{E}-04$ & $-1427 \%$ & $1.53 \mathrm{E}-02$ & $1.72 \mathrm{E}-02$ & $12 \%$ & -0.90 & -0.67 & $-25 \%$ & 9.17 & 4.65 & $-49 \%$ \\
\hline Soybean oil, crude Decatur US\$ Cts/lb & $-8.70 \mathrm{E}-05$ & $1.80 \mathrm{E}-04$ & $-308 \%$ & $1.46 \mathrm{E}-02$ & $1.61 \mathrm{E}-02$ & $11 \%$ & 0.16 & 0.06 & $-65 \%$ & 1.94 & 2.39 & $23 \%$ \\
\hline Palm oil, crude MAL CIF Rdam US\$/MT & $-1.40 \mathrm{E}-04$ & 2.05E-04 & $-246 \%$ & $1.86 \mathrm{E}-02$ & $1.79 \mathrm{E}-02$ & $-4 \%$ & 0.54 & -0.36 & $-167 \%$ & 7.89 & 5.80 & $-26 \%$ \\
\hline Rapeseed oil, Dutch FOB NWE $1 \mathrm{~m}$ fwd EUR/MT & $1.34 \mathrm{E}-04$ & 4.24E-05 & $-68 \%$ & $1.91 \mathrm{E}-02$ & $1.44 \mathrm{E}-02$ & $-25 \%$ & 0.39 & 0.01 & $-99 \%$ & 30.30 & 8.33 & $-73 \%$ \\
\hline
\end{tabular}

Source: Own elaboration.

Note: (I) corresponds to the pre-crisis period 10.1995-12.2005 and (II) corresponds to the post crisis period 01.2006-02.2015. $\Delta \%$ is the percentage change from period (I) to (II).

Table 8 shows that all commodities, except oil, rapeseed oil and sugar, face a declining price trend during the pre-crisis period, evidenced by their negative average log price changes. Average price changes become, however, positive during the post crisis episode owing to the price recovery as experienced by agricultural commodities’ super cycle starting around 2000 (Erten \& Ocampo, 2013). In general, standard deviations increase during this period, too, especially for wheat (64\%) and corn (34\%). In the post crisis period, excess kurtosis, associated either with extremely small or large (return) values, increases for oil (38\%), soybean oil (23\%) and particularly for wheat (100\%). The remaining commodities experience a reduction of excess kurtosis, especially rapeseed (-73\%) and soybean oil (-49\%). From this point and for the subsequent analysis, we separate the agricultural commodities according to their suitability either for ethanol or biodiesel processing. Doing so, we account for substitutability effects among them. We build three four-variable systems, each containing log price changes of oil and three agricultural commodities. The 'Ethanol 
Group’ comprises oil, corn, wheat and sugar. The 'Biodiesel Group’ contains oil, soybean oil, rapeseed oil and palm oil. The last group combines a mix of both ethanol and biodiesel feedstocks, namely oil, corn, wheat and soybean. Corn, wheat and soybean, together with rice, account for almost $75 \%$ of the world's food production in terms of caloric content and are close substitutes in production and/or consumption. On a per-calorie basis their prices are not only similar, but also tend to co-move over time (Roberts and Schlenker, 2009). The addition of oil to every group allows us to measure (co)variation dynamics (direction and magnitude) among energy and agricultural markets.

\subsubsection{Development of market uncertainties in commodity markets}

To understand intensity and direction of volatility transmission dynamics among commodity markets, we depict the evolution of their respective conditional volatilities that are analysed by means of GARCH(1,1) specifications. Doing so, we obtain useful information on the timing and degree of market uncertainties, which allows to identify potentially destabilizing effects originating in commodity markets.

\section{Figure 9. Conditional GARCH variances of agricultural markets}

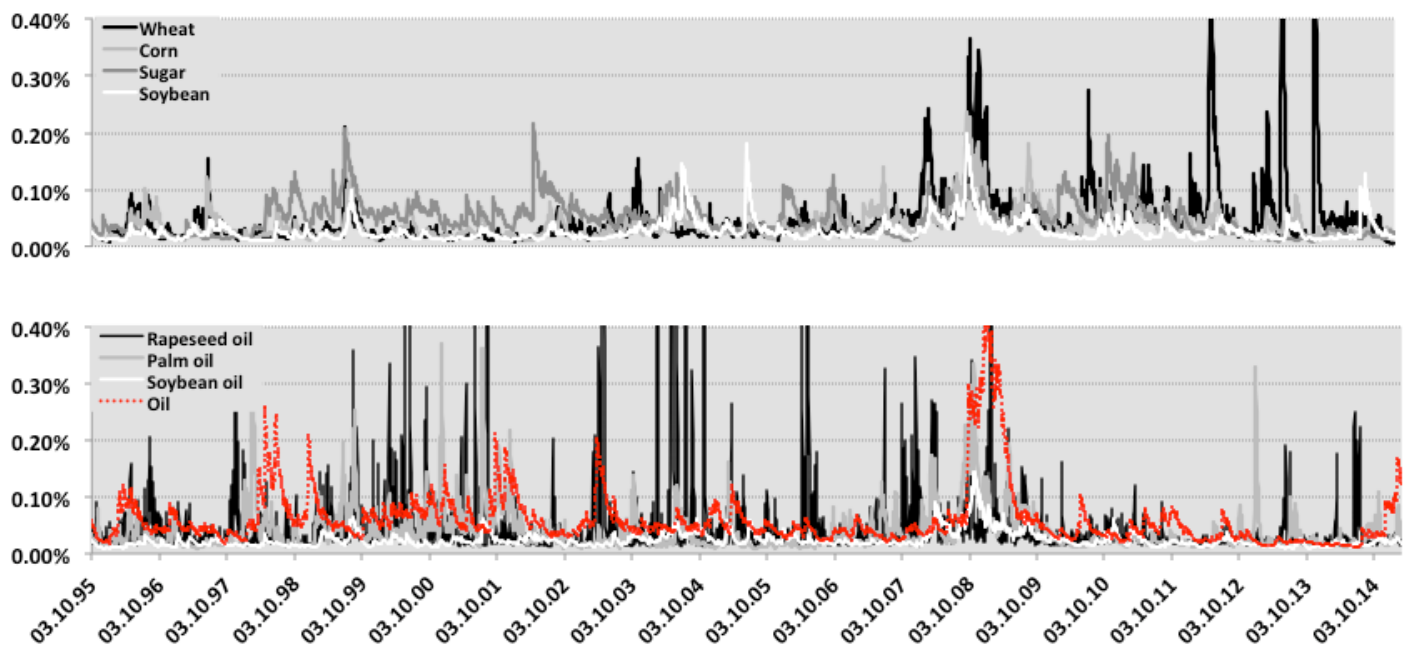

Source: Own elaboration.

Note: This graph exposes the development of the conditional variances estimated by means of a GARCH $(1,1)$ model for the set of agricultural commodities and oil, analyzed in this article.

One can observe from Figure 9 that wheat volatilities remain at low levels until the beginning of 2008. Subsequently, however, and especially between 2012 and 2013 the wheat market exhibits episodes of much larger volatility. Corn, soybean oil and soybean maintain low volatility levels before and after the financial turmoil of 
September 2008. There are only two episodes in mid 2004 and mid 2005 when soybean volatility experienced peak values. Similarly, the sugar market remains relatively tranquil along the entire period, with the exception of some isolated (highly volatile) events at the mid of 1999 and 2002. The oil market behaves volatile until the beginning of 2003 and especially during the last quarter of 2008. In the after crisis period, though, its price volatility is comparatively much lower. The palm oil and, particularly the rapeseed oil market, behave predominantly volatile during the decade preceding the food and financial crisis of 2007/2008. The international rapeseed oil market is relatively thin and subject to discretionary domestic policies of the major producing countries (EU, China and Canada). Based on information from the USDA Foreign Agricultural Service, ${ }^{30}$ between 1995 and 2015, on average, only 13\% of rapeseed oil's production was internationally traded. Additionally, it is also the main biodiesel feedstock in the EU and largely affected by its biofuel policies. Palm oil is a tree crop and its supply is less elastic than annual crops like soybean or rapeseed. It is therefore more responsive to unexpected demand or supply shocks. Between 1995 and 2005 its global production was, on average, only one third of its production in 2015. During the post crisis episode however, both rapeseed oil and palm oil markets stabilise and their volatility levels have been declining sizeably.

\subsubsection{Unconditional second order moment interactions among commodities}

Besides volatility levels, the degree of connection between markets is an important determinant of the direction and intensity of volatility spillovers across markets. Highly volatile but disconnected markets, for instance, are unlikely to transmit shocks. In order to assess the degree of integration among agricultural commodities, and between them and oil, we estimate their respective co-volatilities. Co-volatility, also known as co-kurtosis, shows the strength of linear dependence between second order moments of two random variables. It is positive by construction and ranges from 0 to 1. Building upon Ang et al. (2006), co-volatility between two commodity markets $i$ and $j$ reads as

30 Own estimates based on information from USDA Foreign Agricultural Service http://apps.fas.usda.gov/psdonline/psdQuery.aspx , acceded on March 5 ${ }^{\text {th }}, 2016$. 


$$
C_{i j}=\frac{\sum_{t}^{T}\left(r_{t, i}-\bar{\mu}_{i}\right)^{2}\left(r_{t, j}-\bar{\mu}_{j}\right)^{2}}{\sqrt{\left[\sum_{t}^{T}\left(r_{t, i}-\bar{\mu}_{i}\right)^{2}\right]^{2}} \sqrt{\left[\sum_{t}^{T}\left(r_{t, j}-\bar{\mu}_{j}\right)^{2}\right]^{2}}},
$$

where $r_{t, i}$ and $r_{t, j}$ are the $\log$ price chnages of commodities $i$ and $j$, and $\bar{\mu}_{i}$ and $\bar{\mu}_{j}$ are their respective sample means.

Table 9. Co-volatilities $C_{i j}$ for the commodity groups and periods

\begin{tabular}{|c|c|c|c|c|c|c|c|c|c|c|c|c|}
\hline \multirow[b]{2}{*}{ Ethanol G. } & \multicolumn{4}{|c|}{ Oil } & \multicolumn{4}{|c|}{ Corn } & \multicolumn{4}{|c|}{ Wheat } \\
\hline & $T$ & II & $\Delta \%$ & III & $T$ & II & $\Delta \%$ & III & $T$ & II & $\Delta \%$ & III \\
\hline Corn & 0.16 & 0.29 & $84 \%$ & 0.23 & \multicolumn{4}{|c|}{-} & \multicolumn{4}{|c|}{-} \\
\hline Wheat & 0.13 & 0.17 & $33 \%$ & 0.14 & 0.34 & 0.25 & $-25 \%$ & 0.26 & \multicolumn{4}{|c|}{ - } \\
\hline Sugar & 0.18 & 0.20 & $14 \%$ & 0.19 & 0.16 & 0.29 & $86 \%$ & 0.22 & 0.14 & 0.13 & $-5 \%$ & 0.11 \\
\hline Biodiesel G. & \multicolumn{4}{|c|}{ OII } & \multicolumn{4}{|c|}{ Soybean oil } & \multicolumn{4}{|c|}{ Rapeseed oil } \\
\hline Soybean ofl & 0.15 & 0.42 & $178 \%$ & 0.29 & - & & & & - & & & \\
\hline Rapeseed oil & 0.05 & 0.20 & $278 \%$ & 0.08 & 0.08 & 0.25 & $208 \%$ & 0.11 & - & & & \\
\hline Palm oil & 0.13 & 0.24 & $84 \%$ & 0.17 & 0.18 & 0.36 & $97 \%$ & 0.26 & 0.08 & 0.19 & $149 \%$ & 0.09 \\
\hline Mixed G. & \multicolumn{4}{|c|}{ Oil } & \multicolumn{4}{|c|}{ Corn } & \multicolumn{4}{|c|}{ Wheat } \\
\hline Soybean & 0.08 & 0.31 & $285 \%$ & 0.19 & 0.31 & 0.53 & $69 \%$ & 0.43 & 0.21 & 0.19 & $-10 \%$ & 0.17 \\
\hline
\end{tabular}

Source: Own elaboration. For further notes see Table 8.

Table 9 documents co-volatility estimates for the previously defined commodity groups. With some exceptions, the degree of integration among markets rose steeply during the post crisis period. However, despite the sharp increments, co-volatility levels still remain low to moderate ranging from 0.13 to 0.53 . When considering covolatilities between oil and the different biofuel feedstocks, vegetable oils stand out. Their degree of integration with oil rose in the post crisis episode by a factor of 3 and 4 for soybean oil and rapeseed oil, respectively. The development of the market integration between oil and grains, although not as steep as for vegetable oil, was also important, especially for corn and soybean. When considering dynamics only among agricultural markets, again, vegetable oils experienced the steepest increase of integration during the after crisis episode. Similarly, co-volatilities of corn with sugar and remarkably with soybean are also sizeable.

\subsection{Methodology}

The quantification of volatility/risk transmission in speculative markets has been attracting large interest in the finance literature, in particular, with the emergence of the great financial crisis. Among several interdependence measures that have been put forth recently (e.g. Acharya et al., 2010; Adrian and Brunnermeier, 2016), the spillover indices suggested in Diebold and Yilmaz (2009, 2012, 2014) are closest 
related to standard diagnostics commonly known from the literature on Vector Autoregressive (VAR) models (Lütkepohl, 2007). These statistics are basically forecast error variance decompositions derived from vector systems of realised volatilities. Fengler and Gisler (2015) point out that the concentration on variance spillovers neglects transmission channels operating through market covariations. Furthermore, the implementation of spillover indices in the spirit of Diebold and Yilmaz (2012, 2014) requires the specification of dynamically stable VARs over extended time periods comprising, say, one year of observations. While using moving windows of sample information may offer insights into time variation of market interdependence to some extent, such statistics are representative for medium sized time periods (a trading year, say). Motivated by the natural interest in more timely assessments of (local trends) in market interdependence, Fengler and Herwartz (2015) propose spillover indices in the spirit of the statistics in Diebold and Yilmaz (2012, 2014) but with reference to linearised multivariate GARCH processes in their BEKK form.

To measure cross-market volatility spillovers at the daily frequency, it appears natural to rely on a high frequency model specification such as MGARCH processes. Among the various representations of second order dynamics, ${ }^{31}$ the BEKK model (Engle and Kroner, 1995) appears particularly convenient as it allows a rich cross equation dynamic structure on the one hand. On the other hand it implies positive definite covariance patterns under mild conditions. Fengler and Herwartz (2015) derive measures of volatility propagation (transmission and reception) from a vector $\operatorname{ARMA}(1,1)$ model that is derived from the linear representation of a squared BEKK process (comprising squared returns and return cross-products). Their approach is briefly outlined next. ${ }^{32}$

A BEKK(1,1)-model reads as

$$
\begin{gathered}
r_{t}=\varepsilon_{t}=H_{t}^{1 / 2} \xi_{t}, \\
H_{t}=C C^{\prime}+F^{\prime} \varepsilon_{t-1} \varepsilon_{t-1}^{\prime} F+G^{\prime} H_{t-1} G,
\end{gathered}
$$

\footnotetext{
${ }^{31}$ see Bauwens et al. (2006) for a review treatment of multivariate GARCH models.

${ }^{32}$ see Fengler and Herwartz (2015) for a detailed discussion.
} 
where $r_{t}$ is an $N$-dimensional vector of log price changes, $\xi_{t} \sim N\left(0, I_{N}\right)$ is an $N$ dimensional innovation vector, and $H_{t}=E_{t-1}\left[\varepsilon_{t} \varepsilon_{t}^{\prime}\right]$ is the conditional covariance matrix of $r_{t}$. Throughout, the log price change of oil is the first element of $r_{t}$ in each commodity system. Model parameters are collected in parameter matrices $G, F$ and $C$, with the latter being lower triangular. Table 15 in Appendix 3 provides model estimates for the three commodity groups. To apply decomposition techniques that are common in the VAR literature, the BEKK model is reformulated in its so-called halfvec form describing the determinants of the non-trivial elements of $H_{t}$. With vech (·) denoting an operator that stacks the elements on and below the diagonal of an $N \times N$ square matrix into a $N^{*}=N(N+1) / 2 \times 1$ dimensional vector, the half-vec model is

$$
h_{t}=\omega+A \eta_{t-1}+B h_{t-1}
$$

where $h_{t}=\operatorname{vech}\left(H_{t}\right)$ and $\eta_{t}=\operatorname{vech}\left(\varepsilon_{t} \varepsilon_{t}^{\prime}\right)$. Moreover,

$$
\omega=\operatorname{vech}\left(C C^{\prime}\right), A=D_{N}^{+}(F \otimes F)^{\prime} D_{N} \text { and } B=D_{N}^{+}(G \otimes G)^{\prime} D_{N}
$$

with $D_{N}$ and $D_{N}^{+}$denoting the so-called duplication matrix and its generalised inverse, respectively. From the half-vec model it is convenient to define a linear innovation process as

$$
u_{t}=\eta_{t}-h_{t}
$$

The process $u_{t}$ has mean vector zero by construction, is free of serial correlation but heteroskedastic, $\Omega_{t}=E_{t-1}\left[u_{t} u_{t}^{\prime}\right]$. Hence, apart from second order heterogeneity $u_{t}$ can serve as an innovation process in a vector MA representation of the squared returns and their cross products in $\eta_{t}=\operatorname{vech}\left(\varepsilon_{t} \varepsilon_{t}^{\prime}\right)$. Fengler and Herwartz (2015) show that the vector MA representation of $\eta_{t}$ obtains

$$
\begin{aligned}
\eta_{t} & =\omega+A \eta_{t-1}+B\left(\eta_{t-1}-u_{t-1}\right)+u_{t} \\
& =\widetilde{\omega}+\Theta(L) u_{t} \\
& =\widetilde{\omega}+\Theta(L) \Omega_{t}^{1 / 2} \Omega_{t}^{-1 / 2} u_{t}
\end{aligned}
$$




$$
=\widetilde{\omega}+\Psi_{t}(L) v_{t}
$$

where $\mathcal{A}=A+B$, $\widetilde{\omega}=(I-\mathcal{A})^{-1} \omega$ and $\Theta(L)=(I-\mathcal{A} L)^{-1}(1-B L)$. Invertibility of $(1-\mathcal{A} L)$ holds under assumption that the spectral radius of $\mathcal{A}$ is less than unity (see Engle and Kroner, 1995). Noticing that the elements in $u_{t}$ are contemporaneously correlated, $\operatorname{Cov}\left[u_{t}\right]=\Omega_{t}$, the effects of orthogonalised shocks, denoted $v_{t}=$ $\Omega_{t}^{-1 / 2} u_{t}$, are retrieved from the model in (16) as

$$
\Psi_{t}(L)=\Theta(L) \Omega_{t}^{1 / 2}
$$

Unlike in standard VAR analysis ${ }^{33}$ the impulse response matrices $\Psi_{t}(L)$ are time varying, since they depend on the time local covariance decomposition $\Omega_{t}=$ $\Omega_{t}^{1 / 2} \Omega_{t}^{1 / 2}$, where $\Omega_{t}^{1 / 2}$ is the symmetric matrix constructed from the eigenvalues and (square roots of) eigenvalues of $\Omega_{t}$. Moreover, it is noteworthy that the covariance of $u_{t}$ depends on fourth order moments of the innovations $\xi_{t}$ since $u_{t}$ is the linear innovation of the squared MGARCH process. Fengler and Herwartz (2015) evaluate the fourth order moment structure and show that the half-vec model representation is convenient to solve the prediction problem for $\Omega_{t}$ to obtain spillover measures up to distinguished (forecast) horizons $D$. With the vector MA representation in (13) one can now define spillover measures in the spirit of Diebold and Yilmaz (2012, 2014) which apply at the daily frequency. Specifically, the proportion of the $D$-step ahead forecast-error variance of variable $i$, accounted for by innovations in variable $j$, is given by

$$
\lambda_{i j, t}^{(D)}=\frac{\sum_{d=1}^{D}\left(\psi_{i j}^{(t, d)}\right)^{2}}{\sum_{d=1}^{D} \sum_{j=1}^{N^{*}}\left(\psi_{i j}^{(t, d)}\right)^{2}}
$$

where $\psi_{i j}^{(t, d)}$ is a typical element of the d-step ahead effect matrix determined in time $t$ $\left(\Psi_{d, t}\right)$. To fully assess the result in (18) it is important to notice that the 'variables', comprising $u_{t}$ refer to squared returns (variances) and cross products of returns (covariances). Similar to the interpretation in Diebold and Yilmaz $(2012,2014)$ the $i$ -

\footnotetext{
${ }^{33}$ see Diebold and Yilmaz (2012) or Lütkepohl (2007).
} 
th (j-th) columns (rows) of the matrices $\Psi_{d, t}, d=1, \ldots, D$, quantify transmission (reception) patterns among variables $\eta_{i}$ and $\eta_{j}, i \neq j$.

\subsubsection{Volatility spillover indices}

By means of a linearised BEKK model we deliver subsequently spot measures of spillover dynamics between energy and agricultural markets, incorporating also covariance transmission channels. This methodology provides handy and timely (i.e. daily) tools to monitor the evolution of the degree of volatility transmission among agricultural markets and between them and other potentially destabilising markets like oil. The indices, besides providing information on which market is transmitting and which receiving volatility, in our particular case, also show the development of oil's contributions to uncertainties in (selected) agricultural markets, both at an aggregated level and for individual markets.

\subsubsection{General spillover indices}

The aggregated indices outlined in this section are generic in scope and deliver estimates of spillover dynamics without individualising transmission and reception volatility patterns. To show the scope of the indices and facilitate their interpretation, Figure 10 displays a schematic disaggregation of the information provided by them for the case of the 'Ethanol Group'.

Figure 10. Structure of $\Lambda_{t}$ for the ethanol group

\begin{tabular}{|c|c|c|c|c|c|c|c|c|c|c|c|}
\hline \multirow[b]{2}{*}{ To } & \multicolumn{10}{|c|}{ From } & \multirow[b]{2}{*}{$\begin{array}{c}\text { Receptions of } \\
\text { markets }(j) \\
\end{array}$} \\
\hline & Oil var. & Oil-Corn & Oil-Wheat & Oil-Sugar & Corn var. & Corn-Wheat & Corn-Sugar & Wheat var. & Wheat-Sugar & Sugar var & \\
\hline Oilvar. & & & & & & & & & & & 1 \\
\hline Oil-Corn & & & & & \multicolumn{6}{|c|}{ Agrlaulwrel cross trensmissiend/0il gross } & 2 \\
\hline Oil-Wheat & & Now & Dillov & & & & \multicolumn{2}{|c|}{ receptons } & & & 3 \\
\hline Oil-Sugar & & & & & & & & & & & 4 \\
\hline Corn var. & & & & & & & & & & & 5 \\
\hline Corn-Wheat & & & & & & & & & & & 6 \\
\hline Corn-Sugar & \multicolumn{4}{|c|}{ Oll cross transmissions/ } & & & & & & & 7 \\
\hline Wheat var. & \multicolumn{4}{|c|}{ Agrlcultural cross neceptions } & & & puever & yorr'sp & Wous & & 8 \\
\hline Wheat-Sugar & & & & & & & & & & & 9 \\
\hline Sugar var & & & & & & & & & & & 10 \\
\hline $\begin{array}{c}\text { Transmissions of } \\
\text { markets }(i)\end{array}$ & 1 & 2 & 3 & 4 & 5 & 6 & 7 & 8 & 9 & 10 & $\begin{array}{c}\text { Total Spillover } \\
\text { Index }\end{array}$ \\
\hline
\end{tabular}

Source: Own elaboration.

Note: This graph visualises the relation among the different (co)variation patterns in terms of spillover volatility transmissions from markets ' $i$ ' and rows collect volatility receptions of markets ' $j$ '. The four additional segments, separated by dashed lines, represent specific transmission and reception channels clustered in agricultural and energy (co)variation patterns.

The 'Total Spillover Index' (TSI) provides essentially information about the interdependence among all $i, j=1,2, \ldots, N^{*}$ markets up to horizon ' $D$ '. It is an 
aggregation, either column-wise or row-wise, of the $N^{*}=10$ individual (co)variances shown in Figure 10, i.e.

$$
S_{t}=\frac{\sum_{i, j=1, i \neq j}^{N^{*}} \lambda_{i j, t}}{N^{*}} \cdot 34
$$

Since we are only interested in cross-market dynamics, all 'own-effects', i.e., the diagonal elements of $\Lambda_{t}$ (Figure 10, in grey) are ruled out. Directional spillovers, complementarily, offer evidence on the primacy of the markets in terms of volatility transmission. These indices basically identify which markets are net volatility transmitters or net receptors. In Figure 10, each column (row) corresponds to directional spillover originating in (going to) specific variables in $\eta_{t}$. Formally, directional spillovers are described as

$$
T_{i, t}=\frac{\sum_{j=1, i \neq j}^{N^{*}} \lambda_{i j, t}}{N^{*}} \quad \text { and } \quad R_{j, t}=\frac{\sum_{i=1, j \neq i}^{N^{*}} \lambda_{i j, t}}{N^{*}} .
$$

Row 5 in Figure 10, for instance, contains all the spillovers received by the variance of corn $\left(\eta_{j t}, j=5\right)$ from the six covariances $\left(\eta_{i t}, i=2,3,4,6,7,9\right)$, and the remaining variances of oil, wheat and sugar $\left(\eta_{i t}, i=1,8,10\right)$. Similarly, column 5 collects the spillovers transmitted by corn's variance to the remaining (co)variances. Moreover, it is also meaningful to compute net transmission effects defined for the variables in $\eta_{t}$ as

$$
N_{i, t}=T_{i, t}-R_{i, t}
$$

For instance, the net transmission for the variance of corn $\left(\eta_{i t}, i=5\right)$ is the difference between the sum of elements in column 5 and row 5 . If the result is positive, corn's variance is a net volatility transmitter, whereas a negative outcome quantifies a net reception. By construction, $\sum_{i=1}^{N^{*}} N_{i, t}=0$.

\subsubsection{Measuring the influence of oil in agricultural markets}

As we have argued above, understanding the determinants of volatility in agricultural markets has been a topic of major interest in the international political agenda since the food crisis of 2007/2008. Against this background, the following indices aim at separating volatility spillovers between those originating in energy or agricultural

\footnotetext{
${ }^{34}$ To facilitate the notation of spillover indices the underlying forecast horizon $D$ is omitted from the notation.
} 
markets and identifying whether they spread to similar or different markets. Additionally, these indices are suitable to track oil's volatility transmissions to individual agricultural markets.

To define (group) specific measures of (co)variance spillovers we can decompose the space of total volatility spillovers as displayed in Figure 10 in four more specialised categories of indices.

1. The 'Oil own spillovers' index summarizes volatility originating and spilling over to (co)variations of the oil market

$$
S_{t}^{(O)}=\frac{\sum_{i, j=1, i \neq j}^{4} \lambda_{i j, t}}{N^{*}}
$$

2. Similarly, the index of 'Agricultural own spillovers' collects volatility spillovers originating and impacting only on (co)variations of agricultural markets

$$
S_{t}^{(A)}=\frac{\sum_{i, j=5, i \neq j}^{N^{*}} \lambda_{i j, t}}{N^{*}}
$$

3. The index of 'Agricultural cross transmissions/Oil cross receptions' collects volatility originating in agricultural and transmitting only to oil related (co)variations, i.e.

$$
T_{t}^{(A)}=R_{t}^{(O)}=\frac{\sum_{j=1}^{4} \sum_{i=5}^{N^{*}} \lambda_{i j, t}}{N^{*}} .
$$

4. Analogously, the index of 'Oil cross transmissions/Agricultural cross receptions' gathers volatility spilling from oil related (co)variations to agricultural markets

$$
T_{t}^{(O)}=R_{t}^{(A)}=\frac{\sum_{j=5}^{N^{*}} \sum_{i=1}^{4} \lambda_{i j, t}}{N^{*}}
$$

By construction,

$$
S_{t}^{(O)}+S_{t}^{(A)}+T_{t}^{(A)}+T_{t}^{(O)}=S_{t}^{(O)}+S_{t}^{(A)}+R_{t}^{(O)}+R_{t}^{(A)}
$$

The representation in (26) is convenient to identify volatility transmissions/receptions of particular markets. In our analysis, for instance, we define oil's total volatility transmissions to agricultural markets as $\left(S_{t}^{(O)}+T_{t}^{(O)}\right) / S_{t}$. Moreover, since oil 
market uncertainties potentially threaten the stability of agricultural and food prices, we are also concerned with measuring second order effects of oil on individual agricultural markets. For this purpose let $a_{\bullet}=\left\{a_{1}, a_{2}, a_{3}, a_{4}\right\}$ denote a set of indices of vectors $\eta_{t}$ referring to (co)variations involving a particular agricultural market ' $\bullet$ '. With regard to the 'Ethanol Group' we have, for instance, $\bullet \in\{$ corn, wheat, sugar $\}$, and, focussing on the wheat market $a_{\text {wheat }}=\{3,6,8,9\}$. To unravel the importance of (co)variations of oil prices in shaping the volatility reception of single agricultural markets we consider ratios of the following type $\tilde{R}_{t}^{\bullet}=R \mathrm{f} O_{t}^{\bullet} / R_{t}^{\bullet}$ where $R_{t}^{\bullet}$ is the total volatility received by market '•’ and, $R \mathrm{f} O_{t}^{\bullet}$ is the part transmitted from oil markets. In specific these indices read, respectively, as

$$
R \mathrm{f} O_{t}^{\bullet}=\frac{\sum_{i \in a .} \sum_{j=1, j \neq i}^{4} \lambda_{i j, t}}{N^{*}} \quad \text { and } \quad R_{t}^{\bullet}=\frac{\sum_{i \in a .} \sum_{j=1, j \neq i}^{N^{*}} \lambda_{i j, t}}{N^{*}}
$$

\subsection{Empirical findings}

We start the assessment of overall second order moment dynamics between major staple foods and oil by providing total spillovers $S_{t}$ as defined in (19). Complementarily, we deliver directional spillovers, which order markets according their degree of risk transmissions, spanning from net volatility transmitters to net receptors. In addition, we isolate the influence of oil on the uncertainty of agricultural markets, providing an aggregate estimate of oil risk transmissions to the different groups of biofuel feedstocks. Finally, we disaggregate the effects of oil on particular agricultural markets.

\subsubsection{Total spillovers}

The total spillover indices $S_{t}$ measure the linkage or interdependence among second order moments of agricultural markets, and between them and oil. Figure 11 shows that daily spillover dynamics are, on average, larger for the 'Mixed Group', followed by the Biodiesel and Ethanol groups. In October 2008, after the financial crisis outbreak, all indices reach maximum values (50\% - 60\%) and remain at higher levels (10\% - 40\%) than during the pre-crisis period, particularly between 2009 and 2012. Although for most of the period dynamics in the 'Biodiesel Group' remain lower than for the 'Mixed Group', biodiesel spillovers are remarkably higher between 2000 and 2004, coinciding with periods of high price volatility in vegetable oil markets. 
Figure 11. Evolution of TSI
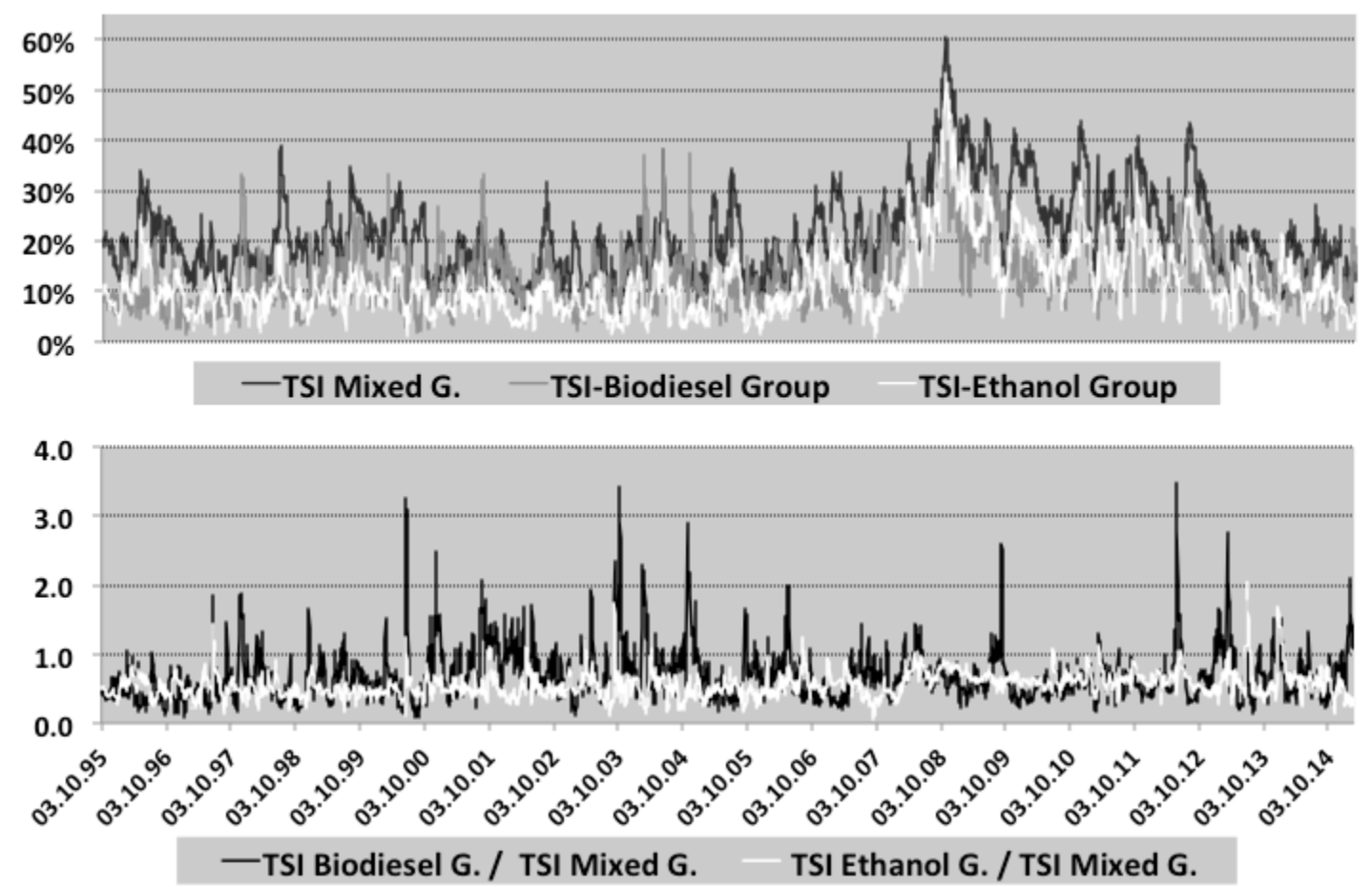

Source: Own elaboration.

Note: The upper graph depicts TSIs for the three commodity groups as measures of connection among markets. The lower graph offers a different perspective, showing the relative size of the group spillover dynamics vis-à-vis the TSI of the Mixed Group.

The close substitutability (in production and consumption) among corn, wheat and soybean reflects a close integration among these markets, yielding consequently the largest TSI for the 'Mixed Group'. Since there is a weaker relation between sugar and corn, and sugar and wheat (see Table 9), the TSI of the 'Ethanol Group' is the lowest on average. The 'Biodiesel Group' shows an intermediate TSI level, owing particularly to the increased interdependence among soybean oil, rapeseed oil and palm oil during the post crisis episode. Additionally, the relation between oil and the vegetable oils has sizeably increased during the same period, coinciding with a growing use of oilseeds for biofuels. Soybean oil, for instance, is the main feedstock for biodiesel in the US, Argentina and Brazil, whereas palm oil is widely used for biodiesel in countries like Indonesia and Thailand, all of them important biodiesel producers (see Appendix 1). Moreover, both vegetable oils are extensively commercialised in international markets and therefore more exposed to oil market swings. On average, between 1995 and 2015, 71\% of palm oil and 25\% of soybean oil 
production was exported. ${ }^{35}$ Although not widely traded, rapeseed oil is the main biofuel feedstock in the EU, an important biodiesel producing and consuming region. Rapeseed oil's market is consequently affected largely by European biofuel policies rather than by international shocks.

\subsubsection{Directional spillovers}

The 'Directional Spillover Indices' $T_{i, t}$ and $R_{j, t}$ defined in (20) allow not only to draw conclusions about the development of the linkages among markets, but also to separate the effects by commodity type and patterns of variations and covariations.

Figure 12. Net directional spillovers
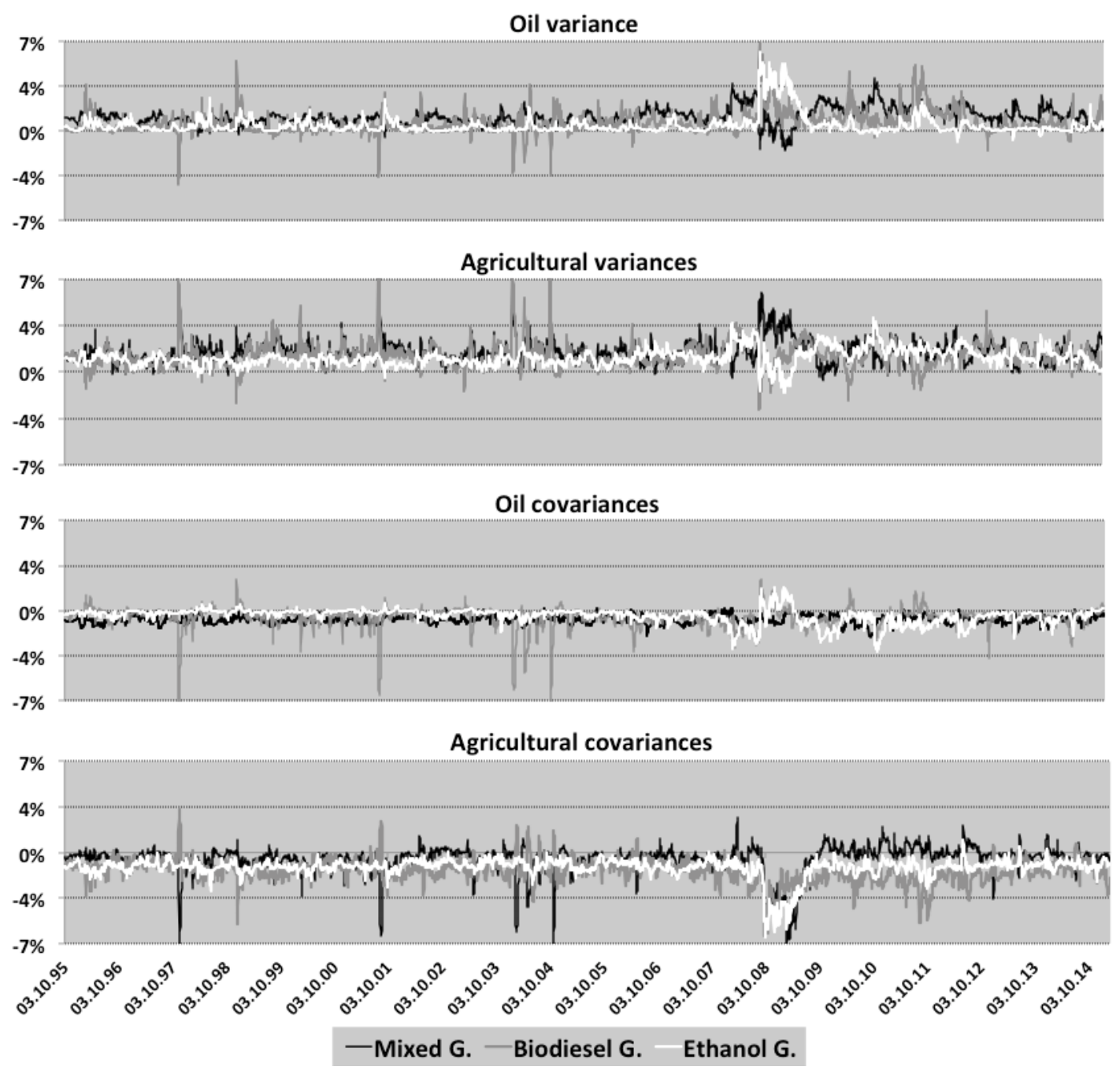

Source: Own elaboration.

Note: This graph describes the net volatility transmission effects of (co)variation patterns separated by type of commodity, namely agricultural and non-agricultural. Net transmissions are calculated as

35 Own estimates based on information from USDA Foreign Agricultural Service http://apps.fas.usda.gov/psdonline/psdQuery.aspx , acceded on March 5 ${ }^{\text {th }}, 2016$. 
the difference of what a particular (co)variance transmits vis-à-vis what it receives. Positive values represent net transmissions, while negative ones denote net volatility receipts.

Figure 12 depicts the net directional effects of variances and covariances for oil and agricultural commodities. In general, for the three commodity groups, oil and agricultural variances have been net volatility transmitters, whereas, in particular, agricultural covariances were mainly volatility receptors. Between the third quarter of 2008 and the first half of 2009, however, oil covariances turned into net transmitters while agricultural variances became net receptors of price volatility. Until December 2005, (co)variation patterns in the 'Ethanol Group' and 'Mixed Group’ were mainly oil volatility receptors, though at a moderate level. Since then, they turned into net transmitters, again excluding the period between September 2008 and June 2009. During these months agricultural markets were severely exposed to oil market uncertainties adding more volatility to already unstable food prices. After this period, agricultural commodities from the 'Ethanol Group' and 'Mixed Group' start transmitting volatility to their respective covariances with oil, driven mainly by the relatively high price volatility levels of wheat. Vegetable oils included in the 'Biodiesel Group', behaved as net volatility transmitters until September 2008 governed by large instability in rapeseed oil and palm oil markets. Between the last quarter of 2008 and the first half of 2012 though, they turned into net oil volatility receptors. The rapeseed oil market was particularly prompt to oil market shocks owing its large degree of co-volatility with oil during the post crisis episode.

Table 10 shows a summary of the average net directional volatility spillovers for the three groups of commodities, distinguishing pre and post crisis developments. As such, it provides complementary information to Figure 12. Negative numbers correspond to net volatility receptors, while positive numbers refer to net transmitters. It is important to notice that the net effects sum up to zero, implying that what one variable transmits (either through variances or covariances), another one receives. On average, covariation patterns represent two thirds of the total spillover indices providing a wealth of information on volatility spillover patterns (see Fengler and Gisler (2015)). Covariances are generally net volatility receptors while variances are net transmitters. In the 'Ethanol Group', wheat and oil are the predominant volatility transmitting markets during the post crisis period. Risk transmissions from the corn market remain at an intermediate level. Although sugar also transmits some volatility, 
compared with the other markets its spillovers are the lowest, while its covariances are sizeable volatility receptors. Analogously, for the ‘Biodiesel Group’ soybean oil

Table 10. Average directional spillover indices, all groups

\begin{tabular}{|c|c|c|c|c|c|c|c|c|c|}
\hline \multirow{2}{*}{$\begin{array}{l}\text { Groups } \\
\text { Ethanol }\end{array}$} & \multicolumn{3}{|c|}{ Transmission } & \multicolumn{3}{|c|}{ Reception } & \multicolumn{2}{|c|}{ Net } & \multirow[b]{2}{*}{$\Delta \%$} \\
\hline & 1 & II & $\Delta \%$ & $\mathrm{I}$ & II & $\Delta \%$ & $I$ & II & \\
\hline Oil var. & 0.0046 & 0.0111 & $142 \%$ & 0.0013 & 0.0051 & $282 \%$ & 0.0032 & 0.0060 & $85 \%$ \\
\hline Oil - Corn & 0.0084 & 0.0156 & $85 \%$ & 0.0097 & 0.0190 & $96 \%$ & -0.0012 & -0.0034 & $171 \%$ \\
\hline Oil - Wheat & 0.0090 & 0.0162 & $81 \%$ & 0.0091 & 0.0168 & $85 \%$ & -0.0001 & -0.0006 & $365 \%$ \\
\hline Oil - Sugar & 0.0032 & 0.0079 & $145 \%$ & 0.0034 & 0.0104 & $205 \%$ & -0.0002 & -0.0025 & $1176 \%$ \\
\hline Corn var. & 0.0132 & 0.0209 & $58 \%$ & 0.0106 & 0.0170 & $60 \%$ & 0.0026 & 0.0038 & $49 \%$ \\
\hline Corn - Wheat & 0.0164 & 0.0255 & $55 \%$ & 0.0246 & 0.0330 & $34 \%$ & -0.0081 & -0.0075 & $-8 \%$ \\
\hline Corn - Sugar & 0.0075 & 0.0132 & $76 \%$ & 0.0091 & 0.0173 & $91 \%$ & -0.0016 & -0.0041 & $164 \%$ \\
\hline Wheat var. & 0.0139 & 0.0221 & $59 \%$ & 0.0092 & 0.0137 & $49 \%$ & 0.0047 & 0.0084 & $78 \%$ \\
\hline Wheat - Sugar & 0.0080 & 0.0138 & $72 \%$ & 0.0087 & 0.0155 & $79 \%$ & -0.0006 & -0.0017 & $174 \%$ \\
\hline Sugar var. & 0.0027 & 0.0064 & $136 \%$ & 0.0014 & 0.0048 & $257 \%$ & 0.0014 & 0.0016 & $16 \%$ \\
\hline Total Spillover Index & $\mathbf{0 . 0 8 7 0}$ & 0.1527 & & 0.0870 & 0.1527 & & - & - & \\
\hline \multicolumn{10}{|l|}{ Biodiesel } \\
\hline Oil var. & 0.0080 & 0.0151 & $89 \%$ & 0.0043 & 0.0059 & $38 \%$ & 0.0037 & 0.0091 & $149 \%$ \\
\hline Oil - Soybean oil & 0.0087 & 0.0174 & $101 \%$ & 0.0109 & 0.0192 & $77 \%$ & -0.0022 & -0.0018 & $-20 \%$ \\
\hline Oil - Rapeseed oil & 0.0090 & 0.0110 & $22 \%$ & 0.0110 & 0.0148 & $34 \%$ & -0.0020 & -0.0038 & $87 \%$ \\
\hline Oil - Palm oil & 0.0102 & 0.0136 & $33 \%$ & 0.0105 & 0.0136 & $30 \%$ & -0.0002 & 0.0001 & $-122 \%$ \\
\hline Soybean oil var. & 0.0118 & 0.0213 & $81 \%$ & 0.0087 & 0.0121 & $40 \%$ & 0.0031 & 0.0092 & $194 \%$ \\
\hline Soybean oil - Rapeseed oil & 0.0103 & 0.0142 & $38 \%$ & 0.0145 & 0.0213 & $46 \%$ & -0.0042 & -0.0071 & $68 \%$ \\
\hline Soybean oil - Palm oil & 0.0138 & 0.0190 & $38 \%$ & 0.0175 & 0.0218 & $24 \%$ & -0.0037 & -0.0027 & $-27 \%$ \\
\hline Rapeseed oil var. & 0.0111 & 0.0094 & $-15 \%$ & 0.0080 & 0.0120 & $51 \%$ & 0.0031 & -0.0027 & $-186 \%$ \\
\hline Rapeseed oil - Palm oil & 0.0123 & 0.0127 & $3 \%$ & 0.0158 & 0.0197 & $24 \%$ & -0.0035 & -0.0070 & $100 \%$ \\
\hline Palm oil var. & 0.0145 & 0.0166 & $14 \%$ & 0.0085 & 0.0098 & $16 \%$ & 0.0060 & 0.0068 & $12 \%$ \\
\hline Total Spillover Index & 0.1096 & 0.1502 & & 0.1096 & 0.1502 & & - & - & \\
\hline \multicolumn{10}{|l|}{ Mixed } \\
\hline Oil var. & 0.0054 & 0.0125 & $134 \%$ & 0.0014 & 0.0055 & $277 \%$ & 0.0039 & 0.0071 & $81 \%$ \\
\hline Oil - Corn & 0.0167 & 0.0251 & $50 \%$ & 0.0140 & 0.0229 & $64 \%$ & 0.0027 & 0.0021 & $-21 \%$ \\
\hline Oil - Wheat & 0.0103 & 0.0189 & $83 \%$ & 0.0098 & 0.0171 & $75 \%$ & 0.0005 & 0.0018 & $242 \%$ \\
\hline Oil - Soybean & 0.0108 & 0.0145 & $35 \%$ & 0.0153 & 0.0247 & $61 \%$ & -0.0045 & -0.0102 & $124 \%$ \\
\hline Corn var. & 0.0299 & 0.0398 & $33 \%$ & 0.0162 & 0.0225 & $39 \%$ & 0.0137 & 0.0173 & $26 \%$ \\
\hline Corn - Wheat & 0.0248 & 0.0368 & $48 \%$ & 0.0274 & 0.0363 & $32 \%$ & -0.0026 & 0.0005 & $-119 \%$ \\
\hline Corn - Soybean & 0.0255 & 0.0303 & $19 \%$ & 0.0362 & 0.0430 & $19 \%$ & -0.0107 & -0.0127 & $19 \%$ \\
\hline Wheat var. & 0.0173 & 0.0277 & $60 \%$ & 0.0104 & 0.0145 & $40 \%$ & 0.0070 & 0.0132 & $90 \%$ \\
\hline Wheat - Soybean & 0.0160 & 0.0207 & $29 \%$ & 0.0257 & 0.0327 & $27 \%$ & -0.0097 & -0.0121 & $25 \%$ \\
\hline Soybean var. & 0.0178 & 0.0176 & $-1 \%$ & 0.0181 & 0.0248 & $37 \%$ & -0.0004 & -0.0072 & $1923 \%$ \\
\hline Total Spillover Index & 0.1745 & 0.2440 & & 0.1745 & 0.2440 & & - & - & \\
\hline
\end{tabular}

Source: Own elaboration. For further notes see Table 8.

and oil are the largest volatility transmitting markets, followed by palm oil. Though palm oil is the most important volatility transmitter during the pre-crisis period, its net transmissions remain almost unchanged after the crisis. This situation points to a more neutral role of palm oil in the after crisis period when its (conditional) volatility declines (see Figure 9). Rapeseed oil is a net volatility receptor in this group, particularly from the soybean oil and palm oil markets. Finally, in the 'Mixed Group', 
while corn and wheat are the largest volatility transmitting markets, oil's volatility transmissions remain moderate. The soybean market fully receives volatility transmissions from the rest of markets in this group.

Owing to the natural dependence of modern agriculture from oil as a key input and as an important determinant of biofuel production, it is unlikely that any shock originating in agricultural markets affects oil prices. Since oil covariances represent linear relations with agricultural markets, the likely channel of price volatility transmission flows from oil variation patterns through both the oil and the agricultural components of the covariances. However, agricultural variation patterns impact only through the agricultural component and not through oil. Moreover, the strength of the volatility transmissions is related to the degree of market integration.

\subsubsection{Composite spillover indices and the contribution of oil}

Based on the directional spillovers discussed in the previous section we build new composite indices, which separate oil's effects from volatilities originating in own agricultural markets. Additionally, we show the distinct indices to shed some light on how the relation between oil and agricultural markets has evolved, especially after the food and financial crisis of 2007/2008. We begin providing a global measure of the contribution of oil volatility to the different groups of commodities and separate subsequently oil's effects on individual agricultural markets.

Figure 13 illustrates the development of the spillover indices defined in (22) - (25) for

the three commodity groups. Indices $S_{t}^{(O)}$ and $S_{t}^{(A)}$ gather volatility initiating and spreading to own oil and agricultural markets, respectively. As depicted by Figure 13, own agricultural volatility spillovers account for ca. $60 \%$ of TSIs, and are particularly significant for the 'Mixed Group'. Although own oil volatility spillovers account also for a large share (20\%), they are comparatively lower. Collecting volatility originating in oil and spilling over to agricultural markets, $T_{t}^{(O)}$ is the most relevant index in our analysis. It is remarkably strong along the entire sample period for the 'Biodiesel Group', suggesting more vulnerability of vegetable oil markets to oil shocks in comparison with grains and sugar. 
Figure 13. Development of own/cross contributions of oil and agricultural spillovers as shares of the TSI

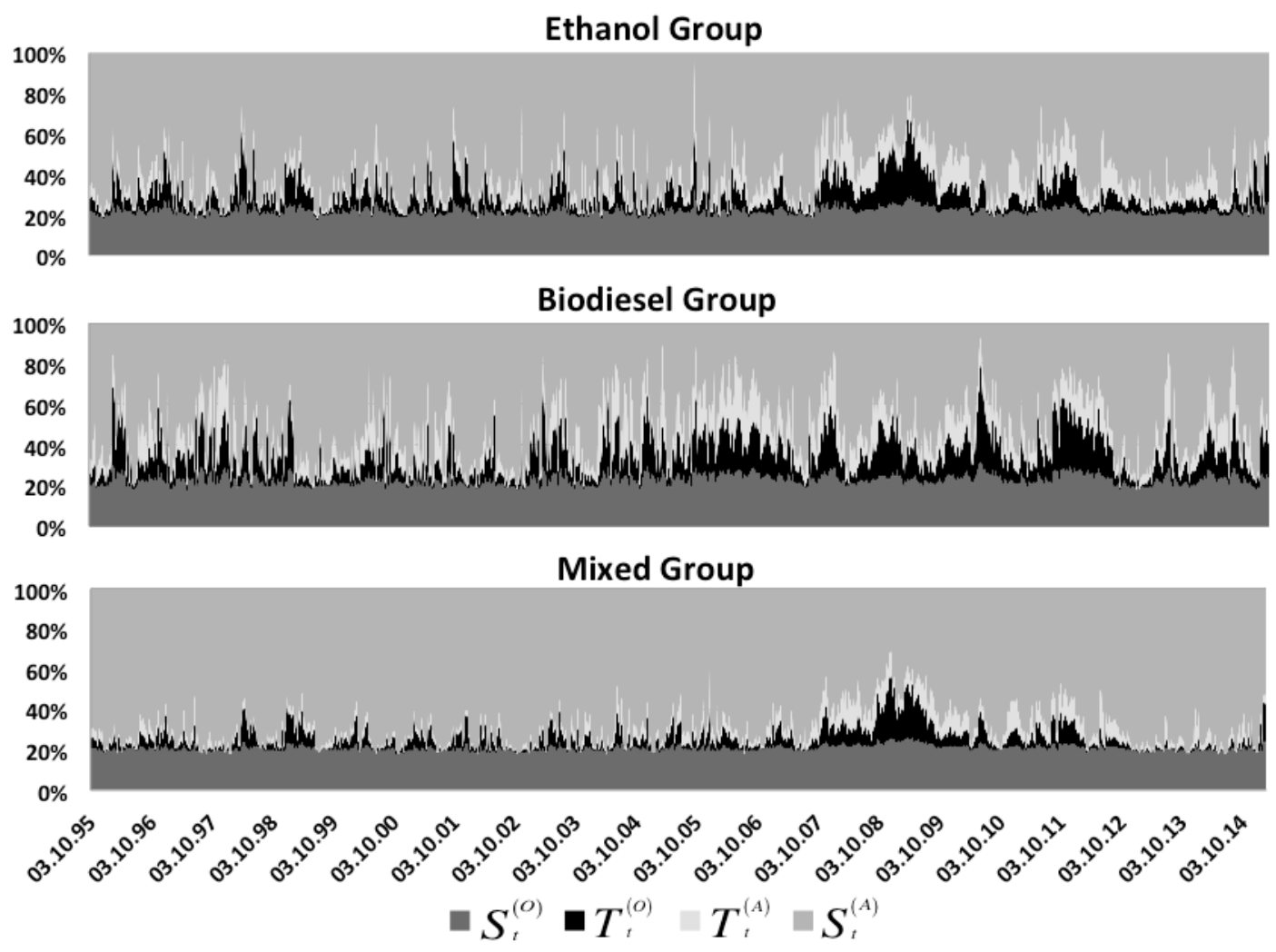

Source: Own elaboration.

Note: This graph depicts the evolution of the four components of the TSI portrayed in Figure 10, and defined in (22) - (25), for each of the commodity groups. It shows how the composition of TSI, as shares of it, has evolved during the sample period, capturing the periods of high and low oil spillover transmissions to agricultural markets $\left(T_{t}^{(O)}\right)$.

Complementarily, Table 11 provides not only average values for the spillover indices shown in Figure 13, but also defines the sum of indices $T_{t}^{(O)}$ and $S_{t}^{(O)}$ as the total

Table 11. Average own/cross contributions of oil and agricultural spillovers as shares of the TSI

\begin{tabular}{|c|c|c|c|c|c|c|}
\hline \multirow{2}{*}{\multicolumn{2}{|c|}{ Period }} & \multirow[b]{2}{*}{$\begin{array}{l}\text { Total contribution of oil } \\
\qquad T_{t}^{(0)}+S_{t}^{(0)}\end{array}$} & \multicolumn{2}{|c|}{ Oil market => } & \multicolumn{2}{|c|}{ Agricultural markets => } \\
\hline & & & $\begin{array}{c}\text { Agr. markets } \\
T_{t}^{(0)}\end{array}$ & $\begin{array}{c}\text { Own market } \\
S_{t}^{(0)}\end{array}$ & $\begin{array}{c}\text { Oil market } \\
T_{t}^{(A)}\end{array}$ & $\begin{array}{l}\text { Own markets } \\
\qquad S_{t}^{(A)}\end{array}$ \\
\hline \multirow{3}{*}{ Ethanol G. } & 1 & $28 \%$ & $7 \%$ & $21 \%$ & $6 \%$ & $66 \%$ \\
\hline & II & $31 \%$ & $9 \%$ & $22 \%$ & $10 \%$ & $59 \%$ \\
\hline & $\Delta \%$ & $11 \%$ & $20 \%$ & $3 \%$ & $82 \%$ & $-10 \%$ \\
\hline \multirow{3}{*}{ Biodiesel G } & $\mathrm{I}$ & $33 \%$ & $11 \%$ & $22 \%$ & $10 \%$ & $57 \%$ \\
\hline & 511 & $38 \%$ & $15 \%$ & $23 \%$ & $13 \%$ & $49 \%$ \\
\hline & $\Delta \%$ & $15 \%$ & $33 \%$ & $6 \%$ & $25 \%$ & $-13 \%$ \\
\hline \multirow{3}{*}{ Mixed G. } & 1 & $25 \%$ & $5 \%$ & $20 \%$ & $3 \%$ & $72 \%$ \\
\hline & II & $27 \%$ & $6 \%$ & $21 \%$ & $7 \%$ & $66 \%$ \\
\hline & $\Delta \%$ & $11 \%$ & $42 \%$ & $4 \%$ & $129 \%$ & $-9 \%$ \\
\hline
\end{tabular}

Source: Own elaboration. 
contribution of oil to volatility spillovers in agricultural markets. It is worth to mention that we consider oil's contributions to own covariances because they characterise relations between oil and agricultural markets. Results show that, on average, approximately one third of volatility spillovers in agricultural markets might be attributed to oil. Moreover, for all the three groups the increment of spillover dynamics between energy and food markets $\left(T_{t}^{(A)}, T_{t}^{(O)}\right)$ points to a stronger linkage between these markets after the crisis outbreak.

Figure 14. Development of the contributions of oil to volatility spillovers in agricultural markets
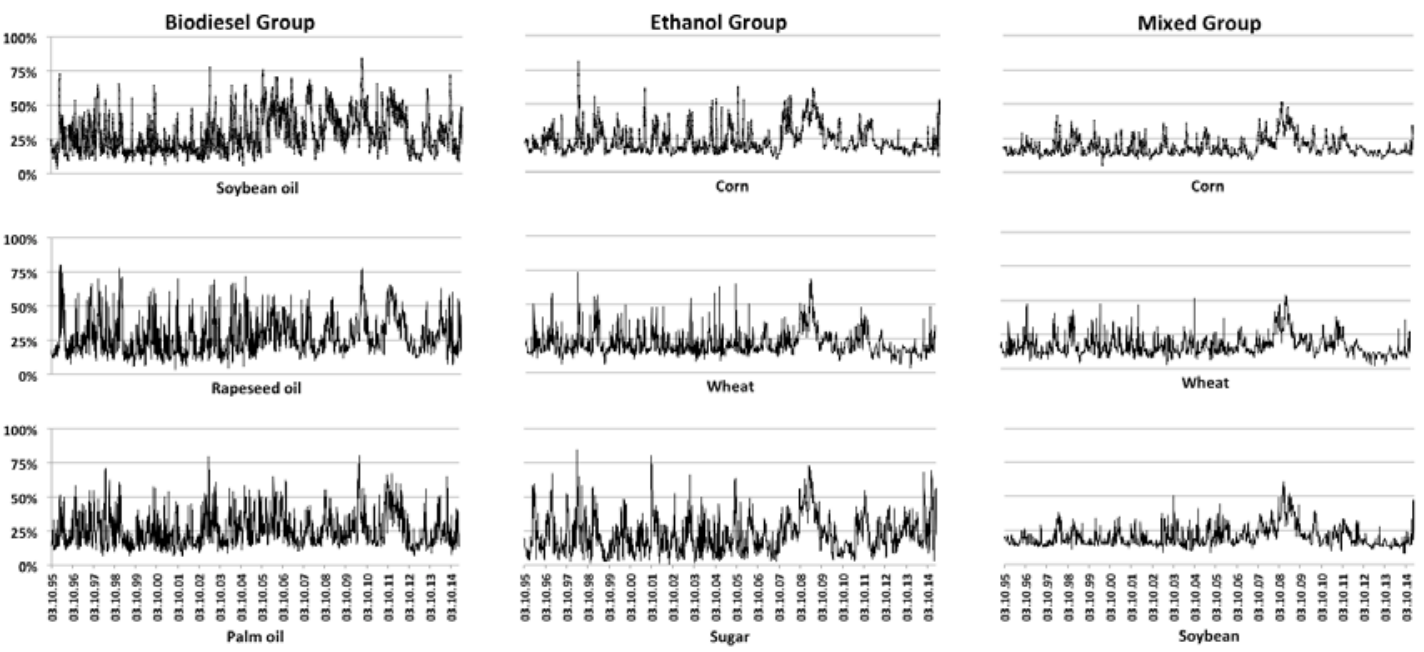

Source: Own elaboration.

Note: This graph illustrates the variability and levels of the contributions of oil to the total spillover dynamics of the different individual agricultural markets during the sample period. Every column gathers the set of agricultural commodities corresponding to the biodiesel, ethanol and mixed groups, respectively.

Figure 14 portrays the contribution of oil to volatility spillovers in individual agricultural markets. One can observe that oil effects on vegetable oil markets are remarkably intense and show the highest variability of the three commodity groups, ranging between $3 \%$ and $85 \%$. Sugar is the main oil volatility receptor within the 'Ethanol Group' and more prone to oil shocks if compared with corn and wheat markets. Its variability is slightly higher than for vegetable oils, fluctuating from $0.5 \%$ to 85\%. Although the 'Mixed Group' exhibits the highest spillover dynamics of the three groups, its oil spillover contributions to the different agricultural markets -as shares of TSI- and its variability $(2 \%-61 \%)$ are the lowest. Spillover dynamics in this group are originating predominantly in agricultural markets. The linkage between 
corn and soybean is remarkably strong in this group during the after crisis episode (see Table 9).

In addition, Table 12 provides average values for the series presented in Figure 14. One can observe that after the crisis soybean, soybean oil and sugar are particularly affected by shocks from the oil market. In the same period, markets like

Table 12. Average contributions of oil to volatility spillovers in agricultural markets

\begin{tabular}{|c|c|c|c|c|}
\hline \multirow{2}{*}{ Ethanol G. } & \multirow[t]{2}{*}{ Period } & \multicolumn{3}{|c|}{ Oil => Agricultural markets } \\
\hline & & Corn & Wheat & Sugar \\
\hline & I & $22 \%$ & $21 \%$ & $20 \%$ \\
\hline & II & $24 \%$ & $22 \%$ & $24 \%$ \\
\hline & $\Delta \%$ & $11 \%$ & $4 \%$ & $22 \%$ \\
\hline \multirow[t]{4}{*}{ Biodiesel G. } & & Soybean oil & Rapeseed oil & Palm oil \\
\hline & $\mathbf{I}$ & $24 \%$ & $26 \%$ & $25 \%$ \\
\hline & II & $34 \%$ & $30 \%$ & $26 \%$ \\
\hline & $\Delta \%$ & $42 \%$ & $16 \%$ & $7 \%$ \\
\hline \multirow[t]{4}{*}{ Mixed G. } & & Corn & Wheat & Soybean \\
\hline & $\mathbf{I}$ & $17 \%$ & $16 \%$ & $19 \%$ \\
\hline & II & $20 \%$ & $17 \%$ & $22 \%$ \\
\hline & $\Delta \%$ & $14 \%$ & $9 \%$ & $20 \%$ \\
\hline
\end{tabular}

Source: Own elaboration.

corn and rapeseed oil experienced an intermediate increase of their exposure to oil, whereas the degree of exposure for (co)variations of wheat and palm oil prices remain unchanged. It is important to notice that although the 'Mixed Group' shows the lowest values of oil's volatility contribution to agricultural markets, they are precluded by the larger spillover dynamics among the agricultural commodities. However, when measuring oil spillovers in absolute terms, their levels are (moderately) larger than for the other groups. Therefore one may conclude that for grains, smoothing wheat prices through a sound stockholding policy, for instance, would be a more effective price stabilising measure as trying to prevent oil shocks. Nonetheless, still between one fifth and one third of uncertainties in important staple food markets originate and spill from the oil market. Therefore, managing oil risk transmissions remains an important task to achieve stable food markets. The decision on how to stabilise food prices, whether through interventions on the oil or on specific agricultural markets, is likely country specific. It depends, inter alia, on the institutional framework, resource availability and political economic considerations. 


\subsubsection{Integration between oil and agricultural markets}

We continue the market integration assessment by offering an additional visual and formal measure of correlation, which confirms an enhanced interdependence between agricultural markets and oil since 2006.

Figure 15. Synchrony between the conditional GARCH variance of oil and its average contribution to the TSI

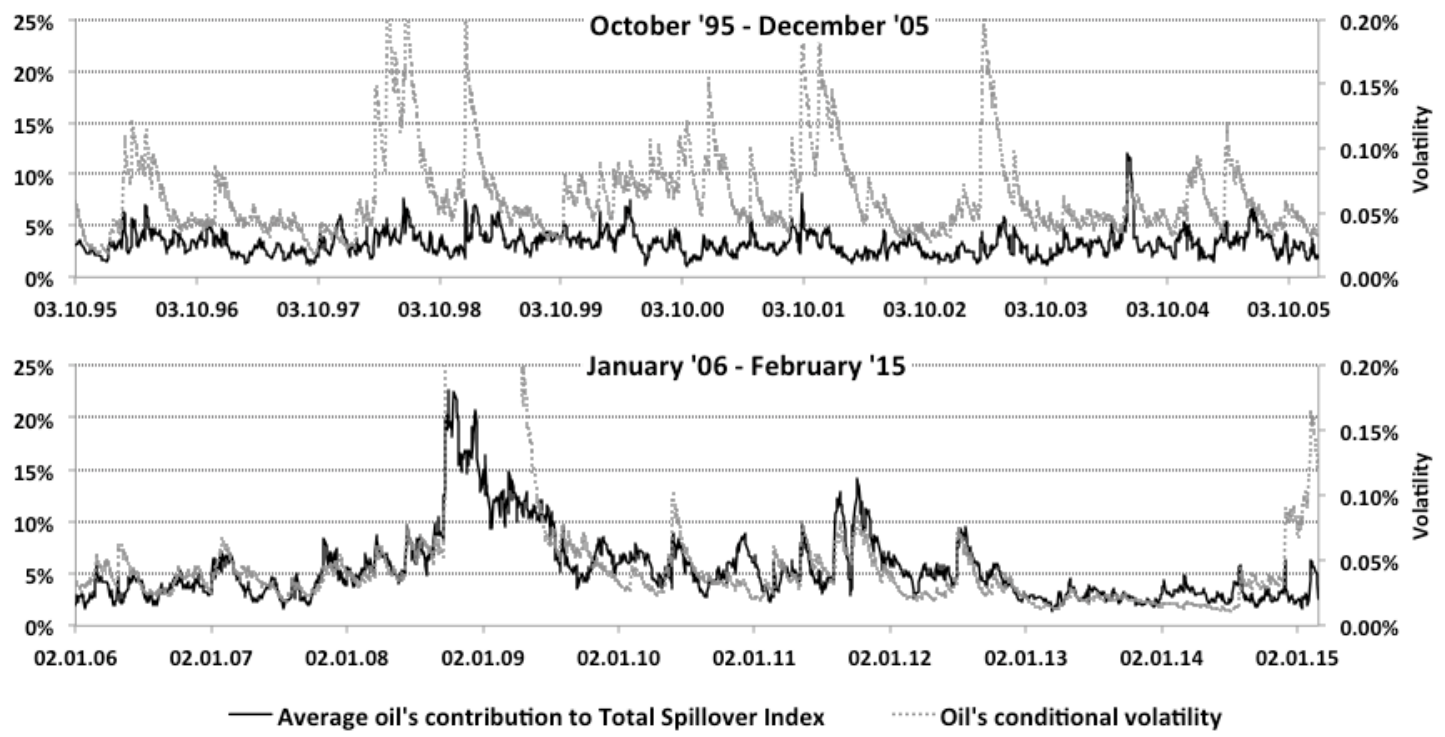

Source: Own elaboration.

Note: The average oil's contribution to the 'Total Spillover Index' is an average of the individual contributions of oil in each of the three commodity groups. The conditional volatility of oil was estimated by means of a univariate $\operatorname{GARCH}(1,1)$ model as already shown in Figure 9.

The upper graph of Figure 15 reveals that although oil's conditional volatility was sizeable during the pre crisis period, its contribution to TSIs remained relatively low. It was particularly high during 1998, the end of 2001 and the beginning of 2003. However, since the beginning of 2006, oil’s synchronisation with agricultural markets has been intensified. One can observe more proportionality between the level of oil volatility and the relative size of its contribution to second order price transmission in systems of oil and agricultural markets. Unlike during the previous period, states of higher oil volatility are coupled more frequently with larger contributions of oil to second order moment spillovers. Since oil markets are intrinsically volatile, stronger linkages with agricultural commodities render more uncertainty for food producers and consumers, a situation which may in turn lead to social and political unrest. 
Table 13. Rank correlations between oil's conditional volatility and its contributions to TSI

\begin{tabular}{|c|c|c|c|}
\hline \multirow{2}{*}{ Groups } & \multicolumn{2}{|c|}{ Periods } & \multirow{2}{*}{$\Delta \%$} \\
\hline & $I$ & II & \\
\hline Ethanol & 0.36 & 0.60 & $67 \%$ \\
\hline Biodiesel & 0.19 & 0.55 & $189 \%$ \\
\hline Mixed & 0.19 & 0.67 & $253 \%$ \\
\hline Average & 0.34 & 0.68 & $100 \%$ \\
\hline
\end{tabular}

Source: Own elaboration.

Note: This table provides Spearman's rank correlation coefficients between oil's conditional volatility and oil's contribution to the 'Total Spillover Index' for the three commodity groups, including the average contribution of them as presented in Figure 15. For further notes see Table 8.

As complementary information to Figure 15, Table 13 provides rank correlations as measures of the degree of integration between oil and agricultural markets. In the after crisis episode, one can observe that the rank correlation between oil's (conditional) volatility and its time contribution to agricultural markets rose by a factor of two. Owing to the larger volatility transmissions (in absolute terms) of oil to the agricultural markets included in the 'Mixed Group', its rank correlation experienced accordingly the largest increase of the three groups. The rank correlation coefficients for the 'Ethanol Group' and the 'Biodiesel Group', though lower, also exhibited a steep increase after the crisis. The significant and sharp increments of all rank correlation coefficients highlight a tightening relation between agricultural commodities and oil over the last decade.

\subsection{Conclusions}

This article provides timely measures to describe the development of volatility spillovers between oil and agricultural commodities, which are not only important staple foods, but also commonly used biofuel feedstocks (sugar, corn, wheat, soybean, soybean oil, rapeseed oil, and palm oil). In order to shed light on the evolution of the degree of interdependence between oil and food commodities, we separate the analysis into two periods: before (October, 1995 to December, 2005) and after (January, 2006 to February, 2015) the 2007/2008 global financial crisis. Starting with a simple measure of linear dependence between second order moments, we show that in the after crisis period the degree of co-volatility among vegetable oils rises considerably, as well as their linkages with oil. Co-volatilities of grains (except soybean) and sugar, on the other hand, remain comparatively more stable and 
moderate. We derive subsequently indices as proposed by Fengler and Herwartz (2015) to measure the degree of volatility spillovers among agricultural commodities and oil. This approach grounds on linearised multivariate GARCH processes in their BEKK form. Hence, different from the measures put forth by Diebold and Yilmaz (2009, 2012, 2014), it allows for on-time volatility spillovers monitoring, and incorporates rich (co)variance dynamics as suggested by Fengler and Gisler (2015). From the three groups of commodities under consideration, the 'Mixed Group' shows the strongest spillover dynamics, owing to the strong risk transmission between corn and soybean markets. We find additionally that oil, wheat and soybean oil markets are predominantly volatility transmitters, particularly during the post crisis period. Corn and palm oil remain moderate volatility transmitting markets, whereas sugar's price volatility transmissions are low to neutral. Rapeseed oil and soybean behave primarily as net volatility receiving markets. Moreover, when considering the whole sample period, oil contributes with around one-fifth to volatility spillovers in grains (corn, wheat, and soybean) and sugar markets, and almost one third to vegetable oil markets (soybean oil, palm oil, and rapeseed oil).

With major economies like the US and EU growing modestly, China lowering its growth rate, and in light of the decision of OPEC countries to maintain oil supplies at their current levels, the mid-term scenario for oil appears to be one of low prices and volatility. Nonetheless, any disruption of the oil market (e.g. an armed conflict in the Middle East; a decision of OPEC to reduce oil supplies; natural disasters, etc.) is likely to bring considerable uncertainties to agricultural markets. Measures aiming at buffering risk transfers from oil markets may therefore contribute to stabilising agricultural prices. 


\section{Appendix 1}

Figure 16. Major biofuel producing countries, 2011
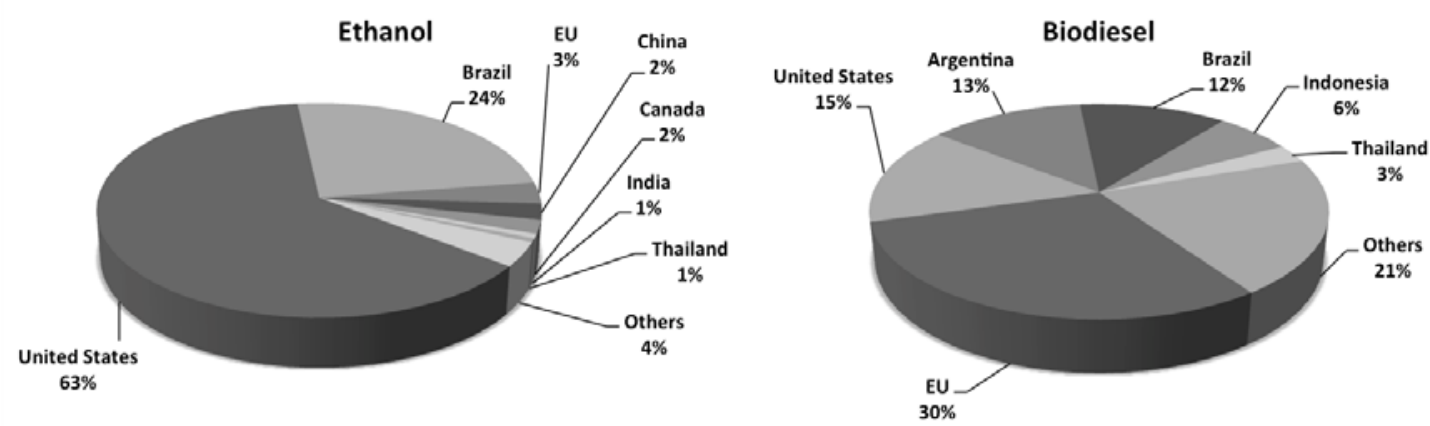

Source: Own elaboration based on estimates of the Earth Policy Institute with data from F.O. Licht.

As Figure 16 shows, in 2011 the US accounted for 63\% of world ethanol production (54 Billion Lt), followed by Brazil with 24\% (21 Billion Lt), the EU with 3\% (2.7 Billion Lt) and China with 2\% (2 Billion Lt). For the same period the US was the largest net ethanol exporter with 2.5 Billion Lt, followed by Brazil (1 Billion Lt) and China (200 thousand Lt). The EU accounted for 30\% of world biodiesel production in 2011. Within the EU, Germany was the largest producer (3 Billion Lt) followed by France (1.6 Billion Lt), Spain (0.7 Billion Lt), Italy (0.6 Billion Lt) and the Netherlands (0.4 Billion Lt). Other large producers were the US with a market share of 15\% (3.2 Billion Lt), Argentina with 13\% (2.8 Billion Lt) and Brazil with 12\% (2.6 Billion Lt). Despite its sizable production capacity the EU remained the world's major biodiesel importer, accounting for almost $100 \%$ of net global imports (2.5 Billion Lt). Argentina, on the other hand, was the leading net exporter with 1.6 Billion Lt, followed by Indonesia (0.3 Billion Lt) and the US (0.2 Billion Lt) (FAPRI and ISU, 2012). 


\section{Appendix 2}

Table 14. Literature review summary

\begin{tabular}{|c|c|c|c|c|c|}
\hline Article & Prices & Period & Frequency & Method & Main findings \\
\hline 1. Algieri (2014) & us & 2005-2013 & Daily & GARCH & $\begin{array}{l}\text { Lagged oil and ethanol retums have a significant influence on } \\
\text { com, wheat, sugar and soybean volatilities. }\end{array}$ \\
\hline 2. Wu and $\operatorname{Li}(2013)$ & China & 2003-2012 & Weekly & GARCH & $\begin{array}{l}\text { Volatility spillovers from oil to corn and ethanol markets, but } \\
\text { bidirectional spillovers between corn and ethanol. }\end{array}$ \\
\hline 3. Serra and Gil (2012) & us & $1990-2010$ & Monthly & GARCH & $\begin{array}{l}\text { Stock forecasts lower corn volatility. Interest rate uncertainty } \\
\text { increases it. Ethanol volatility spills to com volatility. (stocks } \\
\text { and interest rate treated as exogenous in variance equation) }\end{array}$ \\
\hline 4. Trujillo-Barrera et al. (2012) & us & $2006-2011$ & Weekly & GARCH & $\begin{array}{l}\text { Volatility transmission from oil to corn and ethanol markets, as } \\
\text { well as from com to ethanol. }\end{array}$ \\
\hline 5. A lom et al. (2011) & Asia-Pacific & $1995-2010$ & Daily & GARCH & Mean and volatility spillovers from oil to food. \\
\hline 6. Serra (2011) & Brazil & $2000-2009$ & Weekly & GARCH & $\begin{array}{l}\text { Shocks in oil and sugar markets increase ethanol volatility. } \\
\text { Ethanol does not affect neither sugar nor oil volatilities. }\end{array}$ \\
\hline 7. Serra et al. (2011) & Brazil & $2000-2008$ & Weekly & GARCH & $\begin{array}{l}\text { Oil volatility spillover to sugar and ethanol volatilities. } \\
\text { Bidirectional spillovers between ethanol and sugar. }\end{array}$ \\
\hline 8. Wu et al. (2011) & us & $1992-2009$ & Weekly & GARCH & Volatility spillovers from oil to corn spot and futures. \\
\hline 9. Chang and $\mathrm{Su}(2010)$ & us & $2000-2008$ & Daily & GARCH & $\begin{array}{l}\text { Volatility spillovers from oil to corn and soybean (2004-2008). } \\
\text { (oil treated as exogenous in mean equation) }\end{array}$ \\
\hline 10. Zhang et al. (2009) & us & $1989-2007$ & Weekly & GARCH & $\begin{array}{l}\text { Bidirectional volatility spillovers between corn and soybean. } \\
\text { From soybean to ethanol only during } 2000-2007 \text {. }\end{array}$ \\
\hline 11. Mensi et al. (2014) & US, EU & $2000-2013$ & Daily & DCC & $\begin{array}{l}\text { Oil volatility spillovers to corn. Gasoline volatility spillovers to } \\
\text { corn, sorghum and barley volatilities. }\end{array}$ \\
\hline 12. Gardebroek and Hernandez (2013) & us & $1997-2011$ & Weekly & DCC & $\begin{array}{l}\text { Volatility spillovers from the corn to ethanol prices, but no } \\
\text { major cross-market volatility effects between oil and corn. }\end{array}$ \\
\hline 13. Busse et al. (2011) & EU & 1999-2009 & Daily & DCC & $\begin{array}{l}\text { Significant correlations between oil and both rapeseed oil and } \\
\text { soybean. }\end{array}$ \\
\hline 14. Nazlioglu et al. (2013) & International & $1986-2011$ & Daily & Granger causality & $\begin{array}{l}\text { Volatility spillovers from wheat to oil (1986-2005). Bidirectional } \\
\text { causalities between oil and soybean, oil and wheat (2006-2011). }\end{array}$ \\
\hline 15. Kaltalioglu and Soytas (2011) & International & $1980-2008$ & Monthly & Granger causality & $\begin{array}{l}\text { No volatility spillovers from oil to food and agricultural raw } \\
\text { materials. }\end{array}$ \\
\hline 16. Harri and Hudson (2009) & us & 2003-2009 & Daily & Granger causality & Volatility spillovers from oil to corn after the food crisis. \\
\hline 17. Liu (2014) & us & $1994-2012$ & Daily & Cross correlation & $\begin{array}{l}\text { Highly significant and persistent cross correlations between the } \\
\text { volatilities of oil and each of the considered cereals. }\end{array}$ \\
\hline 18. Balcombe (2011) & International & different & Different & Random parameter & $\begin{array}{l}\text { Volatility spillovers from oil to the considered agricultural } \\
\text { products. }\end{array}$ \\
\hline 19. Du et al. (2011) & US & $1998-2009$ & Weekly & Stochastic Volatility & $\begin{array}{l}\text { Volatility spillovers from oil to corn and wheat. Increased } \\
\text { correlations between oil and corn, oil and wheat (2006-2009). }\end{array}$ \\
\hline 20. Alghalith (2010) & Trinidad \& T. & $1974-2007$ & Annual & Non linear OLS & $\begin{array}{l}\text { Increase in oil price and volatility yields higher food prices, } \\
\text { while an increase in oil supply reduces them. }\end{array}$ \\
\hline
\end{tabular}

Source: Own elaboration. 


\section{Appendix 3}

Table 15. BEKK estimates

\begin{tabular}{|c|c|c|c|c|c|c|c|c|c|c|c|c|}
\hline & \multicolumn{4}{|c|}{ Ehtanol Group } & \multicolumn{4}{|c|}{ Biodiesel Group } & \multicolumn{4}{|c|}{ Mixed Group } \\
\hline \multirow{10}{*}{$\begin{array}{l}u \\
\stackrel{x}{\vec{b}} \\
\stackrel{\pi}{\Sigma}\end{array}$} & \multicolumn{4}{|c|}{ Estimates } & \multicolumn{4}{|c|}{ Estimates } & \multicolumn{4}{|c|}{ Estimates } \\
\hline & 0.0024 & 0 & 0 & 0 & 0.0038 & 0 & 0 & $\overline{0}$ & 0.0025 & 0 & 0 & 0 \\
\hline & -0.0003 & 0.0023 & 0 & 0 & 0.0006 & 0.0032 & 0 & 0 & -0.0003 & 0.0023 & 0 & 0 \\
\hline & -0.0005 & -0.0007 & 0.0037 & 0 & 0.0003 & -0.0003 & 0.0018 & 0 & -0.0004 & -0.001 & 0.0026 & 0 \\
\hline & 0.0009 & -0.0002 & 0 & -0.0013 & 0.0015 & -0.0015 & -0.0014 & 0.0012 & -0.0008 & 0.0005 & 0.0012 & 0.0023 \\
\hline & \multicolumn{4}{|c|}{ QML t-ratios } & \multicolumn{4}{|c|}{ QML t-ratios } & \multicolumn{4}{|c|}{ QML t-ratios } \\
\hline & 1.9046 & 0 & 0 & 0 & 0.447 & 0 & 0 & $\overline{0}$ & 2.8362 & 0 & 0 & 0 \\
\hline & -0.4858 & 6.5832 & 0 & 0 & 0.1195 & 0.7897 & 0 & 0 & -0.6113 & 5.4408 & 0 & 0 \\
\hline & -1.139 & -0.5368 & 2.7347 & 0 & 0.6502 & -0.1026 & 0.9015 & 0 & -1.1164 & -1.2112 & 2.4419 & 0 \\
\hline & 0.7735 & -0.2333 & 0.0691 & -0.7158 & 1.4707 & -2.4018 & -0.6113 & 0.9909 & -0.9383 & 0.5918 & 2.0415 & 3.361 \\
\hline \multirow{10}{*}{ 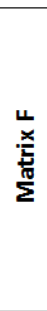 } & \multicolumn{4}{|c|}{ Estimates } & \multicolumn{4}{|c|}{ Estimates } & \multicolumn{4}{|c|}{ Estimates } \\
\hline & 0.1918 & 0.0015 & -0.0057 & 0.0212 & 0.2539 & 0.0257 & -0.0344 & 0.0555 & 0.1993 & -0.0059 & -0.0028 & 0.0028 \\
\hline & -0.0017 & 0.2002 & -0.0533 & -0.0078 & -0.0721 & 0.2178 & -0.1222 & -0.0608 & 0.007 & 0.1786 & -0.0709 & -0.0398 \\
\hline & -0.001 & -0.032 & 0.3252 & 0.0084 & -0.0285 & -0.0145 & 0.304 & -0.0324 & 0.0018 & -0.0261 & 0.2676 & -0.0092 \\
\hline & 0.0221 & -0.0153 & 0.0117 & 0.1684 & 0.1142 & -0.0021 & -0.0561 & 0.2998 & -0.0334 & 0.0481 & 0.0542 & 0.2647 \\
\hline & \multicolumn{4}{|c|}{ QMLt-ratios } & \multicolumn{4}{|c|}{ QML t-ratios } & \multicolumn{4}{|c|}{ QML t-ratios } \\
\hline & 3.4911 & 0.142 & -0.5428 & 0.3667 & 1.0638 & 0.3647 & -0.3406 & 1.3042 & 5.673 & -0.5148 & -0.3315 & 0.2678 \\
\hline & -0.0813 & 9.9912 & -1.5109 & -0.3117 & -0.7482 & 0.8383 & -1.1298 & -0.5363 & 0.4082 & 6.4099 & -2.3173 & -1.0295 \\
\hline & -0.0698 & -1.6893 & 4.2355 & 0.6161 & -0.6497 & -0.2001 & 5.1999 & -0.9418 & 0.1607 & -1.9758 & 3.9923 & -0.7181 \\
\hline & 0.7797 & -0.5073 & 0.4262 & 1.7556 & 2.8123 & -0.085 & -0.2735 & 4.0041 & -0.9033 & 1.6013 & 2.0284 & 4.4095 \\
\hline \multirow{10}{*}{ 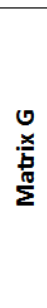 } & \multicolumn{4}{|c|}{ Estimates } & \multicolumn{4}{|c|}{ Estimates } & \multicolumn{4}{|c|}{ Estimates } \\
\hline & 0.9761 & 0.0013 & 0.0035 & -0.0064 & 0.9492 & -0.0119 & 0.0128 & -0.0222 & 0.9734 & 0.0034 & 0.003 & 0.0021 \\
\hline & 0.0001 & 0.963 & 0.0217 & 0.0022 & 0.0375 & 0.9524 & 0.0463 & 0.0315 & -0.0058 & 0.9714 & 0.0277 & 0.0189 \\
\hline & 0.0032 & 0.0225 & 0.927 & -0.0009 & -0.0188 & -0.014 & 0.9406 & 0.016 & 0.0021 & 0.0163 & 0.9524 & 0.0002 \\
\hline & -0.0046 & 0.0039 & -0.0012 & 0.9833 & -0.0347 & 0.0156 & 0.0126 & 0.9367 & 0.0175 & -0.0127 & -0.0248 & 0.9431 \\
\hline & \multicolumn{4}{|c|}{ QML t-ratios } & \multicolumn{4}{|c|}{ QML t-ratios } & \multicolumn{4}{|c|}{ QML t-ratios } \\
\hline & 58.8101 & 0.3734 & 1.1074 & -0.3448 & 8.2898 & -0.2826 & 0.1928 & -0.4899 & 85.3561 & 0.8656 & 1.056 & 0.5489 \\
\hline & 0.0139 & 103.4297 & 1.1764 & 0.3205 & 0.5892 & 8.5522 & 0.3731 & 0.414 & -0.7689 & 103.6485 & 1.9084 & 1.1244 \\
\hline & 0.5782 & 1.4791 & 23.3963 & -0.1654 & -0.3033 & -0.3121 & 19.8549 & 0.8629 & 0.6137 & 1.9948 & 41.1925 & 0.0266 \\
\hline & -0.5051 & 0.4469 & -0.233 & 46.888 & -0.5297 & 0.8582 & 0.0844 & 43.6609 & 0.9489 & -1.0234 & -1.8529 & 35.6299 \\
\hline
\end{tabular}

Source: Own elaboration. 


\section{Discussion}

Volatility is related to unexpected price changes. It measures the variability of the changes in prices associated with market uncertainties. Statistically, it represents the standard deviation of the (logarithmic) price changes. Since volatility is not observable directly, it must be estimated using some approach. The several methodologies to estimate price volatility involve different modelling and assumption settings. At the beginning of this document we stated the importance of explicitly specifying a model for the expected price in order to distinguish between expected and unexpected price changes. Additionally, we identified key elements necessary for the correct interpretation of the selected volatility measure. For instance, besides the method selection, other important considerations are the correct market definition, the data frequency, the time horizon, and whether the analysis is with predictive or explanatory purposes.

The broad objective of this study is to contribute to the understanding of the causes of volatility in agricultural markets. The first step involved searching through specialised literature to identify different volatility drivers. There are structural and short-term factors that provoke uncertainty in agricultural prices. We found that the long-run provision of the main grains has been affected by underinvestment in agriculture, declining yields, the decrease in production scales, and the increasing frequency of weather disruptions. Moreover, consumption in developing countries has been growing due to changes in dietary preferences towards protein rich dairy and meat products, coupled with a demographic expansion. There are also different elements, which exacerbate volatility in the short-term, for instance, unanticipated 'poor' harvests due to climate disturbances, unpredictability of grain stock levels, and shocks coming from cross-related markets like oil. Additionally, market disruptions motivated by arbitrary trade-restrictive measures and 'arguably' the rapid financialisation of agricultural markets further aggravated volatility. Other identified long-lasting potential volatility drivers include the future development of biofuel and macroeconomic policies and the outcome of on going international trade negotiations. 
From all these potential drivers we focus on the tightening relation between oil and agricultural commodities due to biofuels. The purpose of this work is to introduce new evidence on the development of this relationship in order to improve the understanding of the volatility dynamics between energy and food markets. The linkage between oil and agricultural commodities was traditionally driven only by the use of oil as input for crop production, processing, and transporting. Biofuels, however, introduced an alternative use for different crops as direct oil substitutes. Farmers now have to decide -according to the relative prices they face (and where policy incentives play a decisive role)- whether to send crops to the food or fuel industry. Particularly, since the food crisis of 2007/2008, there is a wide debate between the ones that claim against an expansion of biofuels because of food security considerations and others who argue that higher agricultural prices bring more income and therefore development to the rural poor. In a paper by Ivanic and Martin (2014), for instance, the authors find that an increment of food prices in developing countries aggravates poverty in the short run, but in the longer run it raises salaries for unskilled workers as well as income for poor farmers. Biofuels, however, not only have the potential to increase food prices, they also bring more uncertainty to agricultural markets through different channels. According to Wright (2014), owing to the permanent character of the mandates and the low responsiveness of supply, stocks have steadily declined. Without appropriate levels, the price-stabilising role of storage is ineffective against market shocks, resulting in prolonged episodes of high volatility (Bobenrieth et al., 2013). Biofuel policies may also contribute to price instability in agricultural markets by changing the incentives for biofuels in a discretionary manner. Moreover, the strengthened connection between agricultural products and oil, an intrinsically volatile market, adds complexity and unpredictability to the functioning of agricultural markets.

\subsection{Volatility measures}

Since our interest centres on characterising and interpreting the relation and dependences among volatilities in different markets, and not forecasting their values, a natural choice for our analysis is to use ex-post volatility measures (realised volatility and parametric multivariate GARCH) based on spot prices. As observed in Figure 1 (p.26) and corroborated by results presented in Table 1 (p.27), the realised monthly volatility presents more variability than its GARCH counterpart. By 
construction, the realised volatility is the sum of the squared price changes of every observation over a predetermined period, in our case around 20 daily return observations per month. The GARCH only considers the change between two points one month apart i.e. the daily variability is left out. However, if the variation from month to month is equivalent to the sum of the daily variations, then both measures will show similar point volatility levels. As explained previously, the advantage of using realised estimates is that it is a simple, straightforward, model-free measure, which does not require distributional assumptions for fixed structures. However, it is (high-frequency) data demanding and suffers from scaling problems due to intraperiod noise. Nevertheless, there is one fundamental difference between both methods. While realised volatilities are estimated separately for every commodity, the multivariate GARCH model simultaneously accounts for cross relations among the considered variables. Additionally, its BEKK specification (Engle and Kroner, 1995) not only guarantees that implied (co) variances are positive-definite under mild conditions, but also provides richer spillover dynamics.

\subsection{Impulse response analysis}

After estimating volatilities for the different markets, the next step is to interprete their relations across markets. With this purpose we use impulse response methods. Concretely, we describe the development and behaviour of second order moment dynamics between these markets deriving the spillover indices proposed by Diebold and Yilmaz (2009, 2012). The indices are based on forecast error variance decompositions obtained from VARMA representations. VAR models only require hypothetical relations among the considered variables while capturing linear interdependencies among them.

In section 3 we derive a simple volatility index for two systems of variables, one containing ethanol feedstocks (wheat, corn, and sugar) and oil, and an analogous set containing biodiesel feedstocks (soybean oil, rapeseed oil, and palm oil) instead. In order to depict volatility spillover patterns, we adopt the approach proposed by Diebold and Yilmaz (2009, 2012) to run impulse response analysis rolling subsequent windows. They argue in favour of this technique because of the impossibility of fixedparameter models to capture secular and cyclical patterns. However, this measure only provides average volatility effects and their smoothness depends on the length of 
the window. When only considering average instead of point estimates, we lose accuracy with respect to the real spillover level and information on recent innovations.

To control for cross correlations among markets, we use the Cholesky decomposition to orthogonalise impulse responses before obtaining forecast variance decompositions. The ordering to identify contemporaneous effects in every system is established according to empirical market considerations. Due to the size of the oil market and the unfeasibility of being affected by any agricultural market, we assume its precedence in both groups. With respect to agricultural markets, we consider the relevance of every product as biofuel feedstock together with its relative market size. For the Ethanol Group we assume the following declining order: sugar, corn, and wheat, whereas for the Biodiesel Group the order is as fallows: soybean oil, rapeseed oil, and palm oil. Since we imposed a unidirectional causality ordering among the variables, altering this sequence will also modify the direction and magnitude of the volatility spillovers. Oil, for example, affects sugar, corn, and wheat. However, none of these markets impact contemporaneously on oil. Similarly, by assumption, sugar volatility drives volatilities in corn and wheat markets. Corn only impacts on wheat, whereas wheat (contemporaneously) does not affect any of the precedent markets. It is not surprising therefore that wheat is a net volatility receptor, while oil is a net volatility transmitter, though not the largest. Since the chosen agricultural markets are more related to each other than with oil, some of them are even larger volatility transmitters. However, when comparing agricultural commodities alone, the magnitude of their volatility spillovers maintains the pre-imposed ordering sugarcorn-wheat (see Table 5, p.74). In the case of the Biodiesel Group the direction and magnitude of the results are also affected by the ordering selection. In this case, rapeseed oil and palm oil are net receptors while oil and soybean oil are net volatility transmitters. Again, when considering only cross spillovers in agricultural markets, soybean oil leads, followed by rapeseed oil and palm oil respecting the assumed causality (see Table 6, p.75). It was striking, however, to observe an atypically large share of ca. $9 \%$ in the spillover index from corn spillovers to oil.

However, as shown in Figure 17 corn's feedback contribution to oil represents, on average, only $0.88 \%$. Feedbacks to oil from the other products are even lower. Due to the order-dependence feature of the Cholesky decomposition, we run a sensitive 
Figure 17. Volatility feedbacks from agricultural markets to oil

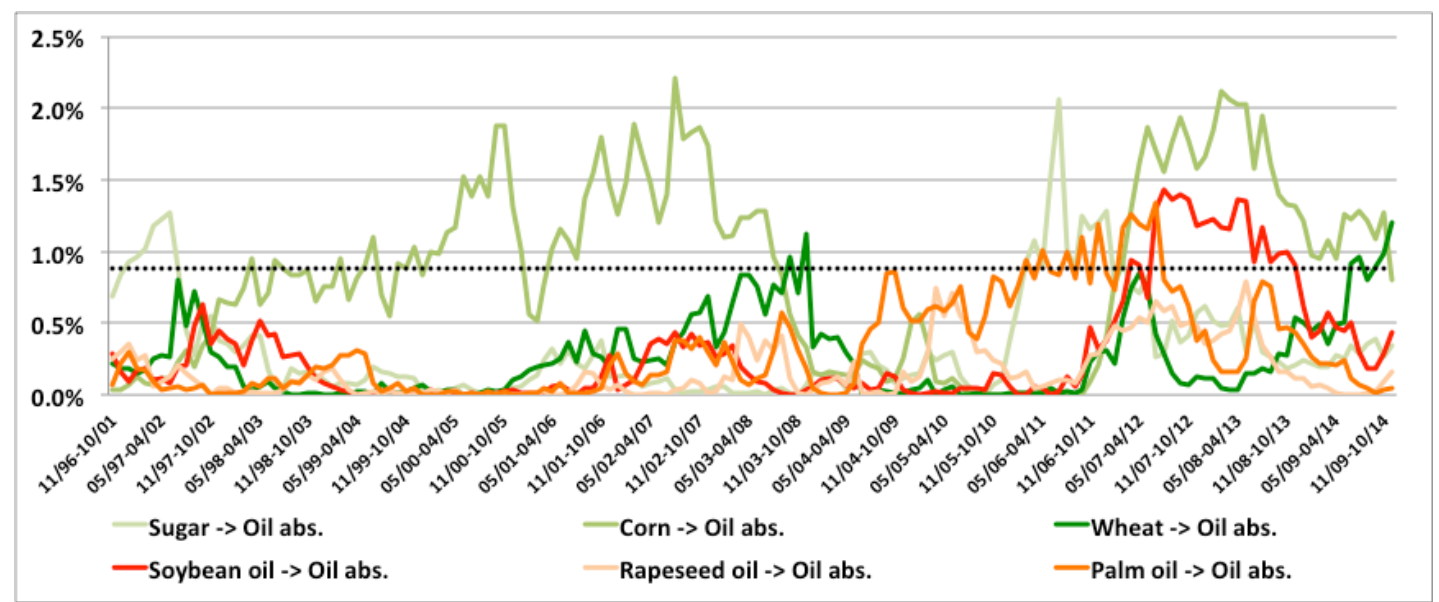

Source: Own elaboration.

Note: The dotted line corresponds to the average of corn's contribution to oil. It is the value obtained from the forecast error variance decomposition.

analysis to check whether the spillover indices change substantially when rotating the causality order among agricultural commodities. We left oil as the dominant market.

Figure 18. Spillover index for different orderings of the variables, Ethanol Group
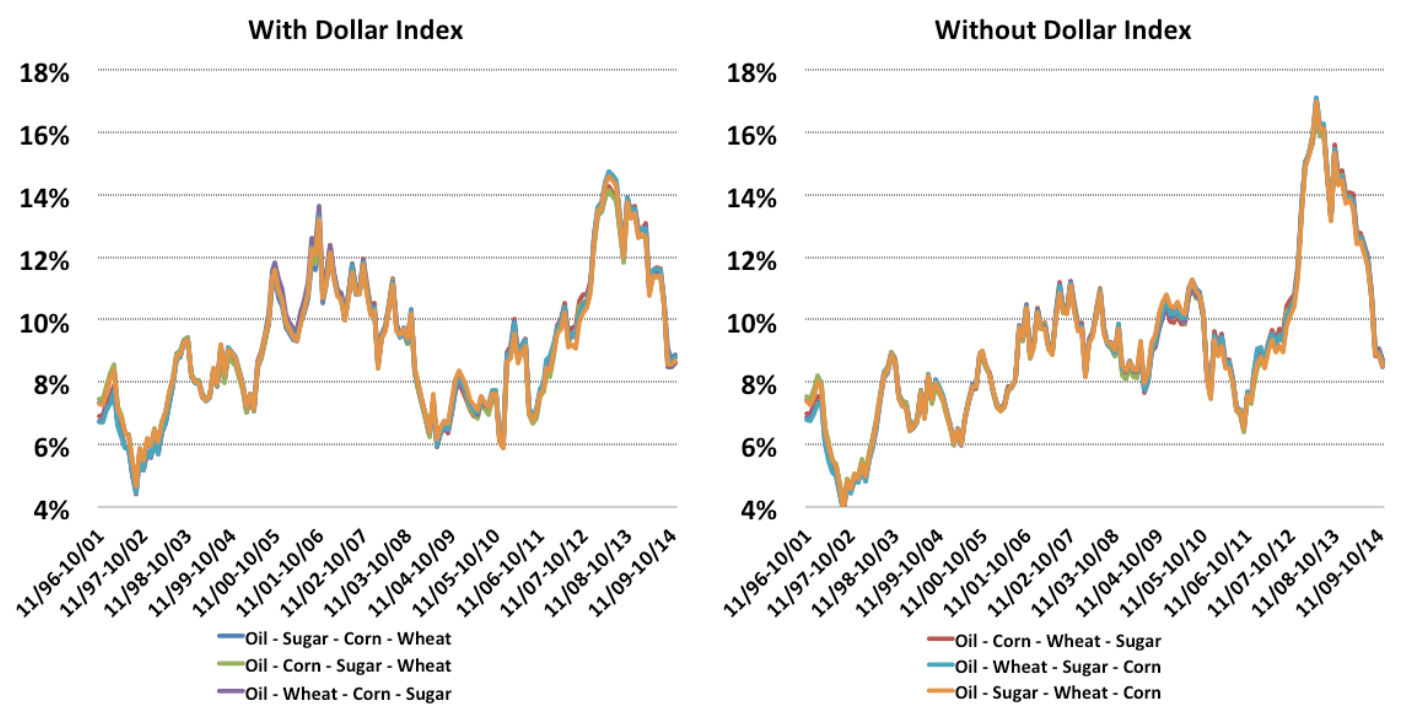

Source: Own elaboration.

As observed in Figure 18, the spillover index for the Ethanol Group remains almost invariant to different orderings. The index adjusted for US dollar exchange rate volatility moves, on average, between $9.15 \%$ for the assumed causality order (sugarcorn-wheat), and $9.20 \%$ for the opposite ordering (wheat-corn-sugar). When not considering the exchange rate influence though, the spillover index declines slightly, but its largest value $(9.11 \%)$ corresponds in this case to the assumed ordering while 
the lowest value (9.05\%) is associated with causality going again from wheat to corn and to sugar.

Figure 19. Spillover index for different orderings of the variables, Biodiesel Group
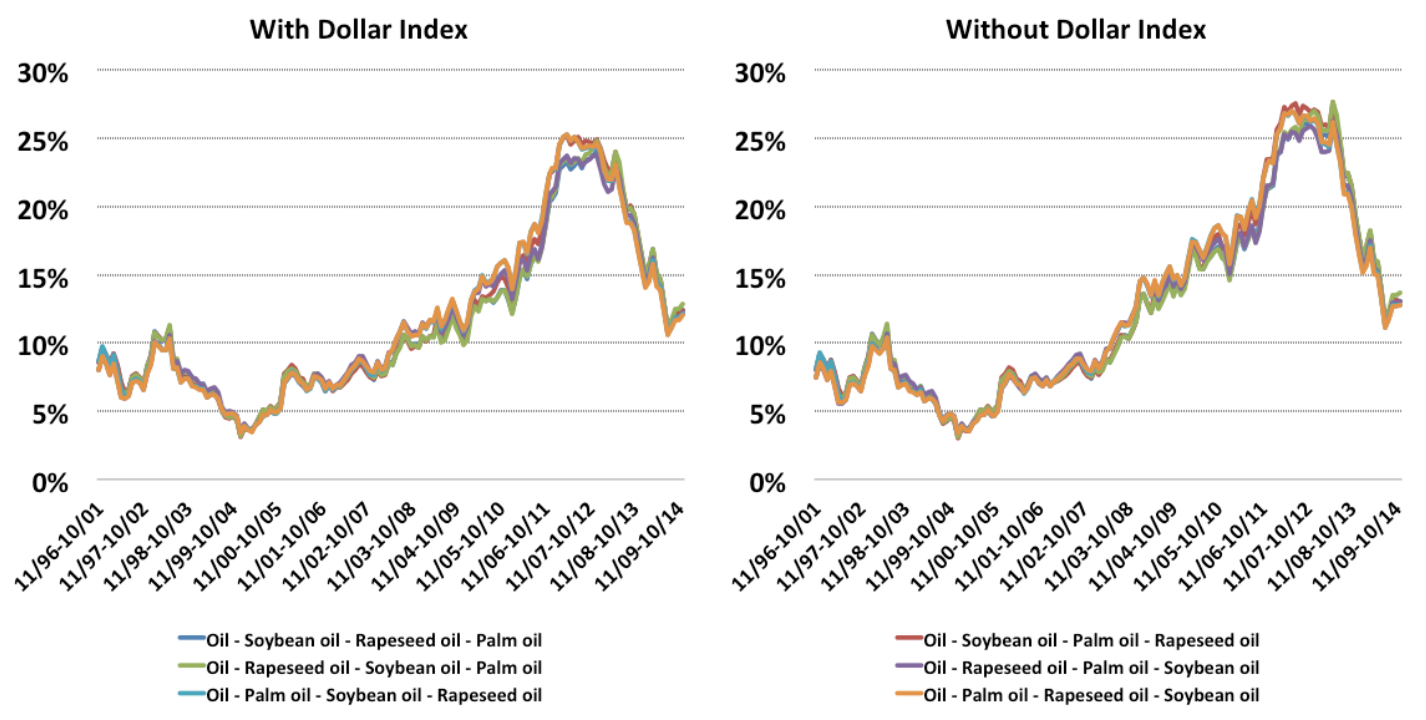

Source: Own elaboration.

In the case of biodiesel feedstocks, different rotations do not significantly affect the spillover index (Figure 19). When adjusting for exchange rate effects, the index moves, on average, between 11.39\% (soybean oil-rapeseed oil-palm oil, assumed order) and $11.71 \%$ (palm oil-soybean oil-rapeseed oil); when not adjusting, it moves from $12.36 \%$ to $12.62 \%$ (soybean oil-palm oil-rapeseed oil), where the lower value corresponds to our causality selection again. In both cases, for ethanol as well as for biodiesel feedstocks, when considering the Dollar Index volatility influence, our spillover estimates are the most conservative. Additionally, we checked autocorrelation functions for the different rotations in both groups and results confirm that auto and cross correlations were removed in each of the 158 rolling periods.

To cope with the issue of ordering dependence of the Cholesky factorisation, Diebold and Yilmaz (2012, 2014) use the generalised impulse response analysis proposed by Pesaran and Shin (1998) which provides invariant-to-ordering forecast errors. This approach does not orthogonalise innovations; instead, it allows shocks to be correlated but account for them using historical information on 'assumed' normally distributed errors. As in Diebold and Yilmaz (2009), they built spillover indices combining the impulse response analysis with rolling windows, arguing in favour of this approach because of its simplicity and consistency with different motives for non-stable model 
parameters. They recognise, however, that this technique is sensitive to the choice of the window width. Moreover, rolling windows only reflect average historical information of every window, being more useful for backward-looking diagnostics rather than for risk surveillance purposes. In section 4 we propose to use the symmetric matrix square root -recognised also in Diebold and Y1lmaz (2014), p.121, - as an alternative invariant-to-ordering identification scheme. The symmetric matrix decomposition, different to the generalised impulse response method, has the additional advantage of avoiding the normality-imposed assumption of the innovation processes. So too, motivated by the convenience of timely information on market interdependence for risk-monitoring purposes, we build spillover indices based on a (linear) VARMA representation of multivariate GARCH processes in their BEKK form (Fengler and Herwartz, 2015). Doing so, instead of obtaining average volatility values (as for rolling windows), we deliver spot volatility estimates conditional on time- $t$ observations. The BEKK model is a suitable choice because of its flexible structure that allows for rich cross-variable interactions while providing positive definiteness of the variance-covariance matrix under mild conditions. Moreover, following the advice of Fengler and Gisler (2015) on the importance of covariance transmission channels, we reformulate the BEKK model in its half-vec form. We provide conservative QML t-ratios for all the implied parameters of this model (Table 15, p.111). Pointing to the criticisms of the normality assumption when deriving BEKK models (see e.g. Chang et al., 2015), Jeantheau (1998), and Comte and Lieberman (2003) prove that QML estimators are consistent and asymptotically normal under specific regularity conditions. However, due to over-parameterisation concerns this type of model is able to handle no more than four variables.

\subsection{The results}

The volatility spillover indices proposed in this study measure the portion of the variance-covariance matrix attributable to shocks spilling across different markets (off diagonal elements). There are individual indices for every system of variables, namely the Ethanol Group, Biodiesel Group and Mixed Group. The different indices reflect to some degree the level of connection or interdependence between second order moments (volatilities) of a set of markets composed basically of oil and commonly used biofuel feedstocks. Owing to the order-dependence of the Cholesky decomposition, the indices delivered in section 3 are not able to provide additional 
information concerning the direction and magnitude of the spillovers. For instance, we can neither isolate the effects of the different markets on each other, nor can we measure their strength, since for every new ordering, both directions and amount of spillovers vary accordingly. In section 4 we build more flexible invariant-to-ordering indices, which are able to capture these additional features. For instance we find that wheat, soybean oil, and oil markets are primarily volatility transmitters during the post-crisis period. Corn, palm oil, and sugar also transmit volatility, though less than previous markets. Rapeseed oil and soybean markets are, on the other hand, the net volatility receptors of the groups. Owing to the pre-imposed causality, the methodology used in section 3 delivers different results. For instance, wheat and palm oil are the largest volatility receptors. This result is not surprising since both wheat and palm oil are assumed to receive volatility spillovers from the remaining markets without transmitting any effect back. Additionally, we find that oil contributes, on average, $20 \%$ to volatility spillovers in grain (corn, wheat, and soybean), $22 \%$ in sugar, and $28 \%$ in vegetable oil markets (soybean oil, palm oil, and rapeseed oil). In section 3, again, for ordering considerations it is not possible to obtain similar conclusions.

Although both methods deliver conceptually analogous volatility spillover measures, each of them has particular features that render any comparison of their findings meaningless. Nevertheless, there is some degree of coherence between their results, which allows some useful generalisations to be made:

$>$ An important share of volatility transmissions originates in agricultural markets, although the role of oil is important.

> After the 2007/2008 food and financial crisis, we find stronger linkages among the considered markets, which also includes oil.

$>$ The linkage among vegetable oils is stronger and therefore transmits more volatility across the system than cereals and sugar do.

$>$ Corn, wheat, and soybean are closely connected markets.

Dynamics of agricultural markets have grown in complexity, especially during the last decade and after the emergence of biofuels. The methodology provided in section 4 is flexible and invariant to ordering; however, applying it to systems containing more than four variables is cumbersome. Nonetheless, adding some exogenous covariates to the system would be a natural step forward in this analysis. The literature suggests 
candidates such as exchange rates, interest rates, index fund activity, and different macroeconomic policies. Another interesting advance would be trying to capture the effects of different biofuel policies in important markets like the US, EU, and Brazil. 


\section{References}

Acharya, V. V., Cooley, T. F., Richardson, M. P., \& Walter, I. (2010). Regulating Wall Street: The Dodd-Frank Act and the New Architecture of Global Finance Viral V. Acharya, Thomas F. Cooley, Matthew P. Richardson, et al. Wiley \& Sons.

Adrian, T., \& Brunnermeier, M. K. (2016). CoVaR. The American Economic Review.

Alghalith, M. (2010). The interaction between food prices and oil prices. Energy Economics, 32(6), 1520-1522.

Algieri, B. (2012). Price Volatility, Speculation and Excessive Speculation in Commodity Markets: sheep or shepherd behaviour? (No. 166). Discussion Papers. Bonn.

Algieri, B. (2014). The influence of biofuels, economic and financial factors on daily returns of commodity futures prices. Energy Policy, 69, 227-247.

Alom, F., Ward, B., \& Hu, B. (2011a). Cross country mean and volatility spillover effects of food prices: multivariate GARCH analysis. Economics Bulletin, 31(2), 1439-1450.

Alom, F., Ward, B., \& Hu, B. (2011b). Spillover effects of world oil prices on food prices: evidence for Asia and Pacific countries. In 52nd Annual Conference of the New Zealand Association of Economists, 29 June - 1 July 2011. Wellington: New Zealand Association of Economists.

Andersen, T. G., \& Bollerslev, T. (1998). Answering the Skeptics: Yes , Standard Volatility Models do Provide Accurate Forecasts. International Economic Review, 39(4), 885-905.

Andersen, T. G., Bollerslev, T., \& Diebold, F. X. (2010). Parametric and Nonparametric Volatility Measurement. In Y. Aït-Sahalia \& L. P. Hansen (Eds.), Handbook of Financial Econometrics (pp. 67-137). Amsterdam: North-Holland.

Anderson, K., \& Nelgen, S. (2012). Trade Barrier Volatility and Agricultural Price 
Stabilization. World Development, 40(1), 36-48.

Ang, A., Chen, J., \& Xing, Y. (2006). Downside Risk. Review of Financial Studies, 19(4), 1191-1239.

Apergis, N., \& Rezitis, A. (2003a). Agricultural price volatility spillover effects: the case of Greece. European Review of Agricultural Economics, 30(3), 389-406.

Apergis, N., \& Rezitis, A. (2003b). Food price volatility and macroeconomic factor volatility: "heat waves” or "meteor showers”? Applied Economics Letters, 10(3), $155-160$.

Aulerich, N. M., Irwin, S. H., \& Garcia, P. (2012). Bubbles, Food Prices, and Speculation: Evidence from the CFTC’s Daily Large Trader Data Files. In The Economics of Food Price Volatility. National Bureau of Economic Research, Inc.

Babcock, B. A. (2012). The impact of US biofuel policies on agricultural price levels and volatility. China Agricultural Economic Review, 4(4), 407-426.

Baffes, J., \& Haniotis, T. (2010). Placing the 2006/08 Commodity Price Boom into Perspective.

Bakshi, G., Kapadia, N., \& Madan, D. (2003). Stock Return Characteristics, Skew Laws, and the Differential Pricing of Individual Equity Options. The Review of Financial Studies, 16(1), 101-143.

Balcombe, K. (2011). The nature and determinants of volatility in agricultural prices: an empirical study. In A. Prakash (Ed.), Safeguarding food security in volatile global markets (1st ed., pp. 89-110). Rome, Italy: Food and Agriculture Organization of the United Nations (FAO).

Bastianin, A., Manera, M., Nicolini, M., \& Vignati, I. (2012). Speculation, Returns, Volume and Volatility in Commodities Futures Markets. Review of Environment, Energy and Economics - Re3.

Bauwens, L., Laurent, S., \& Rombouts, J. V. K. (2006). Multivariate GARCH models: a survey. Journal of Applied Econometrics, 21(1), 79-109.

Black, F. (1976). The Pricing of Commodity Contracts. Journal of Financial Economics, 3, 167-179.

Black, J., \& Tonks, I. (2000). Time series volatility of commodity futures prices. 
Journal of Futures Markets, 20(2), 127-144.

Bobenrieth, E., Wright, B., \& Zeng, D. (2013). Stocks-to-use ratios and prices as indicators of vulnerability to spikes in global cereal markets. Agricultural Economics, 44(s1), 43-52.

Bohl, M. T., Javed, F., \& Stephan, P. M. (2012). Do Commodity Index Traders Destabilize Agricultural Futures Prices? SSRN Electronic Journal. Münster.

Bohl, M. T., \& Stephan, P. M. (2012). Does Futures Speculation Destabilize Spot Prices? New Evidence for Commodity Markets. SSRN Electronic Journal.

Bollerslev, T. (1986). Generalized autoregressive conditional heteroskedasticity. Journal of Econometrics, 31, 307-327.

Britten-Jones, M., \& Neuberger, A. (2000). Option Prices, Implied Price Processes, and Stochastic Volatility. The Journal of Finance, 55(2), 839-866.

Brümmer, B., Korn, O., Schlüßler, K., Jaghdani, T. J., \& Saucedo, A. (2013). Volatility in the after crisis period - A literature review of recent empirical research (No. 1). Göttingen.

Brunetti, C., Buyuksahin, B., \& Harris, J. H. (2011). Speculators, Prices and Market Volatility. SSRN Electronic Journal.

Buguk, C., Hudson, D., \& Hanson, T. (2003). Price Volatility Spillover in Agricultural Markets: An Examination of U.S. Catfish Markets. Journal of Agricultural and Resource Economics, 28(1), 86-99.

Busse, S., Bruemmer, B., \& Ihle, R. (2011). Emerging linkages between price volatilities in energy and agricultural markets. In A. Prakash (Ed.), Safeguarding food security in volatile global markets (1st ed., pp. 111-125). Rome, Italy: Food and Agriculture Organization of the United Nations (FAO).

Busse, S., Brümmer, B., \& Ihle, R. (2012). Price formation in the German biodiesel supply chain: a Markov-switching vector error-correction modeling approach. Agricultural Economics, 43(5), 545-560.

CARBIO. (2015). Camara Argentina de Biocombustibles. Accessed January 23, 2015, from http://www.carbio.com.ar/es/?con=bio_estadisticas

Chandrasekhar, C. P. (2012). Food Price Levels and Volatility: Sources, Impact and 
Implications. IDS Bulletin, 43(Supplement s1), 74-83.

Chang, C. L., Li, Y., \& Mc Aleer, M. (2015). Volatility spillovers between energy and agricultural markets: A critical appraisal of theory and practice (Working Paper No. 1508). Madrid.

Chang, T.-H., \& Su, H.-M. (2010). The substitutive effect of biofuels on fossil fuels in the lower and higher crude oil price periods. Energy, 35(7), 2807-2813.

Cheung, Y.-W., \& Ng, L. K. (1996). A causality-in-variance test and its application to financial market prices. Journal of Econometrics, 72(1-2), 33-48.

Christoffersen, P., Jacobs, K., \& Chang, B. Y. (2012). Forecasting with OptionImplied Information. In G. Elliott \& A. Timmermann (Eds.), Handbook of Economic Forecasting (2nd ed.). Amsterdam: Amsterdam: North-Holland.

Clapp, J. (2009). Food Price Volatility and Vulnerability in the Global South: considering the global economic context. Third World Quarterly, 30(6), 11831196.

Clark, P. K. (1973). A Subordinated Stochastic Process Model with Finite Variance for Speculative Prices. Econometrica, 41(1), 135-155.

Comte, F., \& Lieberman, O. (2003). Asymptotic theory for multivariate GARCH processes. Journal of Multivariate Analysis, 84(1), 61-84.

Dahl, C. M., \& Iglesias, E. M. (2009). Volatility spill-overs in commodity spot prices: New empirical results. Economic Modelling, 26(3), 601-607.

de Gorter, H., Drabik, D., \& Just, D. R. (2015). The Economics of Biofuel Policies. London: Palgrave Macmillan.

Diebold, F. X., \& Yilmaz, K. (2009). Measuring Financial Asset Return and Volatility Spillovers, with Application to Global Equity Markets. The Economic Journal, 119(534), 158-171.

Diebold, F. X., \& Yilmaz, K. (2012). Better to give than to receive: Predictive directional measurement of volatility spillovers. International Journal of Forecasting, 28(1), 57-66.

Diebold, F. X., \& Yilmaz, K. (2014). On the network topology of variance decompositions: Measuring the connectedness of financial firms. Journal of 
Econometrics, 182(1), 119-134.

Du, X., Yu, C. L., \& Hayes, D. J. (2011). Speculation and volatility spillover in the crude oil and agricultural commodity markets: A Bayesian analysis. Energy Economics, 33(3), 497-503.

Dwyer, A., Gardner, G., \& Williams, T. (2011). Global Commodity Markets - Price Volatility and Financialisation. RBA Bulletin, (June), 49-58.

Dwyer, A., Holloway, J., \& Wright, M. (2012). Commodity Market Financialisation: A Closer Look at the Evidence. RBA Bulletin, (March), 65-77.

Egelkraut, T. M., \& García, P. (2006). Intermediate volatility forecasts using implied forward volatility: The performance of selected agricultural commodity options. Journal of Agricultural and Resource Economics, 31(3), 508-528.

Elder, J., \& Jin, H. J. (2007). Long memory in commodity futures volatility: A wavelet perspective. Journal of Futures Markets, 27(5), 411-437.

Engle, R. (2002). Dynamic Conditional Correlation. Journal of Business \& Economic Statistics, 20(3), 339-350.

Engle, R. F. (1982). Autoregressive Conditional Heteroscedasticity with Estimates of the Variance of United Kingdom Inflation. Econometrica, 50(4), 987-1007.

Engle, R. F., \& Granger, C. W. J. (1987). Co-Integration and Error Correction: Representation , Estimation, and Testing. Econometrica, 55(2), 251-276.

Engle, R. F., \& Kenneth F. Kroner. (1995). Multivariate Simultaneous Generalized Arch on JSTOR. Econometric Theory.

Erten, B., \& Ocampo, J. A. (2013). Super Cycles of Commodity Prices Since the MidNineteenth Century. World Development, 44, 14-30.

FAO. (2013). The State of Food Insecurity in the World 2013. The multiple dimensions of food security.

FAO, IFAD, IMF, OECD, UNCTAD, WFP, ... HLTF, U. (2011). Price Volatility in Food and Agricultural Markets: Policy Responses.

FAPRI, \& ISU. (2012). FAPRI-ISU 2012 World Agricultural Outlook. Iowa.

Fengler, M. R., \& Gisler, K. I. M. (2015). A variance spillover analysis without 
covariances: What do we miss? Journal of International Money and Finance, 51, 174-195.

Fengler, M. R., \& Herwartz, H. (2015). Measuring spot variance spillovers when (co)variances are time-varying - the case of multivariate GARCH models. Economics Working Papers. University of St. Gallen, School of Economics and Political Science.

Fong, W. M., \& See, K. H. (2001). Modelling the conditional volatility of commodity index futures as a regime switching process. Journal of Applied Econometrics, 16(2), 133-163.

French, K. R., Schwert, G. W., \& Stambaugh, R. F. (1987). Expected Stock Returns and Volatility. Journal of Financial Economics, 19, 3-29.

Frenk, D., \& Turbeville, W. (2011). Commodity Index Traders and the Boom/Bust Cycle in Commodities Prices. SSRN Electronic Journal.

Gardebroek, C., \& Hernandez, M. A. (2013). Do energy prices stimulate food price volatility? Examining volatility transmission between US oil, ethanol and corn markets. Energy Economics, 40, 119-129.

Gerasimchuk, I., Bridle, R., Beaton, C., \& Charles, C. (2012). State of Play on Biofuel Subsidies: Are policies ready to shift?

Ghosh, N., Chakravarty, S., \& Rajeshwor, M. (2010). Effect of trade liberalisation on volatility: the experience of Indian agriculture. International Journal of Economic Policy in Emerging Economies, 3(3), 253-271.

Gilbert, C. L. (2012). Speculative impacts on grains price volatility. 123rd Seminar, February 23-24, 2012, Dublin, Ireland.

Gilbert, C. L., \& Morgan, C. W. (2010). Food price volatility. Philosophical Transactions of the Royal Society B, 365, 3023-3034.

Gilbert, C. L., \& Pfuderer, S. (2013). The Financialization of Food Commodity Markets. In R. Jha, T. Gaiha, \& A. Deolalikar (Eds.), Handbook on Food: Demand, Supply, Sustainabilty and Security. Forthcoming.

Giot, P. (2003). The information content of implied volatility in agricultural commodity markets. Journal of Futures Markets, 23(5), 441-454. 
Gouel, C. (2012). Agricultural Price Instability: A Survey of Competing Explanations and Remedies. Journal of Economic Surveys, 26(1), 129-156.

Granger, C. W. J. (1969). Investigating Causal Relations by Econometric Models and Cross-spectral Methods. Econometrica, 37(3), 424-438.

Gutierrez, L. (2012). Speculative bubbles in agricultural commodity markets. European Review of Agricultural Economics, 1-22.

Harri, A., \& Hudson, D. (2009). Mean and variance dynamics between agricultural commodity prices and crude oil prices. In Economics of Alternative Energy Sources and Globalization: The Road Ahead meeting, Orlando, FL, November 15-17, 2009. Orlando.

Hayo, B., Kutan, A. M., \& Neuenkirch, M. (2012). Communication matters: US monetary policy and commodity price volatility. Economics Letters, 117(1), 247-249.

Heston, S. L. (1993). A Closed-Form Solution for Options with Stochastic Volatility with Applications to Bond and Currency Options. The Review of Financial Studies, 6(2), 327-343.

Huchet-Bourdon, M. (2011). Agricultural Commodity Price Volatility - Papers OECD iLibrary (No. 52). Paris.

Irwin, S. H., \& Sanders, D. R. (2012). Testing the Masters Hypothesis in commodity futures markets. Energy Economics, 34(1), 256-269.

Ivanic, M., \& Martin, W. (2014). Short- and long-run impacts of food price changes on poverty (No. 7011).

Jeantheau, T. (1998). Strong consistency of estimators for multivariate ARCH models. Econometric Theory, 14(01), 70-86.

Jin, H. J., \& Frechette, D. L. (2004). Fractional Integration in Agricultural Futures Price Volatilities. American Journal of Agricultural Economics, 86(2), 432-443.

Jin, H. J., \& Kim, T. (2012). Structural Changes in the Time Series of Food Prices and Volatility Measurement. American Journal of Agricultural Economics, 94(4), 929-944.

Kaltalioglu, M., \& Soytas, U. (2011). Volatility Spillover from Oil to Food and 
Agricultural Raw Material Markets. Modern Economy, 2(2), 71-76.

Karali, B., Power, G. J., \& Ishdorj, A. (2011). Bayesian State-space Estimation of Stochastic Volatility for Storable Commodities. American Journal of Agricultural Economics, 93(2), 434-440.

Khaligh Khiyavi, P., Moghaddasi, R., Eskandarpur, B., \& Mousavi, N. (2012). Spillover Effects of Agricultural Products Price Volatilities in Iran (Case Study: Poultry Market). Journal of Basic and Applied Scientific Research, 2(8), 79067914

Kostov, P., \& Mcerlean, S. (2004). Agricultural price volatility spill-over effects : a comment. European Review of Agricultural Economics, 31(4), 481-485.

Lence, S. H., \& Hayes, D. J. (2002). U.S. Farm Policy and the Volatility of Commodity Prices and Farm Revenues. American Journal of Agricultural Economics, 84(2), 335-351.

Liu, L. (2014). Cross-correlations between crude oil and agricultural commodity markets. Physica A: Statistical Mechanics and Its Applications, 395, 293-302.

Lo, A. W., \& MacKinlay, A. C. (1988). Stock Market Prices Do Not Follow Random Walks: Evidence from a Simple Specification Test. The Review of Financial Studies, 1(1), 41-66.

Lütkepohl, H. (2007). New Introduction to Multiple Time Series Analysis. Springer.

Manera, M., Nicolini, M., \& Vignati, I. (2012). Returns in commodities futures markets and financial speculation: a multivariate GARCH approach (No. 170). Quaderni di Dipartimento.

McPhail, L. L., Du, X., \& Muhammad, A. (2012). Disentangling corn price volatility: the role of global demand, speculation, and energy. Journal of Agricultural and Applied Economics, 44(3), 401-410.

Mensi, W., Hammoudeh, S., Nguyen, D. K., \& Yoon, S.-M. (2014). Dynamic spillovers among major energy and cereal commodity prices. Energy Economics, 43, 225-243.

Miao, X., Yu, B., Bao, X., \& Tang, Y. (2011). Risk and regulation of emerging price volatility of non-staple agricultural commodity in China. African Journal of 
Agricultural Research, 6(5), 1251-1256.

Mitchell, D. (2008). A Note on Rising Food Prices. Policy Research Working Paper No. 4682. The World Bank, Washington D.C.

Muth, J. F. (1961). Rational Expectations and the Theory of Price Movements. Econometrica, 29(3), pp. 315-335.

Nazlioglu, S., Erdem, C., \& Soytas, U. (2013). Volatility spillover between oil and agricultural commodity markets. Energy Economics, 36, 658-665.

Nissanke, M. (2012). Commodity Market Linkages in the Global Financial Crisis: Excess Volatility and Development Impacts. Journal of Development Studies, 48(6), 732-750.

Ocran, M., \& Biekpe, N. (2007). Trends and volatility in sub Saharan Africa's key primary commodity exports. South African Journal of Economic and Management Sciences, 10(1), 116-129.

OECD, \& FAO. (2010). OECD-FAO Agricultural Outlook 2010-2019. Paris.

Oleg, M. (2011). Volatility Interrelationship between Commodity Futures, Shanghai Stock and 10 Year Bond Indices in China. International Journal of Economics and Finance, 3(6), p265.

Onour, I. A., \& Sergi, B. S. (2011). Modeling and Forecasting Volatility in the Global Food Commodity Prices. Agricultural Economics, 57(3), 132-139.

OPEC. (2015). OPEC Annual Statistical Bulletin. Vienna.

Pesaran, M. H., \& Shin, Y. (1998). Generalized Impulse Response Analysis in Linear Multivariate Models. Economics Letters, 58(1), 17-29.

Pietola, K., Liu, X., \& Robles, M. (2010). Price, inventories, and volatility in the global wheat market | (No. 00996). Washington, D.C.

Poon, S.-H., \& Granger, C. W. J. (2003). Forecasting Volatility in Financial Markets: A Review. Journal of Economic Literature, 41(2), 478-539.

Poon, S.-H., \& Granger, C. W. J. (2005). Practical Issues in Forecasting Volatility. Financial Analysts Journal, 61(1), 45-56.

Power, G. J., \& Turvey, C. G. (2010). Long-range dependence in the volatility of 
commodity futures prices: Wavelet-based evidence. Physica A: Statistical Mechanics and Its Applications, 389(1), 79-90.

Prakash, A. (Ed.). (2011). Safeguarding Food Security in Volatile Global Markets. FAO (1st ed.). Rom, Italy: Food and Agriculture Organization of the United Nations (FAO).

Ramírez, O. A., \& Fadiga, M. (2003). Forecasting Agricultural Commodity Prices with Asymmetric-Error GARCH Models. Journal of Agricultural and Resource Economics, 28(1), 71-85.

Reitz, S., \& Westerhoff, F. (2007). Commodity price cycles and heterogeneous speculators: a STAR-GARCH model. Empirical Economics, 33(2), 231-244.

Rezitis, A., \& Stavropoulos, K. S. (2011). Price volatility and rational expectations in a sectoral framework commodity model: a multivariate GARCH approach. Agricultural Economics, 42(3), 419-435.

Roache, S. K. (2010). What Explains the Rise in Food Price Volatility? .IMF, Washington, D.C.

Roberts, M. J., \& Schlenker, W. (2009). World Supply and Demand of Food Commodity Calories. American Journal of Agricultural Economics, 91(5), 1235-1242.

Robles, M., Torero, M., \& von Braun, J. (2009). When speculation matters (No. 57). Washington, D.C.

Samuelson, P. A. (1965). Proof that properly anticipated prices fluctuate randomly. Industrial Management Review, 6(2), 41-49.

Sanders, D. R., \& Irwin, S. H. (2011). New Evidence on the Impact of Index Funds in U.S. Grain Futures Markets. Canadian Journal of Agricultural Economics/Revue Canadienne D’agroeconomie, 59(4), 519-532.

Schwartz, E. S. (1997). The Stochastic Behavior of Commodity Prices: Implications for Valuation and Hedging. The Journal of Finance, 52(3), 923-973.

Schwert, G. W. (1989). Why Does Stock Market Volatility Change Over Time? The Journal of Finance, 44(5), 1115-1153.

Schwert, G. W. (1990a). Stock Market Volatility. Financial Analysts Journal, 46, 23- 
34.

Schwert, G. W. (1990b). Stock Volatility and the Crash of '87. The Review of Financial Studies, 3(1), 76-102.

Schwert, G. W., \& Seguin, P. J. (1990). Heteroskedasticity in Stock Returns. The Journal of Finance, 45(4), 1129-1155.

Sehgal, S., Rajput, N., \& Deisting, F. (2013). Price Discovery and Volatility Spillover: Evidence from Indian Commodity Markets. The International Journal of Business and Finance Research, 7(3), 57-75.

Sephton, P. S. (2009). Fractional integration in agricultural futures price volatilities revisited. Agricultural Economics, 40(1), 103-111.

Serra, T. (2011a). Food scare crises and price volatility: The case of the BSE in Spain. Food Policy, 36(2), 179-185.

Serra, T. (2011b). Volatility spillovers between food and energy markets: A semiparametric approach. Energy Economics, 33(6), 1155-1164.

Serra, T., \& Gil, J. M. (2012). Price volatility in food markets: can stock building mitigate price fluctuations? European Review of Agricultural Economics, 40(3), 507-528.

Serra, T., Zilberman, D., \& Gil, J. (2011). Price volatility in ethanol markets. European Review of Agricultural Economics, 38(2), 259-280.

Serra, T., Zilberman, D., Gil, J. M., \& Goodwin, B. K. (2011). Nonlinearities in the U.S. corn-ethanol-oil-gasoline price system. Agricultural Economics, 42(1), 3545.

Shanmugam, V. P., Hu, B., \& Chiao, C.-H. (2012). Agricultural Commodity Price Spikes since 2006: A New Look at the Efficiency of U.S. Futures Markets. Bangalore, India.

Smith, A. (2005). Partially overlapping time series: a new model for volatility dynamics in commodity futures. Journal of Applied Econometrics, 20(3), 405422.

Swaray, R. (2007). How did the demise of international commodity agreements affect volatility of primary commodity prices? Applied Economics, 39(17), 2253-2260. 
Symeonidis, L., Prokopczuk, M., Brooks, C., \& Lazar, E. (2012). Futures basis, inventory and commodity price volatility: An empirical analysis. Economic Modelling, 29(6), 2651-2663.

Taylor, N. (2004). Modeling discontinuous periodic conditional volatility: Evidence from the commodity futures market. Journal of Futures Markets, 24(9), 805834.

Timmer, C. P. (2010). Reflections on food crises past. Food Policy, 35(1), 1-11.

Trujillo-Barrera, A., Mallory, M. L., \& Garcia, P. (2012). Volatility Spillovers in US Crude Oil, Ethanol and Corn Futures Markets | Mindy Mallory. Journal of Agricultural and Resource Economics, 37(2), 16.

Udoh, E., \& Egwaikhide, F. O. (2012). Does International Oil Price Volatility Complement Domestic Food Price Instability in Nigeria? An Empirical Enquiry. International Journal of Economics and Finance, 4(1), 235-246.

Voituriez, T. (2001). What explains price volatility changes in commodity markets? Answers from the world palm-oil market. Agricultural Economics, 25(2-3), 295301.

von Braun, J., \& Tadesse, G. (2012). Global Food Price Volatility and Spikes: An Overview of Costs, Causes, and Solutions (No. 161). Discussion Papers. Bonn.

Westerhoff, F., \& Reitz, S. (2005). Commodity price dynamics and the nonlinear market impact of technical traders: empirical evidence for the US corn market. Physica A: Statistical Mechanics and Its Applications, 349(3-4), 641-648.

Will, M. G., Prehn, S., Pies, I., \& Glauben, T. (2012). Is financial speculation with agricultural commodities harmful or helpful? : a literature review of current empirical research. Halle: Martin-Luther-Universität Halle-Wittenberg, Lehrstuhl für Wirtschaftsethik.

Wright, B. (2011). The Economics of Grain Price Volatility. Applied Economic Perspectives and Policy, 33(1), 32-58.

Wright, B. (2014). Global Biofuels: Key to the Puzzle of Grain Market Behavior †. Journal of Economic Perspectives, 28(1), 73-98.

Wu, F., Guan, Z., \& Myers, R. J. (2011). Volatility spillover effects and cross hedging 
in corn and crude oil futures. Journal of Futures Markets, 31(11), 1052-1075.

Wu, H., \& Li, S. (2013). Volatility spillovers in China's crude oil, corn and fuel ethanol markets. Energy Policy, 62, 878-886.

Yang, J., Balyeat, R. B., \& Leatham, D. J. (2005). Futures Trading Activity and Commodity Cash Price Volatility. Journal of Business Finance \& Accounting, 32(1-2), 297-323.

Yang, J., Haigh, M. S., \& Leatham, D. J. (2001). Agricultural liberalization policy and commodity price volatility: a GARCH application. Applied Economics Letters, 8(9), 593-598.

Zhang, Z., Lohr, L., Escalante, C., \& Wetzstein, M. (2009). Ethanol, Corn, and Soybean Price Relations in a Volatile Vehicle-Fuels Market. Energies, 2(2), 320-339.

Zheng, Y., Kinnucan, H. W., \& Thompson, H. (2008). News and volatility of food prices. Applied Economics, 40(13), 1629-1635.

Zilberman, D., Hochman, G., Rajagopal, D., Sexton, S., \& Timilsina, G. (2012). The Impact of Biofuels on Commodity Food Prices: Assessment of Findings. American Journal of Agricultural Economics, 95(2), 275-281. 